
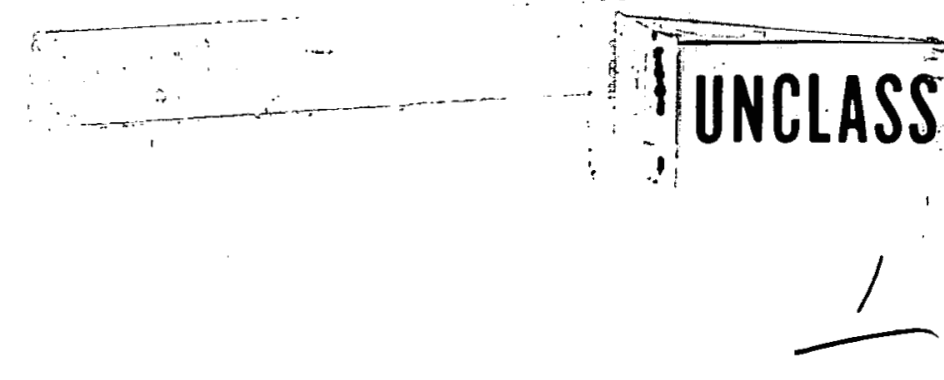

Contract No. W-7405-eng-92

\title{
AN EVALUATION OF DATA ON \\ ZIRCONIUM-URANIUM ALLOYS
}
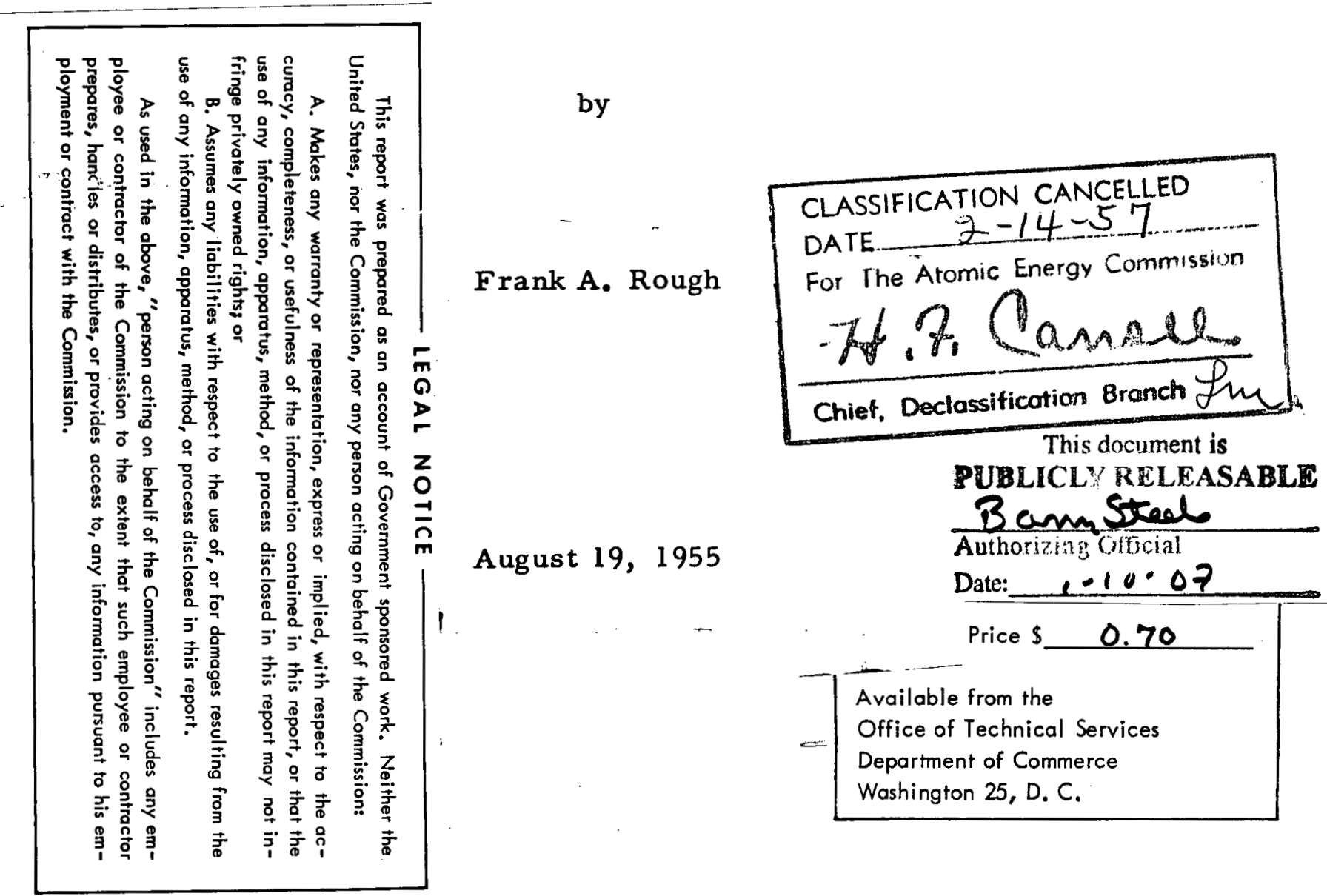

BA TTELLE MEMORIAL INSTITUTE

$505 \mathrm{King}$ Avenue

Columbus 1 , Ohio

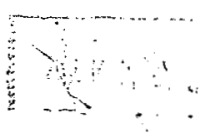




\section{DISCLAIMER}

This report was prepared as an account of work sponsored by an agency of the United States Government. Neither the United States Government nor any agency Thereof, nor any of their employees, makes any warranty, express or implied, or assumes any legal liability or responsibility for the accuracy, completeness, or usefulness of any information, apparatus, product, or process disclosed, or represents that its use would not infringe privately owned rights. Reference herein to any specific commercial product, process, or service by trade name, trademark, manufacturer, or otherwise does not necessarily constitute or imply its endorsement, recommendation, or favoring by the United States Government or any agency thereof. The views and opinions of authors expressed herein do not necessarily state or reflect those of the United States Government or any agency thereof. 


\section{DISCLAIMER}

Portions of this document may be illegible in electronic image products. Images are produced from the best available original document. 


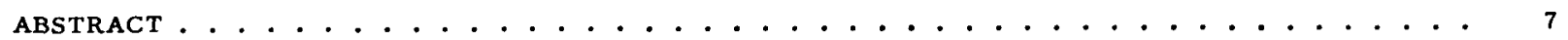

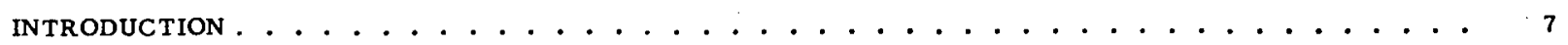

THE ZIRCONIUM-URANIUM CONSTITUTIONAL DIAGRAM . . . . . . . . . . . . . . . 9 V

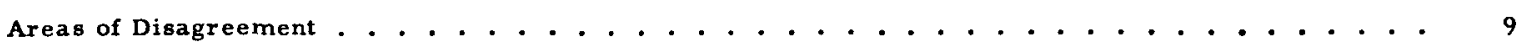

Epsilon Metastability ............................... 12

Epsilon Stability . . . . . . . . . . . . . . . . . . . . . . . . . . . . . 13

The Ternary Zirconium-Uranium-Oxygen System . . . . . . . . . . . . . . . . . . . . 14

Effect of Oxygen on the Epsilon Region . . . . . . . . . . . . . . . . . . . . . . . 17

Effect of Oxygen on the Alpha-Plus-Beta Zirconium Region . . . . . . . . . . . . . . . 17

Crystal Structure of Epsilon. . . . . . . . . . . . . . . . . . . . . . . . 21

Summary . . . . . . . . . . . . . . . . . . . . . . . . . . . . . . . . . . . 23

KINETICS OF TRANSFORMATION OF ZIRCONIUM-URANIUM ALLOYS . . . . . . . . . . . . . . 25

Modes of Transformation . . . . . . . . . . . . . . . . . . . . . . . . 25

Martensite Formation in Zirconium-Rich Alloys . . . . . . . . . . . . . . . . . . . 29

The Mechanism of Epsilon Formation . . . . . . . . . . . . . . . . . . . . . . . . 29

Kinetics of Epsilon Formation . . . . . . . . . . . . . . . . . . . . . . . . 31

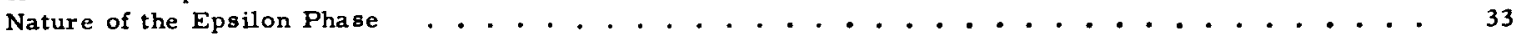

Summary ................................ 36

THE EFFECTS OF HEAT TREATMENT ON THE MICROSTRUCTURE OF ZIRCONIUM-URANIUM

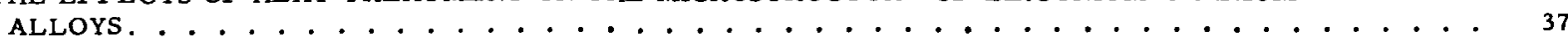

Introduction . . . . . . . . . . . . . . . . . . . . . . . . . . . . 37

Alloys Containing 1 to $20 \mathrm{w} / \mathrm{o}$ Uranium . . . . . . . . . . . . . . . . . . . . . 37

Alloys Containing 20 to $80 \mathrm{w} / \mathrm{o}$ Uranium ...........................4 4

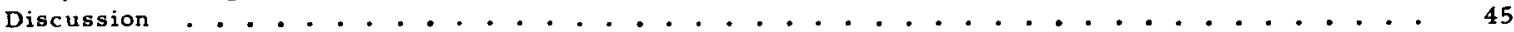

STRENGTH CHARACTERISTICS OF ZIRCONIUM-URANIUM ALLOYS . . . . . . . . . . . . . . . 47

The Effects of Composition on Mechanical Properties in the Annealed Condition . . . . . . . . 48

The Effects of Beta-Phase Decomposition on Mechanical Strength . . . . . . . . . . . . . . 59

Discussion ................................ 67

PHYSICAL PROPERTIES OF ZIRCONIUM-URANIUM ALLOYS . . . . . . . . . . . . . . . . . . 69

Density . . . . . . . . . . . . . . . . . . . . . . . . . 69

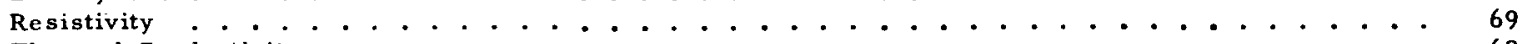

Thermal Conductivity .. . . . . . . . . . . . . . . . . . . . . . 69

Thermal Expansion . . . . . . . . . . . . . . . . . . . . . . . 73

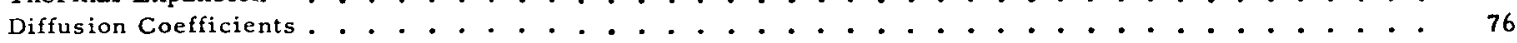

FABRICATING CHARACTERISTICS OF ZIRCONIUM ALLOYS CONTAINING UP TO

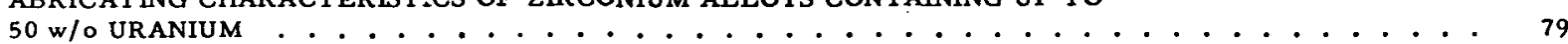

Alloys Containing up to $20 \mathrm{w} / \mathrm{o}$ Uranium. . . . . . . . . . . . . . . . . . . . . . . 79

Alloys Containing 20 to $50 \mathrm{w} / \mathrm{o}$ Uranium. . . . . . . . . . . . . . . . . . . . . . . 80

Discussion .................................. 82 
TABLE OF CONTENTS

(Continued)

THE EFFECTS OF COMPOSITION AND HEAT TREATMENT ON CORROSION OF ZIRCONIUM-URANIUM ALLOYS . . . . . . . . ....................83

Corrosion Behavior of Uranium . . . . . . . . . . . . . . . . . . 83

Corrosion Behavior of Zirconium . . . . . . . . . . . . . . . . . . . . . . . . .

Corrosion of Binary Alloys in $100 \mathrm{C}(212 \mathrm{~F})$ Water . . . . . .

Corrosion of Binary Alloys in High-Temperature Water . . . . . . . . . . . . . . . 86

Corrosion of Zirconium-Uranium-Base Ternary Alloys . . . . . . . . . . . . . . . . . . 91

Analysis of Data . . . . . . . . . . . . . . . . . . . . . . . . . 93

THE EFFECT OF COMPOSITION AND HEAT TREATMENT ON THE IRRADIATION

PERFORMANCE OF ZIRCONIUM-URANIUM ALLOYS . . . . . . . . . . . . . . . . . . 97

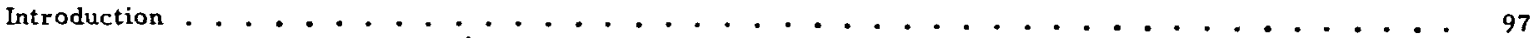

Alloys Containing Less Than 20 w/o Uranium

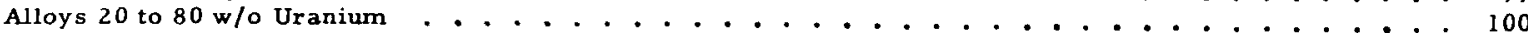

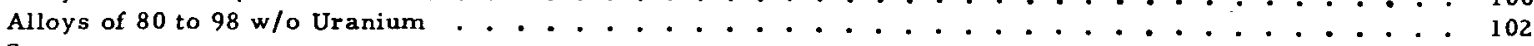

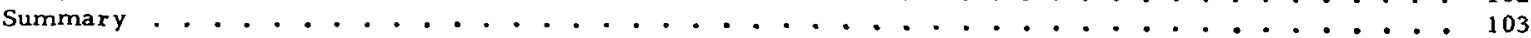

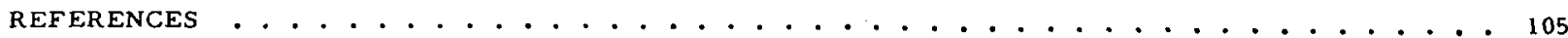




\title{
AN EVALUATION OF DATA ON ZIRCONIUM-URANIUM ALLOYS
}

\author{
Frank A. Rough
}

\begin{abstract}
A survey of the literature relative to zirconium-uranium alloys has_been made. The available data have been analyzed in an attempt to present the most coherent and reliable picture of the behavior and nature of the zirconium-uranium alloys as a system. The constitutional diagram has been reviewed, and an attempt has been made to reconcile the divergent forms of this diagram found in the literature. The structure of the intermediate phase, epsilon, is discussed. The two modes of transformation of the beta (high temperature) phase are described; one mode. resembles the martensite transformation found in steels; the other mode resembles in some respects the age-hardening-type transformation found in titanium alloys.
\end{abstract}

Typical microstructures produced by transformation of beta, by cold working and annealing, and by duplex heat treatments are shown. An attempt is made to correlate structure with the manner in which it was produced and with the resultant mechanical properties. The available data on the hardness, tensile, and creep properties of zirconium-uranium alloys are tabulated and evaluated in the light of recent developments in the field of transformation kinetics. The physical properties of the alloys are presented in graphical form. The best available techniques for hot rolling, extruding, cold rolling, and swaging are detailed.

The corrosion resistance of zirconium-uranium alloys in water at various temperatures is reviewed. The effect of temary additions upon corrosion resistance is discussed with a view toward improving the alloys by this means.

The effect of neutron irradiation upon metals is discussed, in general with respect to fuel alloys, and specifically with respect to zirconium-uranium alloys.

\section{INTRODUCTION}

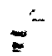

The low thermal-neutron-absorption cross section of zirconium and the development of the corrosion-resistant Zircaloys make the use of Zircaloy-clad zirconium-uranium fuel elements attractive. Because of the similar properties and fabricational characteristics of these materials, the cladding of zirconium-uranium alloys with Zircaloy has proven to be very successful, with good metallurgical bonds being obtained. 
Although successful results have already been produced with core alloys of zirconium-uranium, continued research directed toward improved performance may be worthwhile. Also, the design of reactors varies and different compositions of core alloys are required in each application. As a result, a program of research has begun which is intended to refine our knowledge of the zirconium-uranium alloys and to tie together the data currently available. The first step of the program, an analysis of the available data, is represented by this report.

In order to avoid confusion in presenting data, a standard system of designation of phases has been adopted. Alpha zirconium is referred to as alpha, and the solid solution of beta zirconium and gamma uranium is called beta. The intermediate phase, occurring at about $50 \mathrm{w} / \mathrm{o}$ uranium, is designated as epsilon. In a few instances where the uranium-rich phases are involved, they are referred to specifically as alpha uranium, beta uranium, and gamma uranium. 
 \\ THE ZIRCONIUM-URANIUM CONSTITUTIONAL DIAGRAM}

Arthur A。Bauer

The constitution of zirconium-uranium alloys has been studied extensively $(1,2,3,4,5,6)$. What is felt to be the best interpretation of the system, based on the present state of knowledge, is shown in Figure 1.

At elevated temperatures, body-centered cubic beta zirconium and gamma uranium are isomor phous. This region converges to a eutectoid at about $600 \mathrm{C}(1110 \mathrm{~F})$, below which an intermediate phase, epsilon, forms. The epsilon phase is stable below about $610 \mathrm{C}(1130 \mathrm{~F})$ where it forms peritectoidally.

A unique gamma uranium (beta zirconium) composition exists at the uranium end of the system which decomposes by a monotectoid reaction at about 86 a/o uranium and $685 \mathrm{C}(1260 \mathrm{~F})$.

Solubilities of zirconium in alpha and beta uranium and of uranium in alpha zirconium are limited. Solubility of uranium in alpha zirconium is less than 1 a/o.

$\underline{\text { Areas of Disagreement }}$

While agreement exists on a number of features of the diagram, such as the monotectoid reaction and the eutectoid decomposition of the bodycentered cubic phase, there are also areas of widely diverging opinions.

The nature of the intermediate epsilon phase is of particular interest and importance. While there appears to be general agreement that a phase does form below $600 \mathrm{C}(1110 \mathrm{~F})$ in alloys of intermediate composition, agreement has not been reached on the stability of the phase. If the phase were metastable, then the equilibrium phases below $600 \mathrm{C}(1110 \mathrm{~F})$ would be alpha uranium and alpha zirconium, and the resulting phase relations would appear as shown in Figure $2^{(4)}$.

The effect of zirconium on the phase relationships of the beta uranium $\approx \quad$ phase is not clear cut either. While the diagram shown in Figure 1 shows beta uranium existing in equilibrium only with alpha uranium and gamma uranium (beta zirconium) up to the monotectoid composition, data have also

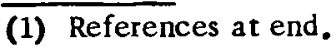




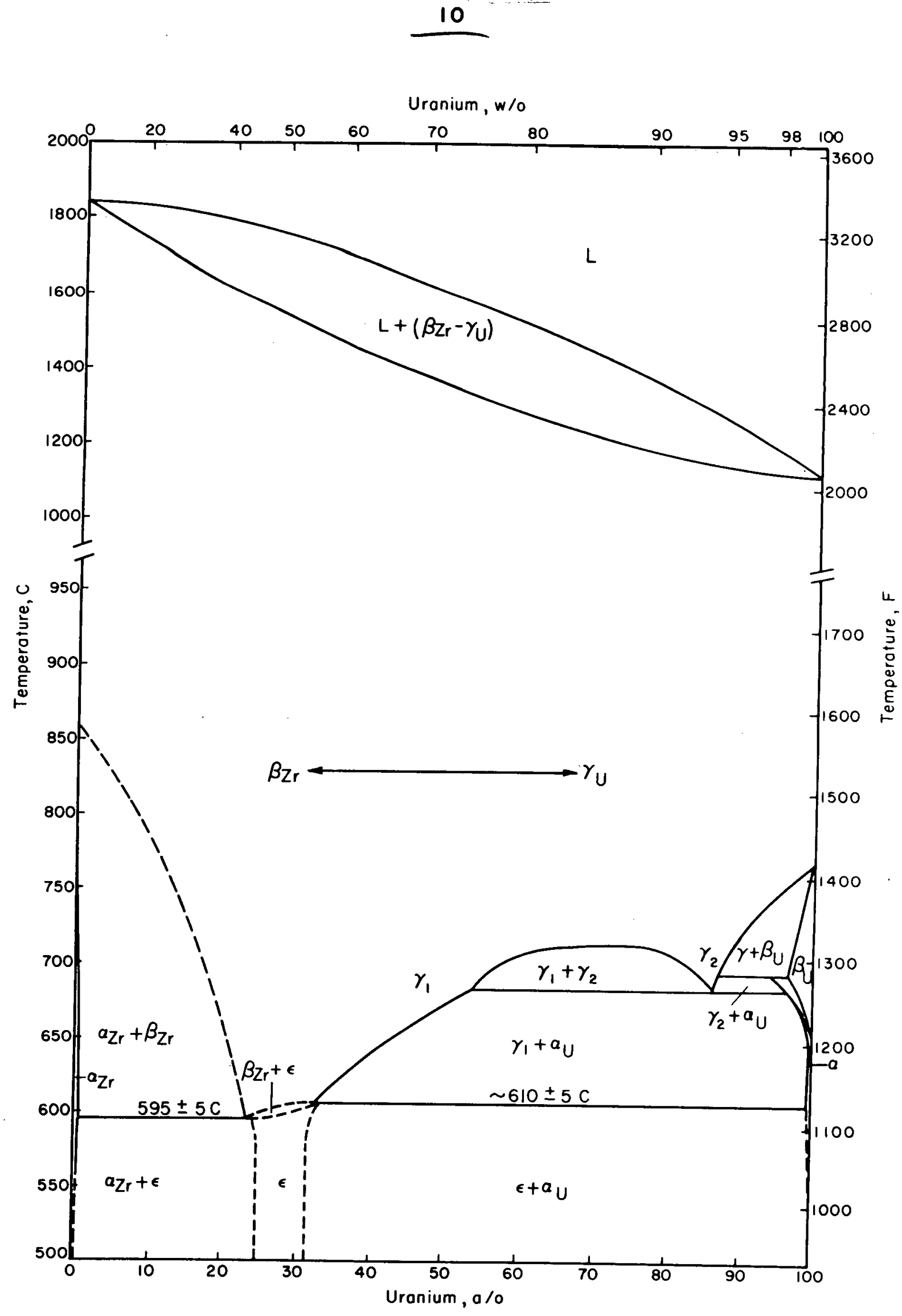

FIGURE I. PROPOSED ZIRCONIUM-URANIUM CONSTITUTIONAL DIAGRAM 


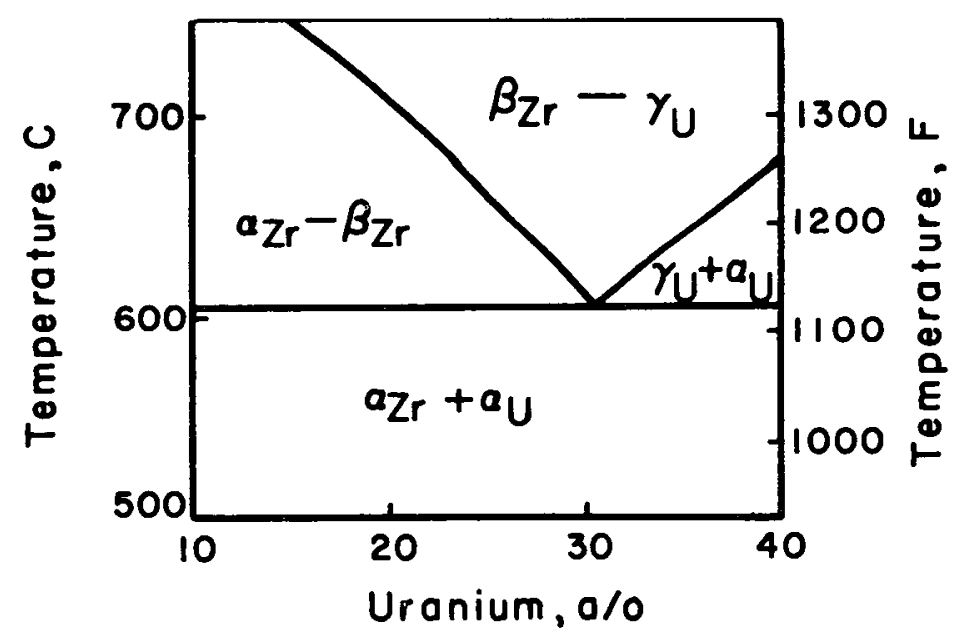

FIGURE 2. SECTION OF ZIRCONIUM-URANIUM CONSTITUTIONAL DIAGRAM FOR METASTABLE EPSILON CASE

A-15779

$=$

$\overline{8}$

s 
been reported which indicate an isotherm at about $672 \mathrm{C}(1240 \mathrm{~F})(7)$ as a result of the peritectoid decomposition of alpha uranium to beta uranium and the zirconium-rich gamma uranium phase $(4)$ on heating. This feature of the system is currently under investigation, and its discussion is not within the scope of the present report which is concentrated on alloys of intermediate and high-zirconium compositions.

\section{Epsilon Metastability}

Decomposition of epsilon occurs quite readily in alloy filings at temperatures between 400 and $600 \mathrm{C}(750$ and $1110 \mathrm{~F})(8)$. The rate of decomposition apparently increases with temperature; at temperatures near $600 \mathrm{C}$ $(1110 \mathrm{~F})$, only a few hours are required for the epsilon decomposition to alpha uranium and alpha zirconium to begin. Prolonged annealing results in complete disappearance of the epsilon phase, and its disappearance is reportedly accelerated by cold work $(7,8)$.

Conver sely, decomposition in a bulk binary-alloy specimen has never been reported. Annealing below $600 \mathrm{C}(1110 \mathrm{~F})$ for periods up to 4 weeks, and alternately cold working and annealing below $600 \mathrm{C}$ (1110 F) have not resulted in formation of either alpha phase in alloys of epsilon composition.

The apparent discrepancy in behavior between filings and bulk specimens suggests either a surface or a size effect. That this is a surface effect is indicated by the results obtained on thin-wire specimens of epsilon composition. X-ray examination of annealed specimens indicated the formation of alpha uranium and alpha zirconium. However, etching to remove the surface layer revealed unreacted epsilon underneath $(7,9)$.

If the epsilon phase is viewed as metastable, a number of explanations are available to interpret this surface decomposition. Surface contamination would be one of the likely requirements for decomposition. Oxygen and nitrogen, either in solid solution, or as oxide and nitride particles, could act to accelerate decomposition of epsilon to the equilibrium alpha uranium and alpha zirconium phases. The presence of an unrestrained surface, implying a surface nucleation effect, has also been suggested as a possible requirement for initiating decomposition(9).

While no complete description of metastable epsilon formation and decomposition has been offered as yet, a rough analogy has been drawn between epsilon and the transition phase, omega, which is observed during the aging of beta-quenched titanium alloys $(10,11)$. Analogous behavior of zirconium and titanium alloys might be expected on the basis of similar atomic and structural configurations of the two metals. 
A number of similarities exist for the two phases. The X-ray patterns of both phases are very much alike, since both structures are related to the high-temperature beta structure from which they form. Both phases show a typical age-hardening peak during isothermal formation(12), and both occur over a range of compositions. The range over which epsilon has been reported is particularly wide, having been reported in alloys containing 10 to at least 35 a/o uranium, although the range does narrow, on annealing, to a single-phase region of limited extent.

However, significant differences between omega and epsilon formation also exist. While the age-hardening peak is apparently associated with formation of both phases, overaging is accompanied by decomposition of the omega phase to alpha titanium, while the epsilon phase itself softens.

Also, omega apparently does not exist alone, but always in conjunction with retained beta. Whether beta is retained for appreciable periods along with epsilon is uncertain. On the basis of present experimental data, it does not appear that it is, although this facet of epsilon formation has not been thoroughly explored, and requires examination.

Another difference between omega and epsilon formation is that, in the titanium alloys, beta is retained and alloy enrichment of the beta phase accompanies the formation of omega. However, epsilon formation, at least in the 10 and 20 a/o uranium alloys, would of necessity require uranium depletion of the beta phase.

Thus, while an analogy may be drawn between epsilon, of the zirconium-uranium system, and the transition-phase omega, occurring in titanium systems, the mechanisms of formation and decomposition are not parallel. The sequence of omega formation and decomposition is $\beta \rightarrow \beta+$ $\omega \rightarrow \beta+\alpha$, while the sequence for epsilon appears to be $\beta \rightarrow \beta+\epsilon \rightarrow \epsilon \rightarrow \epsilon+$ $\alpha_{U}+\alpha_{Z r} \rightarrow \alpha_{U}+\alpha_{Z r}$. If these two phases are similar, acceleration of epsilon decomposition by oxygen might be expected, since oxygen is known to accelerate the decomposition of omega.

\section{Epsilon Stability}

It is apparent that a good case may be made for epsilon metastability, both upon the basis of experimental observations and by analogy with the transition phase omega which occurs in titanium alloys. However, in a recent experiment, epsilon was formed from zirconium and uranium powders by annealing at $540 \mathrm{C}(1000 \mathrm{~F})^{(13)}$. At no time did the compacted powders exceed this temperature. The ability to form epsilon from the elemental powders, without first forming the high-temperature beta zirconium phase, 
shows that epsilon is not a transition phase in the decomposition of beta, but is a stable phase.

The observed decomposition of epsilon evidently occurs as a result of either oxygen or nitrogen contamination, or both. The addition of roughly $0.8 \mathrm{w} / \mathrm{o}$ oxygen, or nitrogen, to the $25 \mathrm{a} / \mathrm{o}$ uranium alloy during melting has been found to result in the formation of alpha uranium and alpha zirconium, after annealing $16 \mathrm{hr}$ at $590 \mathrm{C}(1100 \mathrm{~F})(14)$. In another experiment, zirconium-27 a/o uranium alloys, to which 0 to 20 a/o oxygen was added, were annealed at $550 \mathrm{C}(1020 \mathrm{~F})$ for $100 \mathrm{hr}(13)$. X-ray diffraction and metallographic examination revealed that with increasing oxygen content the epsilon phase gradually disappeared, being replaced by the zirconium and uranium alpha phases.

That the disappearance of epsilon occurs as a consequence of ternary alloying is indicated by the results of a study of the system zirconiumuranium dioxide (15). While another explanation has been offered to explain the surface decomposition of epsilon observed, namely, that a surface oxide layer forms which on annealing decomposes to the two alpha phases as the oxygen diffuses into the epsilon, the ternary alloy studies do not support the supposition that it is necessary to form the oxide as a step in the decomposition of epsilon.

The Ternary Zirconium-Uranium-Oxygen System

Recently a study was made of the zirconium-uranium dioxide system(15). This study consisted primarily of X-ray diffraction and metallographic studies of alloys ranging in composition between zirconium and uranium dioxide. The phase relationships shown in Figures 3 and 4 appear to fit all the experimental data obtained during this investigation, although compositional limits may vary slightly from those shown. The data reported and mentioned previously for the zirconium-27 a/o uranium alloys to which 0 to 20 a/o oxygen was added, are in excellent agreement with the $540 \mathrm{C}(1000 \mathrm{~F})$ section shown.

These same sections may be predicted thermodynamically. Oxygen has a pronounced stabilizing effect on alpha zirconium. Since alpha uranium is little affected by oxygen, and if the same is assumed for the epsilon and beta zirconium phases, then free-energy considerations will lead to the ternary sections shown. The same behavior may be inferred for the effect of nitrogen. 


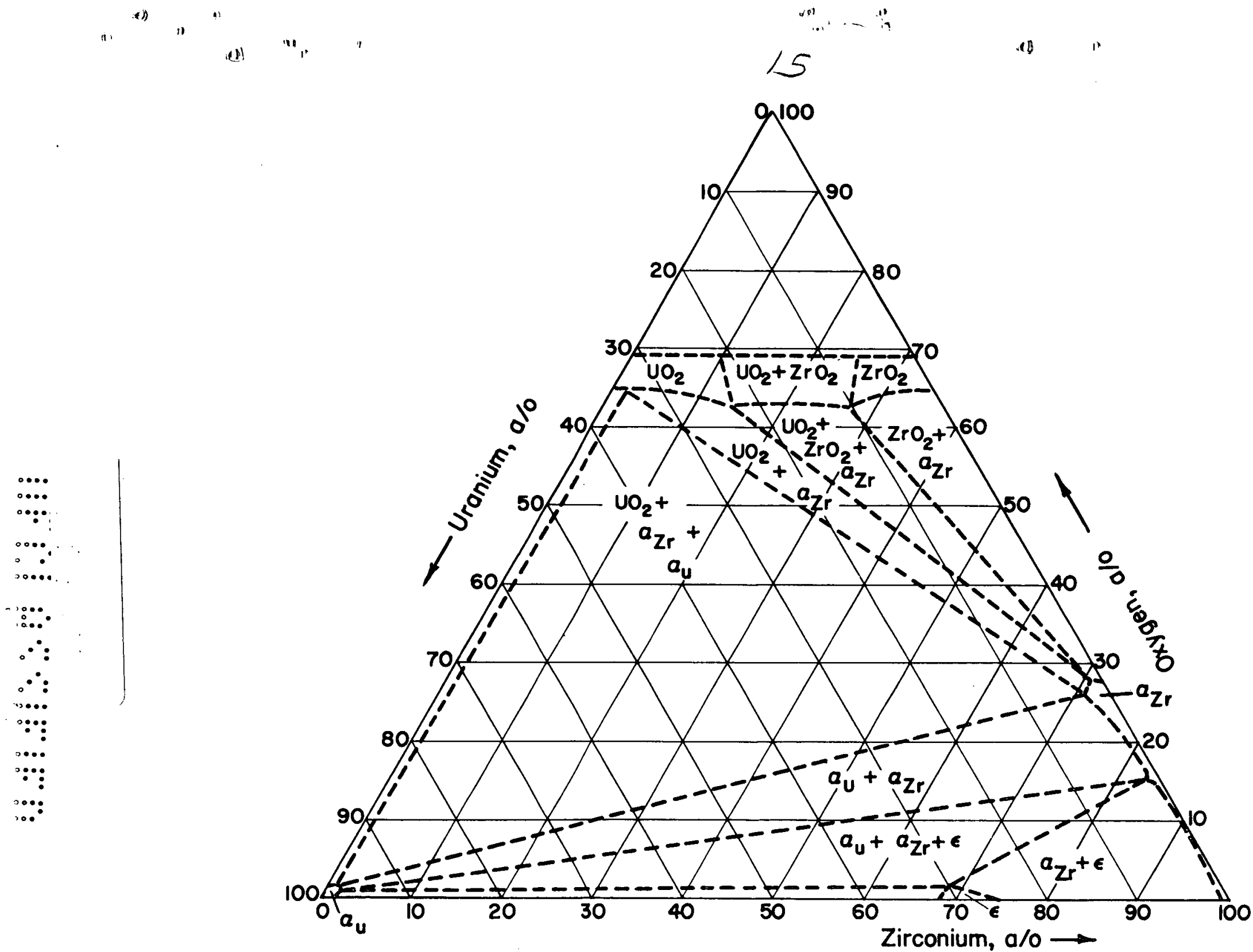

FIGURE 3. TENTATIVE ZIRCONIUM-URANIUM-OXYGEN TERNARY SECTION AT $540 \mathrm{C}(1000 \mathrm{~F})$

$A-15780$ 


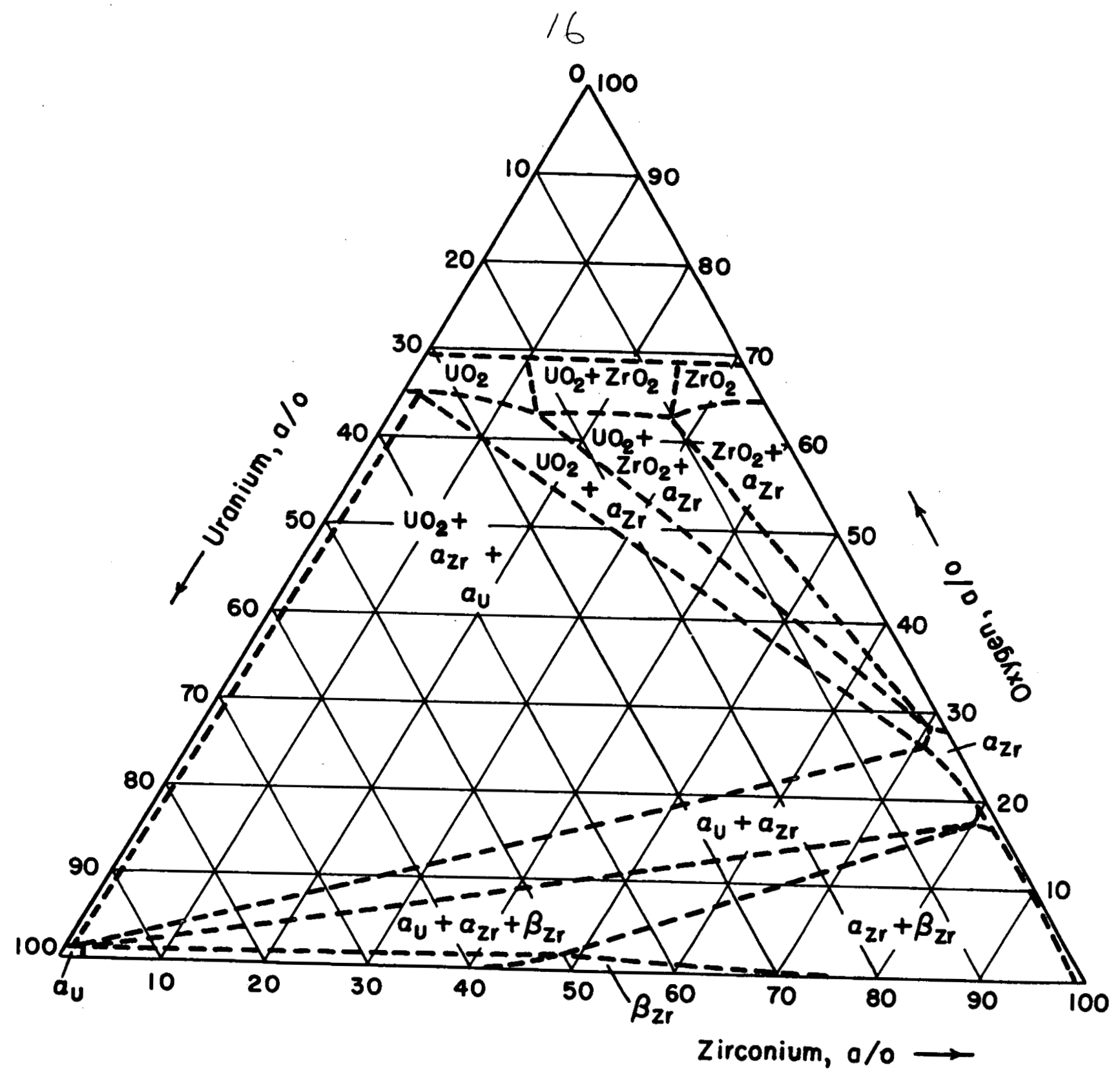

FIGURE 4. TENTATIVE ZIRCONIUM-URANIUM-OXYGEN TERNARY SECTION AT $650 \mathrm{C}(1200 \mathrm{~F})$ 
Effect of Oxygen on the Epsilon Region

It is apparent from the se sections that a logical explanation for the observed epsilon decomposition may be offered merely on the basis of oxygen diffusing into the alloys. The sequence of observed decomposition coincides with the sequence shown for alloys of increasing oxygen content, with comparatively small amounts of oxygen required for the decomposition. The apparent effect of cold work in accelerating decomposition of the epsilon phase to alpha uranium and alpha zirconium is regarded as arising from increased pickup of oxygen and nitrogen during working, which is particularly likely to occur in filings, where the surface-to-volume ratio is large.

If the phase is stable then the differences in transformation isotherms $(2,7,9)$ of high-uranium versus high-zirconium alloys (Figure 1) must be real. It should be recognized that this difference, 10 to $15 \mathrm{C}$, could not be accepted as unequivocal proof of the existence of the epsilon phase, as the variations in reported temperatures of the isotherms are as much or more than the difference in the isotherms themselves.

The various existence ranges reported for the epsilon region may be related to different oxygen levels. Existence ranges of approximately 17 to $47 \mathrm{a} / \mathrm{o}^{(2)}, 25$ to $31.5 \mathrm{a} / \mathrm{o}^{(16)}$, and 27 to $32 \mathrm{a} / \mathrm{o}^{(17)}$ uranium have been reported. The last two values are regarded as representing more likely solubility limits than the first, although the se may be expanded in true binary alloys.

Effect of Oxygen on the Alpha-Plus-Beta Zirconium Region

Varying data with respect to the limits of the alpha-plus-beta zirconium region can be explained in terms of oxygen or nitrogen pickup.

The inset, Figure 5, showing the phase relationships in the region of the epsilon phase, was based on the observation that while a 25.5 a/o uranium alloy was single phase when annealed at $575 \mathrm{C}(1070 \mathrm{~F})$, it was twophase alpha-plus-beta zirconium when annealed at temperatures between 620 and $690 \mathrm{C}(1150 \text { and } 1280 \mathrm{~F})^{(18)}$. On the basis of the constitutional diagram shown in Figure 1, this alloy should be single phase in this temperature range. However, examination of the ternary sections reveals that small amounts of oxygen may lead to the formation of alpha zirconium and the reby produce a two-phase structure. 


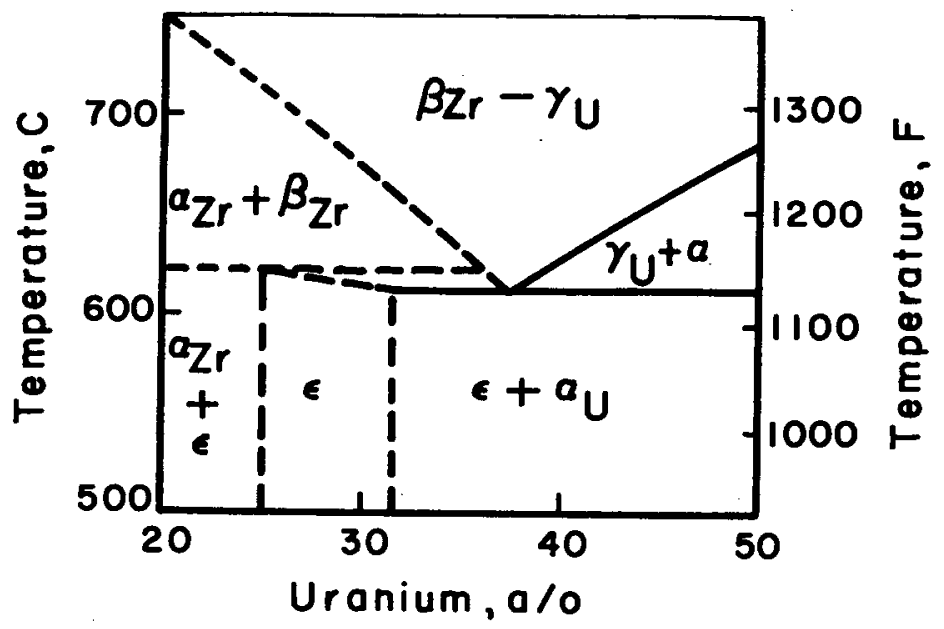

\section{FIGURE 5. SECTION OF CONSTITUTIONAL DIAGRAM BASED ON ALLOYS CON- TAINING SMALL AMOUNTS OF OXYGEN}

Similarly, two phases have been reported in alloys containing about 21 to 31 a/o (41 to $54 \mathrm{w} / \mathrm{o}$ ) uranium when quenched from a temperature of $800 \mathrm{C}(1470 \mathrm{~F})$ and below $(19)$. While the suggestion has been made that the entire middle section of the system may be metastable, these two-phase structures may also be interpreted in terms of oxygen or nitrogen pickup.

Quantitative metallographic data, of similar implication, have been obtained on a series of alloy specimens annealed and quenched from $680 \mathrm{C}$ $(1255 \mathrm{~F})^{(18)}$. According to the lever law, when weight per cent of either phase is plotted versus composition, a straight line should result, with 0 and 100 per cent of the phase coinciding with the composition limits of the region. The applicability of this approach has been established experimentally and has been successfully applied to uranium-rich alloys of the uranium-zirconium system(3).

However, when applied to alloys of alpha-plus-beta zirconium structures, the plot of weight per cent of the phases present versus composition was found to be nonlinear. The general trend observed experimentally is shown by the dotted line of Figure 6. Increasing departure from equilibrium with increasing uranium content cannot account for this trend, for then the reverse effect should be observed, the plotted curve showing negative instead of positive curvature. However, it can be accounted for on the basis of ternary alloy behavior in the zirconium-uranium-oxygen system. The zirconium-rich corner of the ternary system is shown in Figure 7. The 


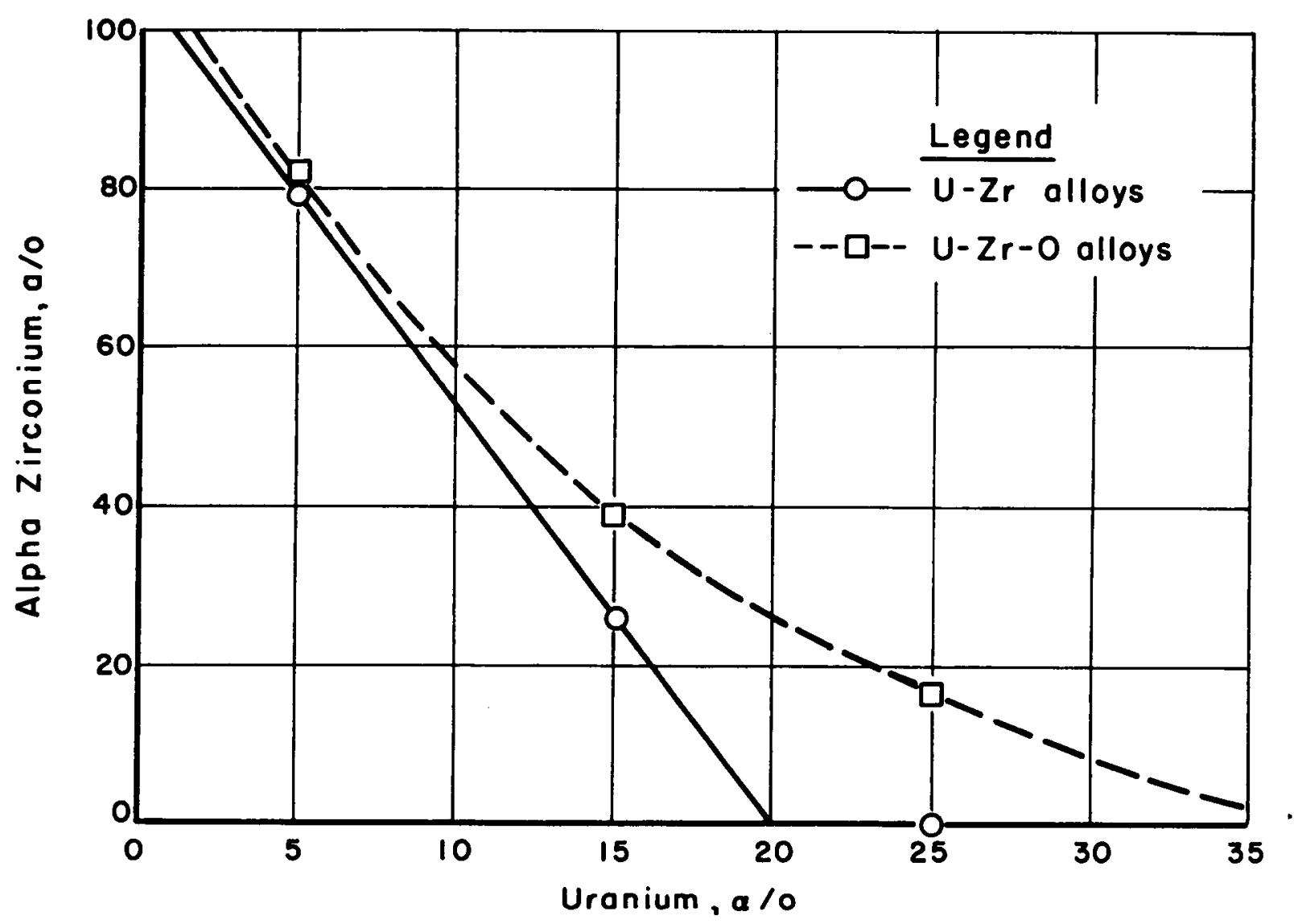

FIGURE 6. QUANTITATIVE ANALYSIS OF ZIRCONIUM-URANIUM AND ZIRCONIUM-URANIUM-OXYGEN ALLOYS BASED ON FIGURE 7

A- 15783

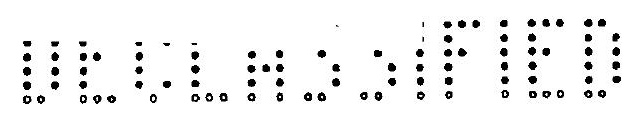



compositions of 5, 15, and 25 a/o uranium alloys, all of which are assumed to be contaminated to the same oxygen level, are indicated. Tie lines drawn through these alloy compositions connect the equilibrium phases. The lever rule may now be applied to the se tie lines and the percentage of alpha zirconium present in each alloy calculated from the relationship $\frac{a}{a+b} \times 100$.

When these values are plotted against composition and the oxygen content is disregarded, they lead to the dotted line of Figure 6 again, and provide a logical explanation for the nonlinearity observed experimentally.

It is also obvious from Figure 7 that the 25 a/o uranium alloy is two phase with the oxygen level assumed, while as a true binary alloy it would be single phase.

If the same type of analysis is applied to the binary alloys of Figure 7, the solid line shown in Figure 6 results. The wide divergence of the two lines, particularly with increasing uranium content, clearly indicates the lack of applicability of quantitative analysis to this region unless it is made as a ternary study and includes an evaluation of the effect of oxygen and nitrogen. Essentially the same problem was encountered in another attempt to estimate the composition limits of the alpha-plus-beta region. Quantitative lineal measurements were made of the phases present in a 10 a/o uranium alloy annealed for $100 \mathrm{hr}$ at $700 \mathrm{C}(1300 \mathrm{~F})$. Calculations, based on the phase percentages present and assuming a solubility limit of $0.5 \mathrm{a} / 0$ uranium in alpha zirconium, placed the two-phase alpha-plus-beta boundary at $17 \mathrm{a} / 0$ uranium. However, a $25.5 \mathrm{a} / 0$ uranium alloy annealed for the same time at $690 \mathrm{C}(1275 \mathrm{~F})$ was still two-phase alpha plus beta. Again, the nonlinearity in the relationship between composition and phase percentage, when treating a ternary alloy as a binary alloy, accounts for this inability to tie down the phase boundaries of the region.

While quantitative lineal analysis would normally be based on weight percentages of the phases and constituents present, atomic values have been used in this presentation for the sake of simplicity.

\section{Crystal Structure of Epsilon}

The crystal structure of epsilon has not been fully determined. Attempts have been made to index the $X$-ray diffraction powder-pattern data on various complex cubic cells based on the beta zirconium body-centeredcubic cell. These attempts have been unsuccessful, although close matches have been obtained. This may indicate a slight distortion of the bodycentered-cubic structure in the formation of epsilon. 
Recently, it has been found that the powder pattern can be accounted for by either a hexagonal or rhombohedral structure. The hexagonal cell has a volume requiring nine atoms with cell constants of $a_{0}=5.05 \mathrm{~A}$ and $c_{0}=9.30 \mathrm{~A}$. The rhombohedral cell has a volume of $205 \mathrm{~A}^{3}$ and requires nine atoms with a cell constant of $a_{0}=5.95 \mathrm{~A}$ and angle $\alpha=94.6$ degrees. This rhombohedral cell corresponds with a hexagonal cell having cell constants of $a_{0}=8.75 \mathrm{~A}$ and $c_{0}=9.30 \mathrm{~A}$. Both hexagonal cells are similar in that the $c$ axis is about one and one-half times the body diagonal of the beta zirconium body-centered-cubic cell.

Data obtained from rotation, Weissenberg and precession patterns of single beta grains indicate the likeliest structure to be hexagonal $(20,21)$ with cell constants of $a_{0}=5.05$ and $c_{0}=9.25 \mathrm{~A}$. The periodicity of $9.25 \mathrm{~A}$ appears to be quite definite from rotation patterns. The suggestion has been made that the uranium atoms are positioned just above and below the basal plane with two zirconium atoms between uranium atoms in the c-axis direction normal to the basal plane. This interpretation appears reasonable, although further work on intensity calculations is needed to confirm the structure.

The structures discussed above all have nine atoms in the unit cell, suggesting a composition for epsilon of $\mathrm{U}_{3} \mathrm{Zr}_{6}$, or $\mathrm{U}_{2} \mathrm{Zr}_{7}$, while the apparent existence range for epsilon, about 25 to 32 a/o uranium, lies between these limits. This may indicate that a cell larger than the primitive hexagonal one discussed is required. However, random replacement of uranium atoms by zirconium atoms in the basal plane could also account for the variation in composition.

On the basis of the crystal-structure studies, the epsilon phase may be either an ordered structure, or a compound, or may have some of the characteristics of both. Since the true structure is not yet known, conclusions cannot be drawn with certainty at this time. Evidence that epsilon has. characteristics of an ordered phase is presented in the section on "Kinetics of Transformation of Zirconium-Uranium Alloys".

\section{Summary}

A constitutional diagram for the system zirconium-uranium has been presented. The stability of the intermediate phase, epsilon, is regarded as being established.

Upon the basis of ternary zirconium-uranium-oxygen diagrams presented, the observed decomposition of epsilon, in filings and at the surface of wire specimens, is explained as a consequence of ternary alloy behavior, the epsilon phase region being restricted by the addition of small amounts

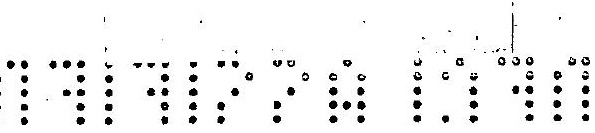




\section{$23 \quad 23$ and 24}

of oxygen. Nitrogen additions to the binary alloys may be expected to lead to similar behavior.

Metallographic observations of two-phase alpha-plus-beta zirconium structures in alloys which, upon the basis of the constitutional diagram presented, should be single phase, are also explained by oxygen or nitrogen contamination of supposedly binary alloys. The need for a quantitative investigation of the effects of oxygen and nitrogen on the binary zirconiumuranium system is indicated. 


\section{KINE TICS OF TRANSFORMATION OF ZIRCONIUM-URANIUM ALLOYS}

Arthur A. Bauer

Studies of the kinetics of transformation in zirconium-uranium alloys have been made by a number of techniques. Electrical-resistivity, hardness, and dynamic-modulus, as well as X-ray and metallographic studies are available and offer information on transformation in these alloys.

Primary emphasis has been placed on studying the beta zirconium to epsilon decomposition. Most of these studies have been of limited scope, no attempt having been made to study the system in its entirety by any single technique. As a result, correlation of the data requires interpolation between the various ranges covered.

On the basis of the data presented in the section on the constitutional diagram, the epsilon phase is now regarded as a stable phase. Since epsilon decomposition has been observed only on the surfaces of bulk samples, it appears safe to assume that studies of bulk samples represent the beta-toepsilon transformation reasonably well.

Only limited data are available on the kinetics of decomposition of epsilon to alpha uranium and alpha zirconium phases. These data indicate(8) that the rate of epsilon decomposition increases with temperature, only a few hours at $600 \mathrm{C}(1110 \mathrm{~F})$ being required for epsilon filings to begin decomposing. Since the kinetics of this reaction are now believed to depend upon oxygen, they are of little interest to this study.

\section{Modes of Transformation}

From all indications, the beta phase can be retained in alloys containing 20 to $80 \mathrm{w} / 0$ uranium $(4,22)$. The alloys from 1 to $20 \mathrm{w} / \mathrm{o}$ uranium transform martensitically on quenching. The transformation of pure zirconium is not fully understood, but beta-quenched zirconium exhibits an acicular, or Widmanstätten, structure. It has been reported that high-purity zirconium does not exhibit acicular microstructures when quenched from the beta phase, but does when alloyed with oxygen, or other elements. (26)

A change in mode of beta-phase transformation appears to occur at about $20 \mathrm{w} / \mathrm{o}$ uranium. (22) A 19 w/o uranium alloy exhibits a martensitic structure when quenched, while the 22 w/o uranium alloys shows a retainedbeta structure. The suggestion that the $M_{s}$ temperature drops sharply to below room temperature in this range may account for the transition. An 
overlap in mechanism of transformation in this region appears possible. However, insufficient experimental data are available to establish this point.

Evidence of the different behavior of 10 and $22 \mathrm{w} / \mathrm{o}$ uranium alloys is indicated by Jominy end-quench tests $(22)$, while the same tests indicate a similarity in mode of transformation for the 22 and $41 \mathrm{w} / \mathrm{o}$ uranium alloys. The results of these tests are shown in Figure 8. While the 22 and $41 \mathrm{w} / 0$ uranium alloys show an aging peak at cooling rates intermediate to water quenching and air cooling, the $10 \mathrm{w} / \mathrm{o}$ uranium alloy does not.

The comparatively low hardness of the martensite formed in the $10 \mathrm{w} / \mathrm{o}$ uranium alloy is probably the result of limited lattice strain produced by the solution of uranium in zirconium. If the martensite transformation is incomplete, some coherent hardening would be expected, but this effect would probably not be great, since the beta phase in this range may not have sufficient strength to support the stresses associated with a high degree of coherent hardening.

In another study(12), alloys containing 41 to $57 \mathrm{w} / \mathrm{o}$ uranium were all found to exhibit the same behavior as the $22 \mathrm{w} / \mathrm{o}$ uranium alloy when isothermally transformed below $600 \mathrm{C}(1110 \mathrm{~F})$. A typical hardness plot is shown in Figure 9, in which an aging peak occurs after about 100 sec at $500 \mathrm{C}(930 \mathrm{~F})$. The similarity in response of all these alloys indicates that the same transformation mechanism is operative in alloys containing 22 to $57 \mathrm{w} / \mathrm{o}$ uranium. On the basis of similarity in response of the 50 and $60 \mathrm{w} / \mathrm{o}$ uranium alloys as shown by electrical-resistivity measurements (20), the upper limit may be further extended.

This mechanism of transformation must involve the beta-to-epsilon decomposition, as these are the only phases common to all these alloys. That the aging peak observed in these alloys is due to the beta-to-epsilon transformation, rather than the precipitation of either alpha zirconium or alpha uranium, is indicated by the very similar behavior of the 41 to $57 \mathrm{w} / \mathrm{o}$ uranium alloys when transformed isothermally. This range of composition includes single-phase epsilon alloys as well as duplex alloys of epsilon with either alpha zirconium or alpha uranium.

Upon this basis, there appear to be essentially two regions to be considered: alloys containing up to $20 \mathrm{w} / \mathrm{o}$ uranium which transform to alpha zirconium martensite when quenched; and alloys containing 20 to at least $60 \mathrm{w} / \mathrm{o}$ uranium which, when quenched, retain beta zirconium that later transforms to epsilon. This last region could be further divided on the basis of the second phase appearing in conjunction with epsilon, whether alpha uranium or alpha zirconium. However, no experimental data on kinetics, differentiating these alloys on this basis, are available. 

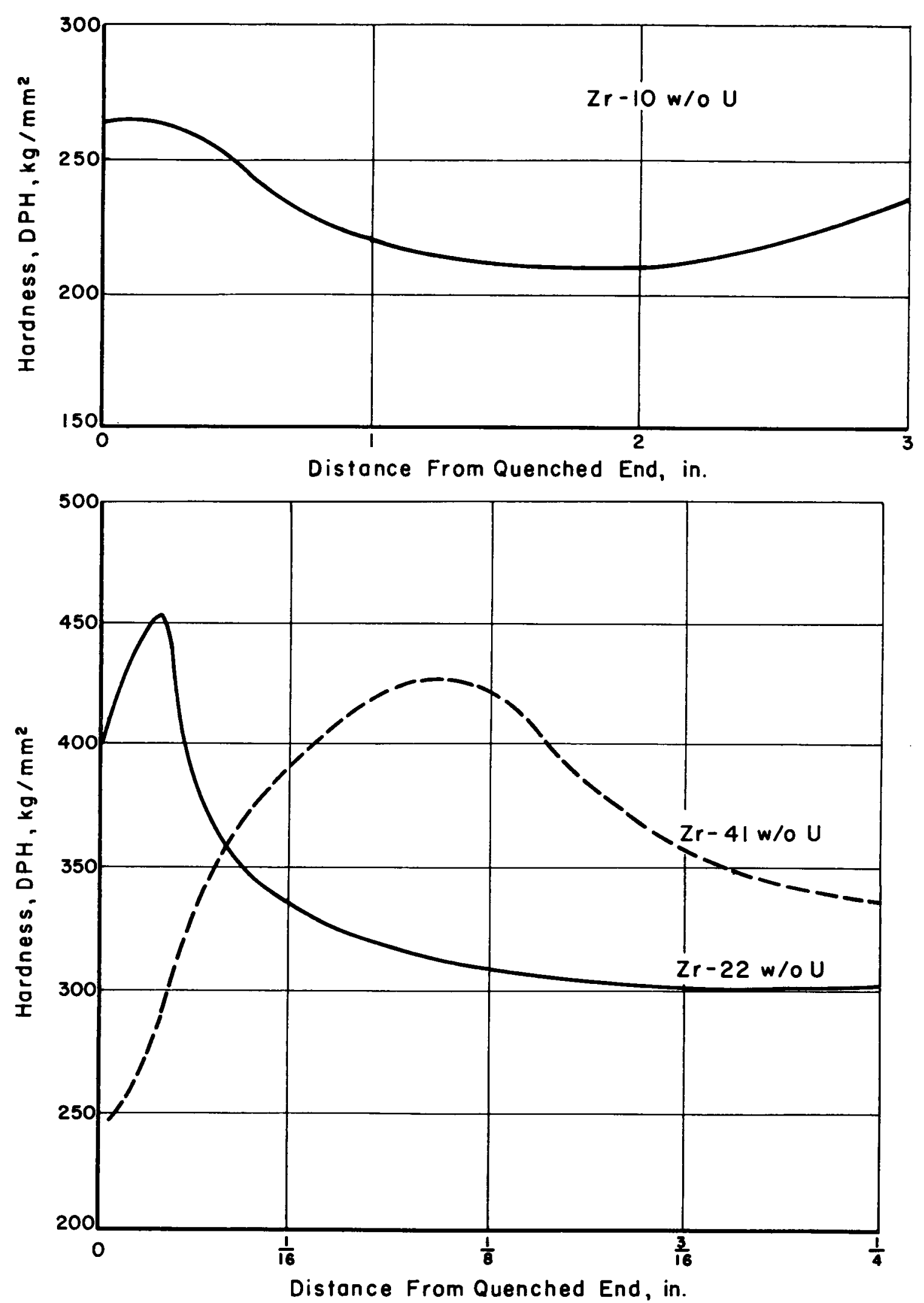

FIGURE 8. JOMINY END-QUENCH TESTS OF ZIRCONIUM-URANIUM ALLOYS QUENCHED FROM $900 \mathrm{C}(1650 \mathrm{~F})$ 


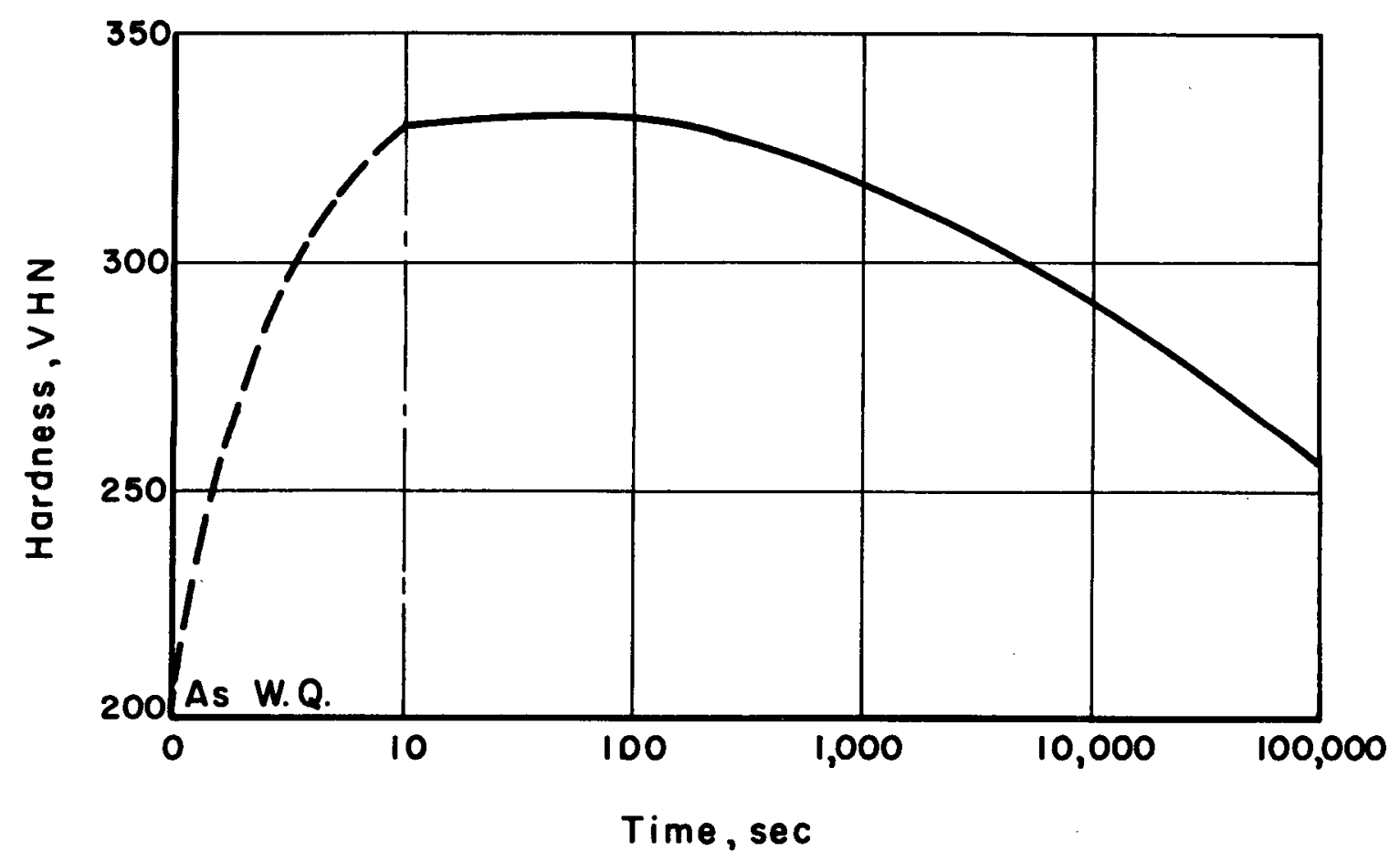

FIGURE 9. HARDNESS OF BETA-OUENCHED ZIRCONIUM-49 W/O URANIUM ALLOY ISOTHERMALLY TRANSFORMED AT $500 \mathrm{C}(930 \mathrm{~F})$

$4-15786$

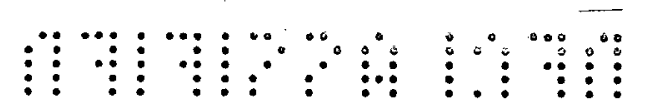


No division exists when air cooling or cooling rates slower than this are employed with alloys covering the alpha-plus-beta range. At these rates, alpha zirconium precipitates from the beta phase above $600 \mathrm{C}(1110 \mathrm{~F}$ ) and the transformation of the remaining beta zirconium phase to epsilon is dependent on the resulting zirconium-depleted beta composition.

It appears that the decomposition of beta zirconium above $600 \mathrm{C}$ $(1110 \mathrm{~F})$ is essentially the same in all the zirconium-rich alloys. A great similarity in structure of the 10,18 , and $22 \mathrm{w} / 0$ zirconium alloys is shown (22) on either air or furnace cooling, indicating a similarity in transformation mechanism. Presumably the $41 \mathrm{w} / 0$ alloy transforms in the same manner, although due to the decreased amount of alpha zirconium and the lower temperature at which precipitation begins, the microstructures are not entirely similar. The difference in the temperature at which precipitation starts is probably the greatest difference in the transformation of these alloys.

Martensite Formation in Zirconium-Rich Alloys

Few data are available on the kinetics of transformation of the martensite-forming alloys. Martensite forms on water quenching the 10 and $19 \mathrm{w} / \mathrm{o}$ uranium alloys from the beta region, while on cooling in air, or at slower cooling rates, alpha zirconium precipitates from the beta. The minimum quenching rate with which it is possible to obtain martensite is not known. Also, the martensite temperature and its dependence on composition are uncertain.

Martensite formation in these alloys is dependent on the quenching temperature. The beta produced by annealing in the two-phase, alpha-plusbeta region may become sufficiently enriched in uranium for beta to be retained on quenching. This beta will then transform to epsilon in a manner characteristic of alloys containing more than $20 \mathrm{w} / 0$ uranium.

The Mechanism of Epsilon Formation

In order to describe the kinetics of epsilon formation from beta zirconium containing 20 to at least $60 \mathrm{w} / \mathrm{o}$ uranium, the mechanism of trans formation should first be understood. Although the mechanism cannot clearly be established on the basis of reported data, there appear to be essentially two possible mechanisms. The first is described by the sequence, $\beta \rightarrow \beta+\epsilon \rightarrow \epsilon \rightarrow \epsilon+\alpha_{Z r}$ or $\alpha_{U}$; the second by the sequence, $\beta \rightarrow \beta+\epsilon \rightarrow \epsilon+$ $\alpha_{\mathrm{Zr}}$ or $\alpha_{U}$. 
In the first sequence, epsilon which may be supersaturated with respect to zirconium or uranium forms from the beta phase and precipitation of either alpha uranium, or alpha zirconium, from the epsilon occurs.

In the second sequence, epsilon of equilibrium composition forms from beta zirconium, and zirconium depletion, or enrichment of the beta phase, follows, depending on the initial composition. The alpha phase then forms from the depleted, or enriched, beta phase.

A third sequence is also possible whereby epsilon and alpha zirconium, or alpha uranium, precipitate concurrently from the beta zirconium phase. However, this sequence appears improbable on the basis of X-ray and metallographic observations reported. The structure of an as-cast $22 \mathrm{w} / \mathrm{o}$ uranium alloy revealed only the epsilon phase when examined by X-ray diffraction techniques. (20) Metallographic examination also indicated the alloy was single phase except for a domain-type structure characteristic of the epsilon phase. This same alloy when annealed for short times below $550 \mathrm{C}(1020 \mathrm{~F})$ remained single phase, while when annealed at higher temperatures a precipitate was observed. These results indicate that epsilon formation precedes the precipitation of alpha zirconium in alloys containing 20 to $60 \mathrm{w} / \mathrm{o}$ uranium.

$\mathrm{X}$-ray diffraction examination of a $41 \mathrm{w} / \mathrm{o}$ uranium alloy bar, end quenched from $900 \mathrm{C}(1650 \mathrm{~F})$ also indicated that the precipitation of alpha zirconium is preceded by the formation of epsilon. (22) Retained beta zirconium and epsilon near the center of the bar and retained beta, epsilon, and alpha zirconium at the air-cooled end were reported. While these observations indicate that epsilon of equilibrium composition forms directly from the beta phase by depletion of the beta, and alpha zirconium forms from the depleted beta, the report of epsilon and retained beta being separately identified is questionable. This is the only reported instance of such a separation being obtained. Normally it has been found to be impossible to identify beta once epsilon has formed, as the lines due to beta coincide with part of those due to epsilon.

The major portion of reported data apparently support the formation of supersaturated epsilon directly from beta zirconium, single-phase epsilon initially occurring over a fairly wide range of compositions. X-ray data generally indicate that epsilon forms in short periods of time and beta is no longer identified. Unfortunately, until beta and epsilon, when appearing in conjunction, can be unequivocally and separately identified, this point will remain in doubt. The rapidity with which beta decomposes, as indicated by electrical-resistivity measurements, also points to supersaturated phase formation by small atomic movements rather than a transformation controlled by extensive diffusion. 
That epsilon can exist over a wide composition range is indicated by $\mathrm{X}$-ray data. Its structure is closely related to the beta structure and appears to be best described as resulting from rearrangement of the beta into a hexagonal cell, with uranium atoms occupying preferred positions above and below the basal plane. X-ray data indicate that random substitution of uranium by zirconium atoms accounts for the formation of epsilon supersaturated with respect to zirconium in the zirconium- $22 \mathrm{w} / \mathrm{o}$ uranium alloy. (25) On annealing, alpha zirconium precipitates and the epsilon approaches its equilibrium composition.

\section{Kinetics of Epsilon Formation}

Upon the basis of electrical-resistivity measurements $(8,9,20,23)$, transformation of beta to epsilon occurs quite rapidly in zirconium alloys containing 20 to $60 \mathrm{w} / 0$ uranium. Data for the 50 and $60 \mathrm{w} / 0$ uranium alloys are considered more reliable than the data for the 20 and $40 \mathrm{w} / \mathrm{o}$ uranium alloys due to the differences in experimental techniques used on the two sets of alloys.

On cooling the 50 and $60 \mathrm{w} / 0$ uranium alloys at a rate of about $50 \mathrm{C}$ per sec ( $90 \mathrm{~F}$ per sec), it is found that beta transforms to epsilon. A typical heating and cooling curve obtained at this rate is shown(25) schematically in Figure 10. The transformation on cooling is supercooled to about $400 \mathrm{C}$ (750 F) and appears to be complete in about 9 sec. On cooling the 20 and $40 \mathrm{w} / \mathrm{o}$ uranium alloys under the same conditions, beta is retained. Apparently, transformation occurs more rapidly in the 50 and $60 \mathrm{w} / \mathrm{o}$ uranium alloys than in the 20 and 40 w/o alloys.

Attempts to study the beta-to-epsilon transformation isothermally were not successful. The fastest cooling rates obtained by the techniques used were on the order of $60 \mathrm{C}$ per sec (110 F per sec). These rates were not fast enough to prevent transformation before the temperature for isothermal transformation was reached. A typical curve of resistance versus time for the 50 and $60 \mathrm{w} / \mathrm{o}$ uranium alloys during attempted isothermal transformation is shown(25) in Figure 11. The initial and final resistance is characteristic of the epsilon phase at the ambient furnace temperature desired for transformation. The break in the curve on cooling is the result of transformation. No matter what the attempted temperature of transformation for these alloys, transformation appeared to be complete in 6 to $10 \mathrm{sec}$.

Because of the method of heating the 20 and $40 \mathrm{w} / 0$ uranium alloys for isothermal transformation, the resistance change during heating and the initial stages of cooling could not be followed. This made interpretation of data for these alloys difficult. General indications are that the transformation is slightly slower in these alloys than in the 50 and $60 \mathrm{w} / 0$ uranium alloys. 


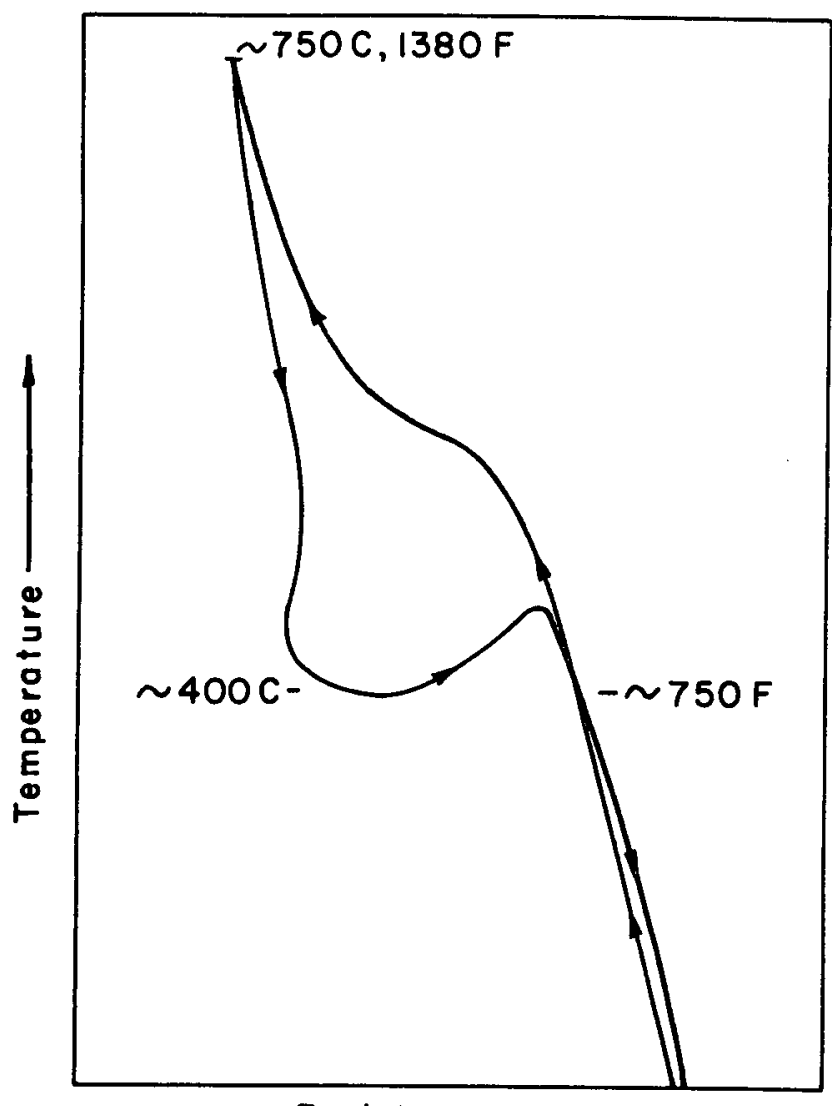

Resistance $\longrightarrow$

FIGURE IO. RESISTANCE-TEMPERATURE CURVE FOR ZIRCONIUM-50 AND 60 w/O URANIUM ALLOYS Heating and cooling rate approximately $50 \mathrm{C} / \mathrm{sec}$ $(90 \mathrm{~F} / \mathrm{sec})$

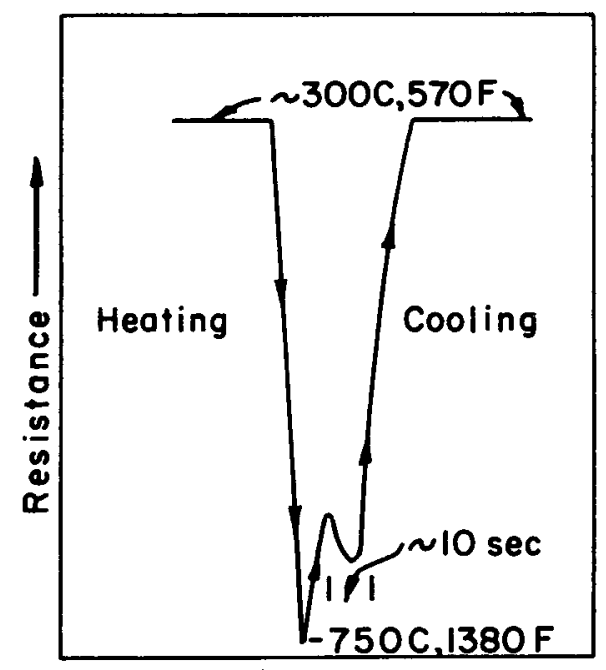

Time $\longrightarrow$

FIGURE II. RESISTANCE CURVE OBTAINED FOR ZIRCONIUM50 AND $60 \mathrm{w} / O$ URANIUM ALLOYS DURING ATTEMPTED ISOTHERMAL TRANSFORMATION 
Jominy end-quench tests indicate that the $22 \mathrm{w} / \mathrm{o}$ uranium alloys transform more quickly than the $41 \mathrm{w} / 0$ uranium alloy. This is inferred from the position of peak hardness on a quenched Jominy bar (Figure 8). However, the time difference for transformation in all of these alloys is evidently small.

Comparing electrical-resistivity data with hardness data seems to indicate that the end of resistance change in these alloys coincides with peak hardness, and, therefore, that a high hardness corresponds to essentially complete transformation of beta to epsilon. Dynamic-modulus measurements also indicate that essentially complete transformation is characterized by high hardness. (22) These measurements were made as a result of the observation that the moduli of samples containing retained beta were about $9 \times 10^{6} \mathrm{psi}$, while fully transformed samples had moduli of about $16 \times 10^{6} \mathrm{psi}$.

The transformation of retained beta in a $41 \mathrm{w} / 0$ uranium alloy as indicated by dynamic-modulus measurements is shown in Figure 12. Initial and final hardnesses for partially and fully transformed samples are given. On the basis of the times between and at the holding temperatures shown, it appears that transformation proceeds slowly at $200 \mathrm{C}(390 \mathrm{~F})$ and below. Extrapolation of the modulus value for Sample A at $400 \mathrm{C}(750 \mathrm{~F}$ ) down to room temperature indicates that the transformation is about 90 per cent completed by the time $400 \mathrm{C}(750 \mathrm{~F})$ is reached. Data obtained during transformation of Sample B at $200 \mathrm{C}(390 \mathrm{~F})$ showed that the reaction proceeds as a hyperbolic function of time. If the same function is applicable at other temperatures, the last vestiges of beta disappear slowly with time.

Dynamic-modulus measurements are a very useful tool in following a transformation, as the modulus of a material is sensitive to crystal structure, while it is relatively insensitive to grain size. Hardness and electricalresistance measurements are sensitive to both.

\section{Nature of the Epsilon Phase}

While epsilon may not form in a manner that fits the classical concept of ordering, the best description that can be applied to epsilon is that it is an ordered phase. The short time required for epsilon to form does not indicate an extensive nucleation-and-growth mechanism but, rather, reorientation of atoms from random to preferred positions on the crystal lattice, which involves diffusion over atomic distances only.

The ordered particles which form from the beta may be the domains or subcells observed metallographically. These domains are restricted to the beta grains from which they form as a result of their orientation dependence on the beta structure. The domains apparently represent different cell 


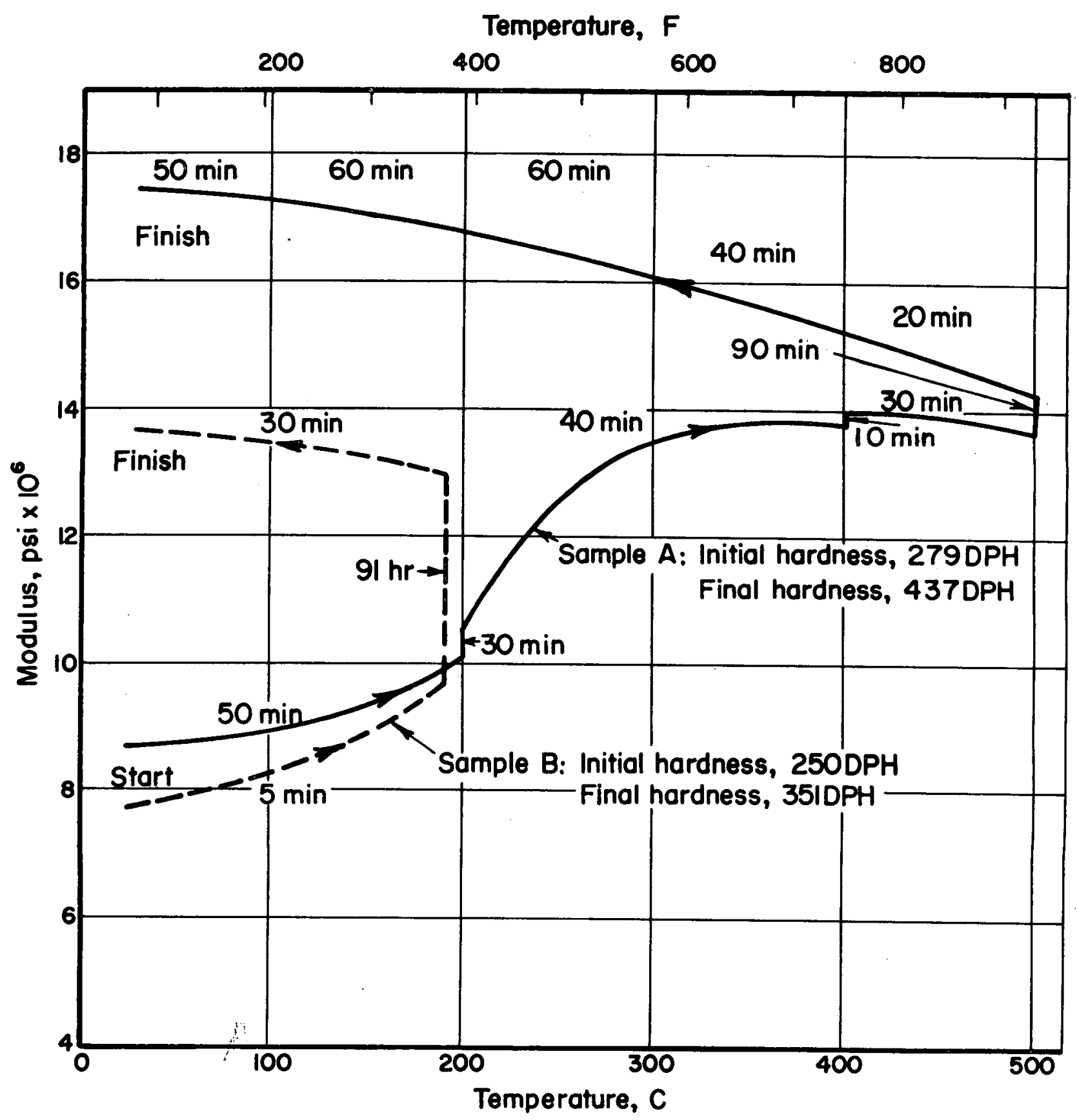

FIGURE 12. DYNAMIC MODULUS TEST OF ZIRCONIUM-4Iw/0 URANIUM Samples water quenched from $1000 \mathrm{C}(1830 \mathrm{~F})$. 
orientations arising from the movement of the uranium and zirconium atoms to different lattice planes. Cold working and annealing the alloys to cause recrystallization of the epsilon eliminates the domains and produces discrete epsilon grains.

The formation of epsilon is accompanied by an increase in hardness. This increase in hardness may possibly be accounted for on the basis of strain associated with the transformation. However, as indicated previously, the diffraction lines due to beta and epsilon overlap with little if any shift in lattice dimensions accompanying the transformation, and there should be little if any strain.

However, high hardness might be expected in epsilon alloys transformed for short times on the basis of the domain structure. The variation in orientation across the domain boundaries appears to inhibit slip, as reported for a transformed $22 \mathrm{w} / \mathrm{o}$ uranium alloy. (8) The high hardness could thus be accounted for as a result of the resistance to deformation offered by the very fine domain substructure. Overaging, or softening, would then accompany growth of the domains.

Such growth would also account for the continuous gradual decrease in electrical resistance of epsilon in a $50 \mathrm{w} / \mathrm{o}$ uranium alloy. (24) The greater portion of resistance change is accomplished in a relatively few seconds during isothermal transformation of these alloys, and results in an increase in resistance when compared with the electrical resistance of retained beta. However, prolonged annealing can result in a final resistivity which is lower than that of retained beta. The initial increase is attributed to the formation of domain boundaries which act to impede electron flow. The gradual decrease could again be accounted for by growth of these domains. This growth is slow, since diffusion is slow at the temperatures at which epsilon exists.

Upon the basis of available data, the description offered for the mechanism of hardening in these alloys is felt to be the best that can be made at this time. However, the theory that the hardening reaction is a result of coherency between the beta and epsilon phases appears possible. Coherency and attendant stresses would also lead to the increase in resistance observed as beta decomposes to epsilon. Since the structure of epsilon has not been unequivocally established, the possibility of a transition phase in the betato-epsilon decomposition may also be considered. In order for these points to be defined, the structure of the epsilon phase must be established and, as indicated earlier, the ability to identify the beta phase, when appearing in conjunction with epsilon, is required. 

THE EFFECTS OF HEAT TREATMENT ON THE MICROSTRUCTURE

OF ZIRCONIUM-URANIUM ALLOYS

Walston Chubb

$\underline{\text { Introduction }}$

A number of studies have been carried out which involve the heat treatment of zirconium-uranium alloys. Much of this work was concerned primarily with the fabricability of alloys $(12,22,28,29)$; however, in a few cases, the effects of heat treatment on microstructure were specifically determined $(27,30)$. Drawing data from all of these studies, there is sufficient information to give a fairly good, though not complete, picture of the microstructural variations that can be achieved in zirconium-uranium alloys.

Alpha zirconium can form from beta zirconium in two ways, but both mechanisms involve a crystallographic relation between the phases. If alloys containing 1 to $20 \mathrm{w} / \mathrm{o}$ uranium are water quenched from the beta phase, they will transform to alpha by a martensitic process. If alloys containing 1 to $46 \mathrm{w} / \mathrm{o}$ uranium are slow cooled from the beta phase, alpha zirconium is nucleated by a time-dependent process and grows by diffusion into an acicular, or Widmanstätten structure. A fine, acicular alpha structure has the appearance of martensite, but is usually much finer.

The beta phase can be retained by water quenching alloys of 20 to 80 w/o uranium. These alloys go through an aging phenomenon, if not quenched rapidly enough, or if aged briefly after quenching. In this condition, they are hard and brittle.

In the transformed condition, epsilon consists of many small grains, or domains, formed within the old beta boundaries. When it is cold worked and annealed, an equiaxed structure is produced.

\section{Alloys Containing 1 to $20 \mathrm{w} / \mathrm{o}$ Uranium}

Alloys containing up to $20 \mathrm{w} / \mathrm{o}$ uranium transform on quenching from the beta phase by a martensitic process. The martensite structure found in alloys containing up to $20 \mathrm{w} / \mathrm{o}$ uranium is shown in Figure 13. This structure is quite soft (240 DPH) and has a hexagonal lattice similar to that of alpha zirconium(22). The effect of heat treatment on this structure is unknown, but, because the structure is supersaturated in uranium, it might be embrittled by aging for short periods. Longer aging periods would produce discrete particles of epsilon. 
When an alloy containing 1 to $20 \mathrm{w} / 0$ uranium is air cooled, furnace cooled, or isothermally transformed from the beta phase, alpha zirconium is nucleated by a process which is time-dependent in nature. The product is not clearly distinguishable, in some cases, from the martensite produced on water quenching. The very fine, acicular structure produced on air cooling a zirconium- $10 \mathrm{w} / \mathrm{o}$ uranium alloy is illustrated in Figure 14 . The acicular zirconium structure produced on air cooling a zirconium-19 w/o uranium alloy is illustrated in Figure 15. These structures are relatively soft (230 and $240 \mathrm{DPH}$, respectively), indicating that any strains arising from transformation have been relieved. It is probable that some growth of the needles in Figures 14 and 15 occurred during air cooling, for it would appear that only time is required for the structures of Figures 14 and 15 to evolve into the structure of Figure 16. The Widmanstätten plates in Figure 16 are evidently the product of considerable diffusion, having a hardness of only $210 \mathrm{DPH}$. Additional time at temperature, or slower cooling rates, would undoubtedly produce a more equiaxed structure. Acicular alpha zirconium tends to form at beta grain boundaries as shown in Figure 15. This effect has been observed in 10,19 , and $22 \mathrm{w} / \mathrm{o}$ uranium alloys.

The point at which epsilon phase appears during heat treating is not apparent from Figures 14, 15, and 16. The phase between the Widmanstätten plates in Figure 16 is presumably epsilon, but, if epsilon had formed in the structures of Figures 14 and 15 , it would not be readily observed.

If alloys containing 1 to $20 \mathrm{w} / 0$ uranium are hot worked at temperatures between 600 and $800 \mathrm{C}$ (1110 and $1470 \mathrm{~F}$ ), a structure similar to that shown in Figure 17 is obtained. This structure shows some elongation of the alphazirconium particles in the rolling direction. Such preferred orientation can be removed by solution treating at 900 or $1000 \mathrm{C}(1650$ or $1830 \mathrm{~F})$ for a few minutes (22). If alloys containing 1 to $46 \mathrm{w} / 0$ uranium are warm worked, or cold rolled and annealed at temperatures below $600 \mathrm{C}(1110 \mathrm{~F})$, a structure similar to that shown in Figure 18 is obtained. The structure produced exhibits considerable preferred orientation, and, depending on the time and temperature, may retain cold work. The treatment given the sample shown in Figure 18 is sufficient to cause recrystallization, but beta treatment would be required to remove preferred orientations.

When an alloy containing 1 to $20 \mathrm{w} / \mathrm{o}$ uranium is equilibrated at temperatures in the alpha-plus-beta region, $\alpha$ is precipitated and the beta becomes enriched in uranium. If the enriched beta contains more than $20 \mathrm{w} / \mathrm{o}$ uranium, then this portion of the alloy will transform on cooling like alloys of more than $20 \mathrm{w} / \mathrm{o}$ uranium content. 


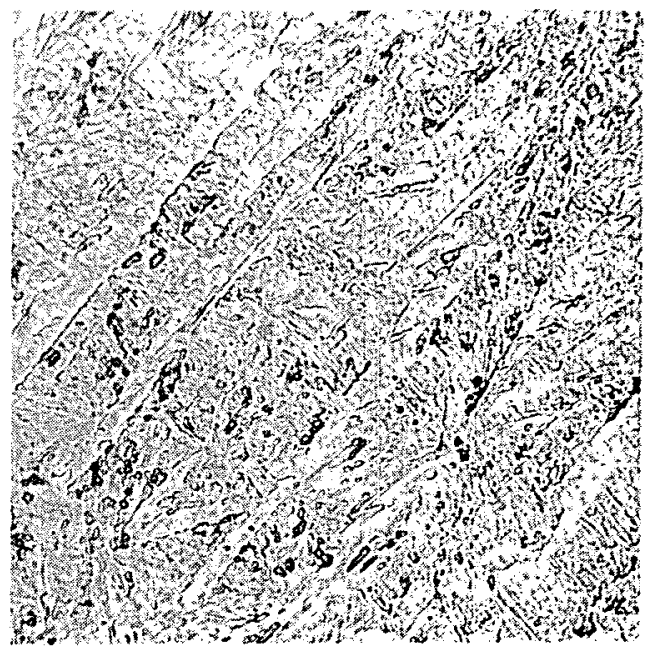

$500 \mathrm{X}$

N17531

FIGURE 13. ZIRCONIUM-10 w/o URANIUM: $1 \mathrm{HR}$ AT $900 \mathrm{C}(1650 \mathrm{~F})$, WATER QUENCHED; MARTENSITIC STRUCTURE

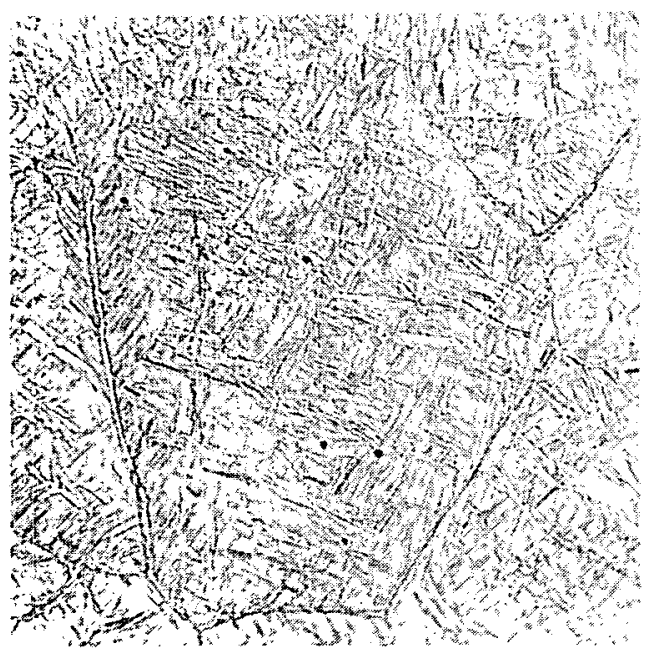

$500 \mathrm{X}$

N17532 1 HR AT $900 \mathrm{C}(1650 \mathrm{~F})$, AIR COOLED; ACICULAR ALPHA ZIRCONIUM STRUCTURE

FIGURE 14. ZIRCONIUM-10 w/o URANIUM:

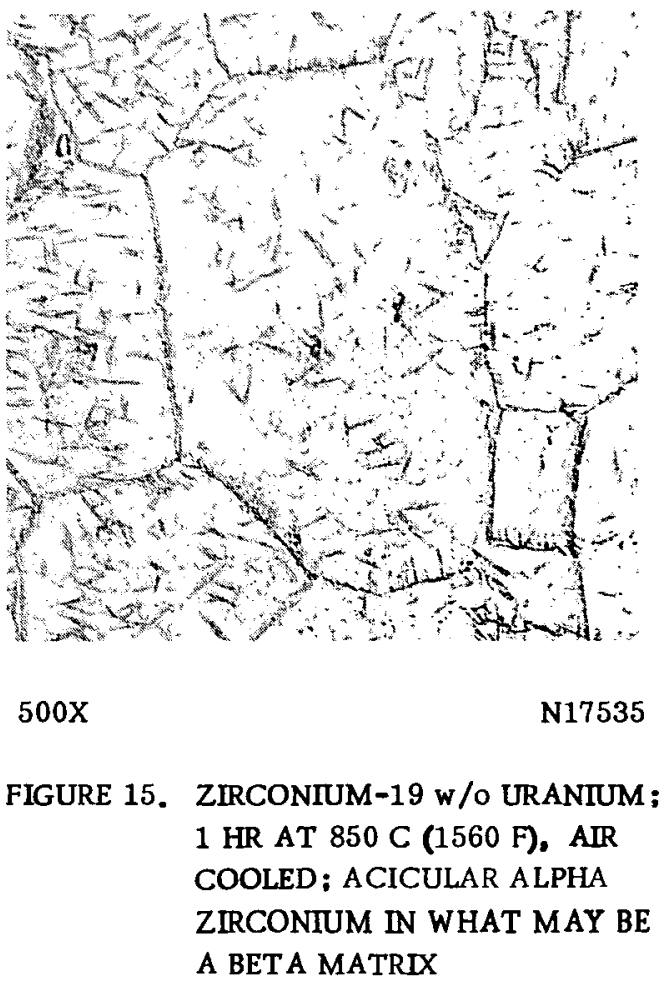

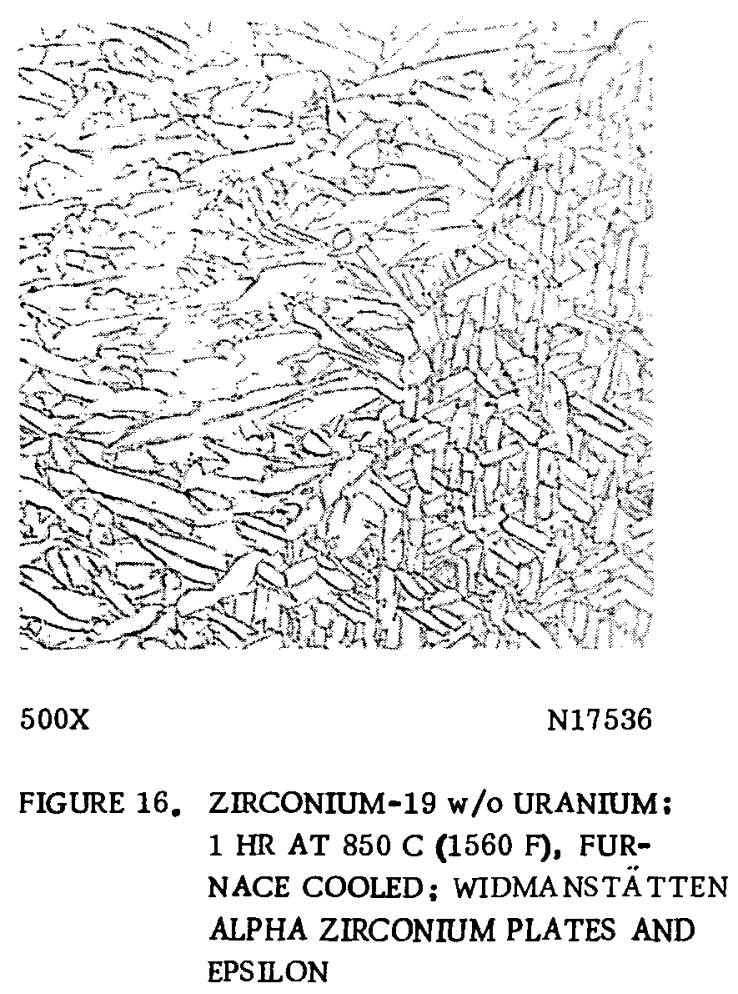

FIGURE 16. ZIRCONIUM-19 w/o URANIUM: 1 HR AT 850 C (1560 F), FURNACE COOLED; WIDMANSTÄTTEN ALPHA ZIRCONIUM PLATES AND EPSILON 


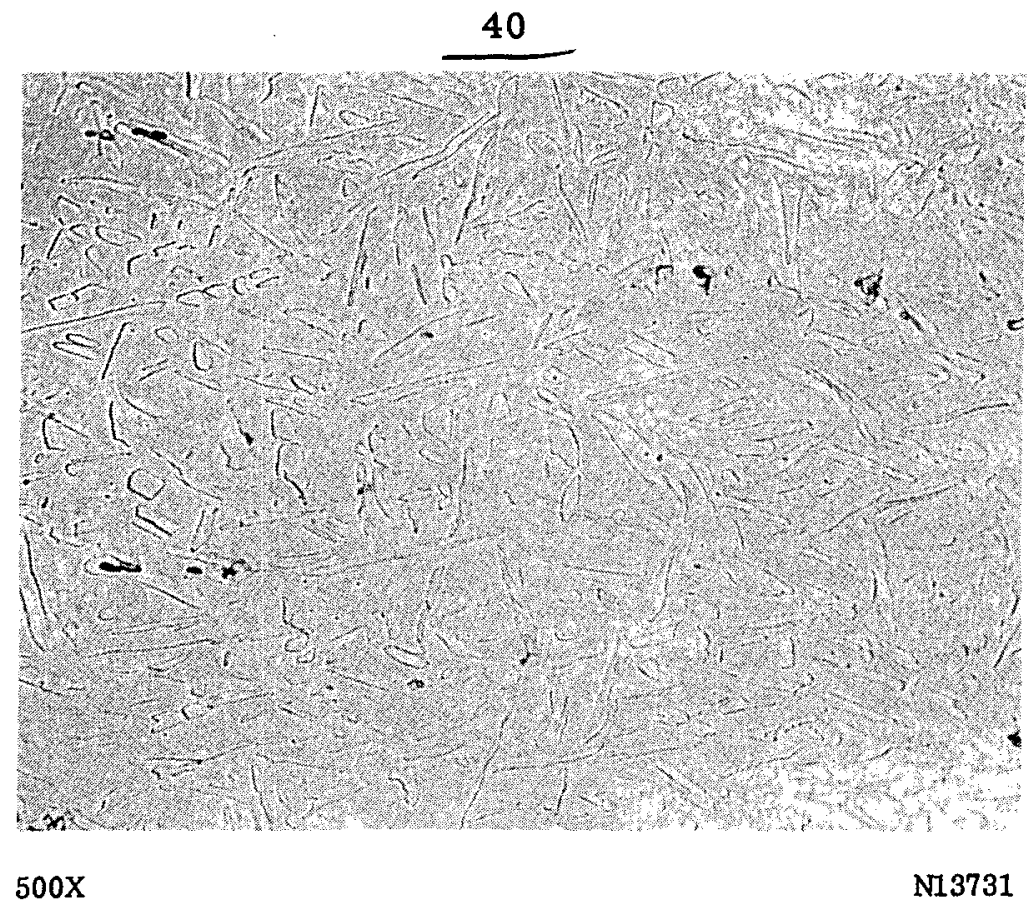

FIGURE 17; ZIRCONIUM-19 w/o URANIUM; HOT ROLLED AT 675 C (1250 F), WATER QUENCHED; ALPHA ZIRCONIUM PLATES IN A RETAINED BETA MATRIX

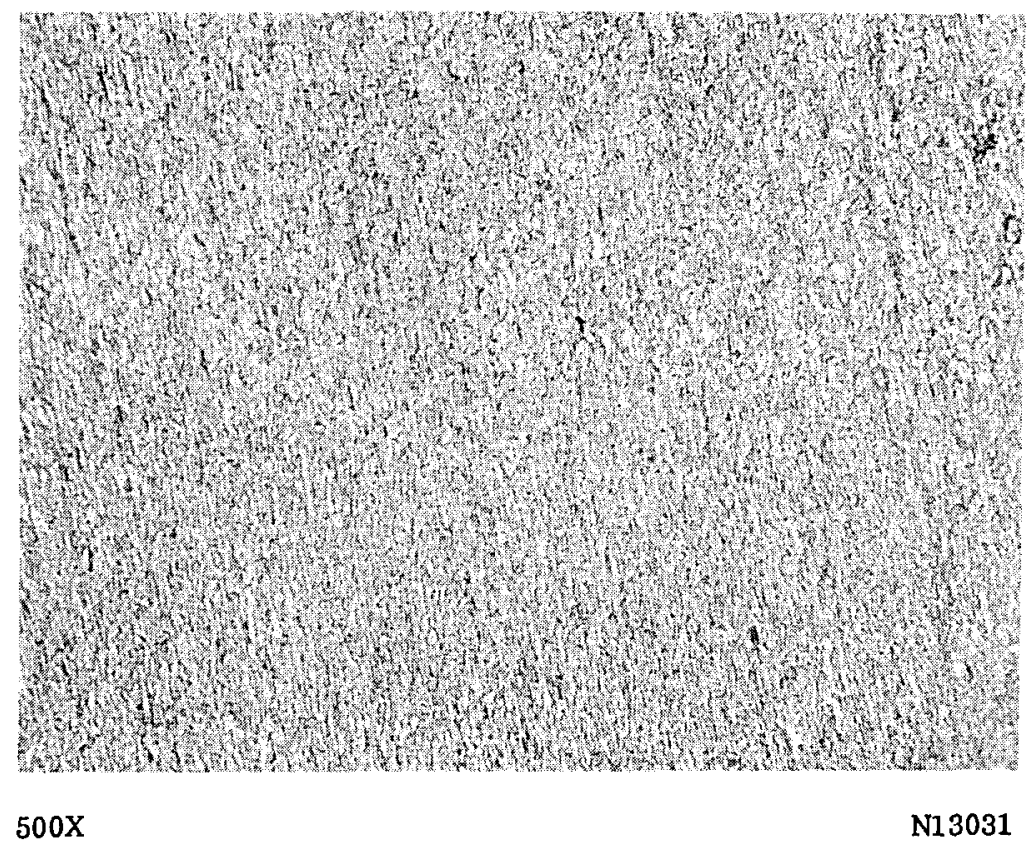

FIGURE 18. ZIRCONIUM-19 w/o URANIUM; COLD ROLLED, ANNEALED 20 HR AT 570 C (1060 F); ALPHA ZIRCONIUM AND EPSILON

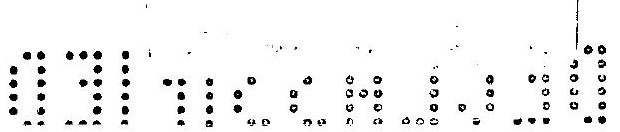


Usually, coarsened microstructures somewhat similar to that shown in Figure 17 are produced by alpha-plus-beta treatments, and the appearance of these two-phase structures is nearly unchanged by transformation of the beta to epsilon. The epsilon structure formed within second-phase particles of beta by transformation has not been observed.

\section{Alloys Containing 20 to $80 \mathrm{w} / \mathrm{o}$ Uranium}

The distinction between alloys containing less than $20 \mathrm{w} / \mathrm{o}$ uranium and those containing more than $20 \mathrm{w} / \mathrm{o}$ uranium is based on the absence of martensitic structures in alloys of $20 \mathrm{w} / \mathrm{o}$ uranium or higher. Instead, the beta phase is retained by water quenching these alloys.

A typical retained-beta structure is shown in Figure 19. The retention of beta is accompanied by the onset of a new reaction which is time dependent and has the characteristics of an age-hardening reaction. While the structure shown in Figure 19 appears to be retained beta, it is very hard (430 $\mathrm{DPH})$, indicating that the decomposition reaction has begun in the $22 \mathrm{w} / \mathrm{o}$ uranium alloy during quenching.

In a $41 \mathrm{w} / \mathrm{o}$ uranium alloy the decomposition reaction can be suppressed entirely by rapid quenching. The beta retained in this alloy, Figure 20, is soft (240 DPH), but can be aged to $450 \mathrm{DPH}$ by heat treating a few seconds at $500 \mathrm{C}(930 \mathrm{~F})$. It is unknown whether this degree of aging can be observed by metallographic means, but, if the $41 \mathrm{w} / \mathrm{o}$ uranium alloy is air cooled, overaging occurs and some transformation is detectable. The resulting hardness is about $400 \mathrm{DPH}$. The corresponding structure, shown in Figure 21 , probably consists of epsilon, some retained beta, and some alpha zirconium.

The nucleation of alpha zirconium in alloys containing 20 to $46 \mathrm{w} / \mathrm{o}$ uranium should result in an acicular structure similar to that found in alloys containing 1 to $20 \mathrm{w} / \mathrm{o}$ uranium. That this is indeed true can be seen by comparing Figure 22 with Figure 15. The hardness of the structure shown in Figure 22 is only about $290 \mathrm{DPH}$.

The effect of slower cooling rates on the structure of these alloys is shown in Figure 23. The hardness of this structure is about $230 \mathrm{DPH}$, indicating that the phases present are approximately equilibrium alpha zirconium and epsilon. Still slower cooling rates result in the nearly equiaxed structure shown in Figure 24, where epsilon is the matrix phase.

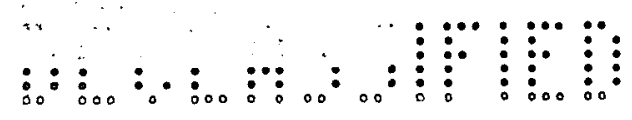




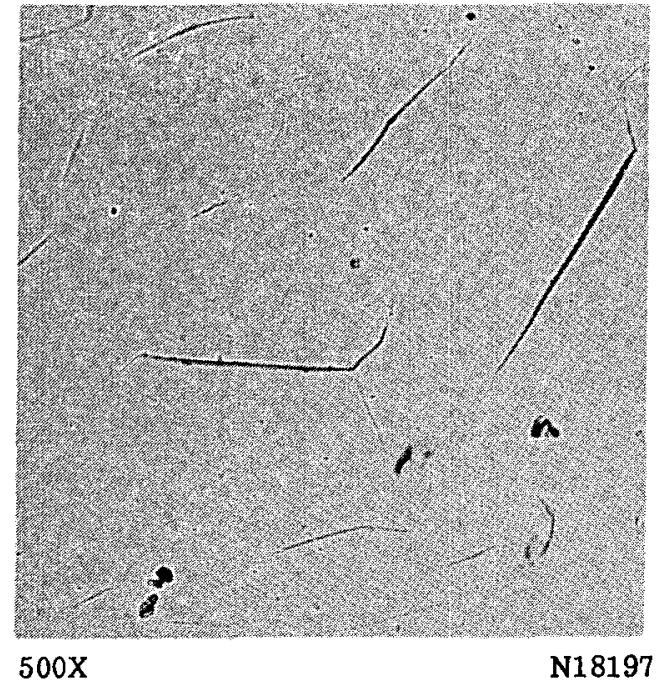

FIGURE 19. ZIRCONIUM-22 W/o URANIUM; 1 HR AT $900 \mathrm{C}$ (1650 F), WATER QUENCHED; RET AINED BETA STRUCTURE (SEE TEXT)

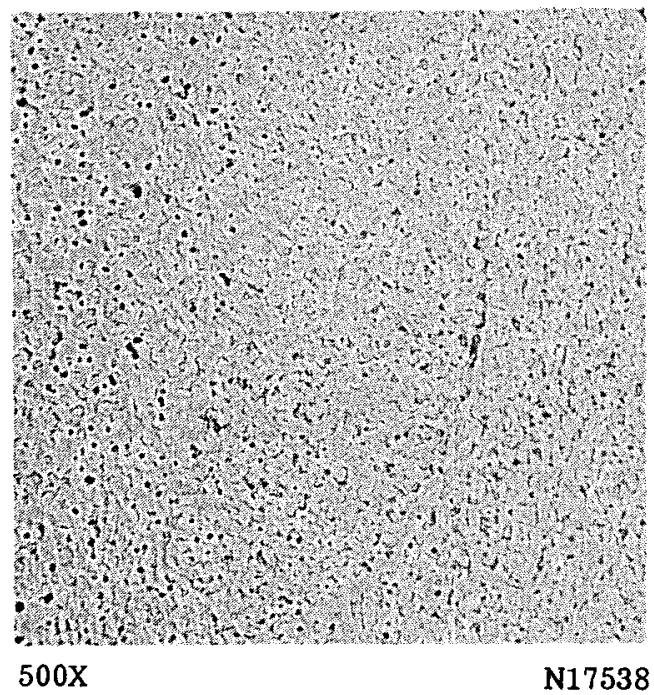

FIGURE 21. ZIRCONIUM-41 w/o URANIUM; 1 HR AT $850 \mathrm{C}(1560 \mathrm{~F})$, AIR COOLED; EPSILON PLUS POSSIBLY SOME RET AINED BETA AND SOME ALPHA ZIRCONIUM

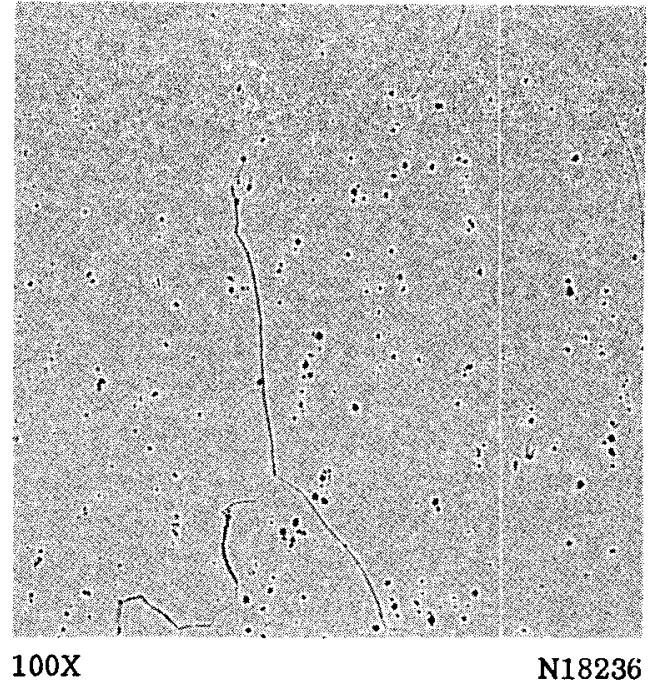

FIGURE 20. ZIRCONIUM-41 w/o URANIUM; 1 HR AT $850 \mathrm{C}(1560 \mathrm{~F})$, WATER QUENCHED; RETAINED BETA STRUCTURE

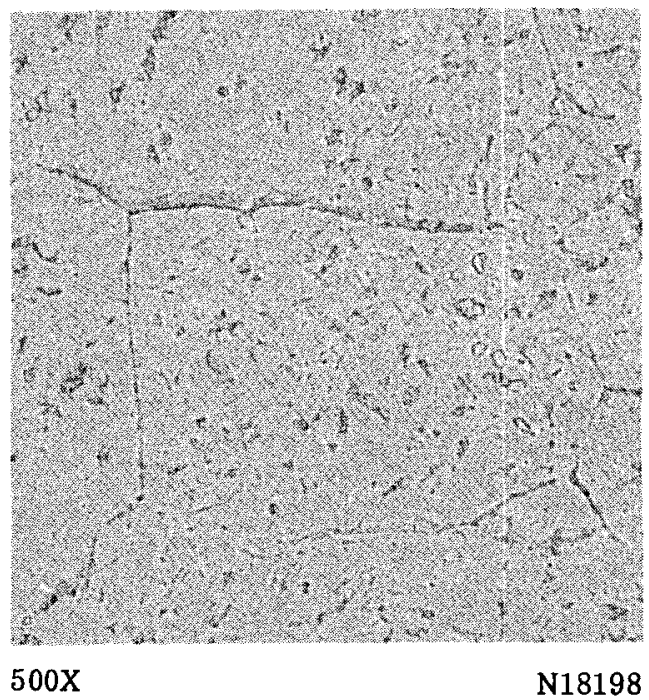

FIGURE 22. ZIRCONIUM-22 W/O URANIUM; 1.HR AT $900 \mathrm{C}(1650 \mathrm{~F})$, AIR COOLED; ACICULAR ALPHA FORMING IN A MATRIX OF BETA

Beta boundaries outlined by a precipitate of alpha. 


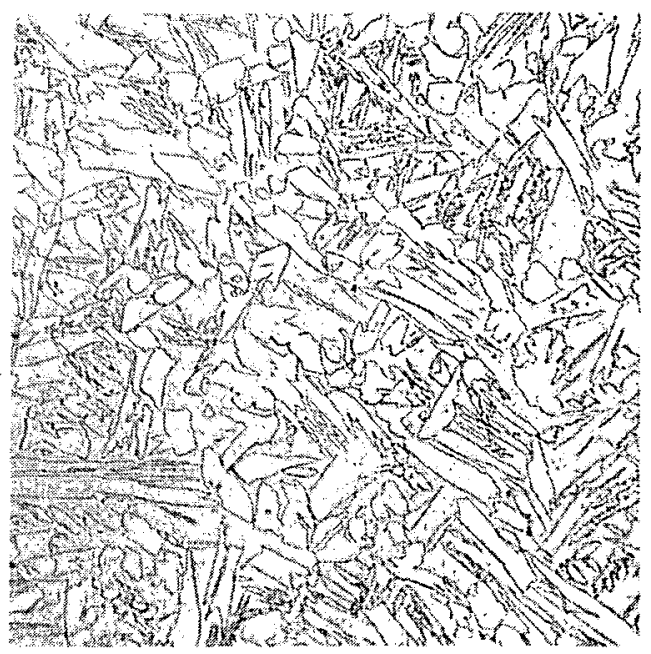
$500 \mathrm{X}$

N18199

FIGURE 23. ZIRCONIUM-22 W/o URANIUM; 1 HR A T 900 C (1650 F). FURNACE COOLED; WIDMANSTÄ TTEN ALPHA ZIRCONIUM AND EPSILON

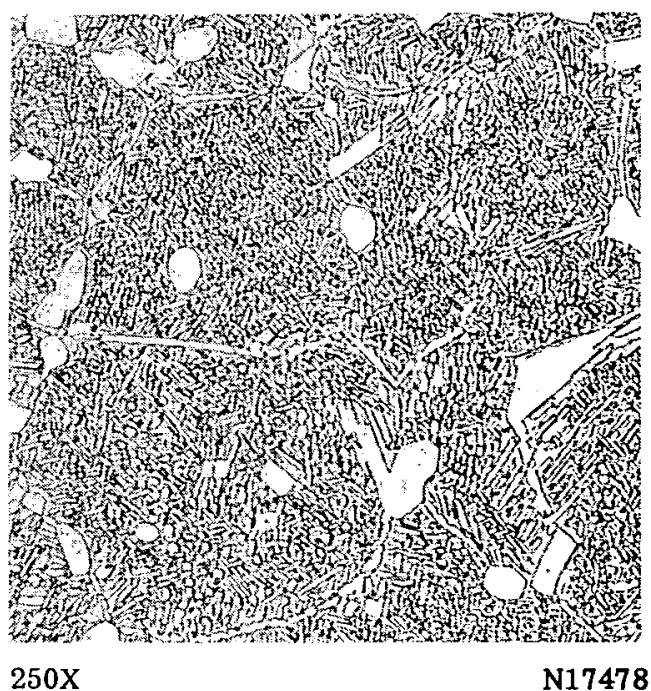

FIGURE 25. ZIRCONIUM-22 W/O URANIUM; 36 HR AT 840 C (1550 F), WATER QUENCHED; REHEATED TO $760 \mathrm{C}$ (1400 F) FOR $5 \mathrm{HR}$, FURNACE COOLED; ALPHA ZIRCONIUM AND EPSILON

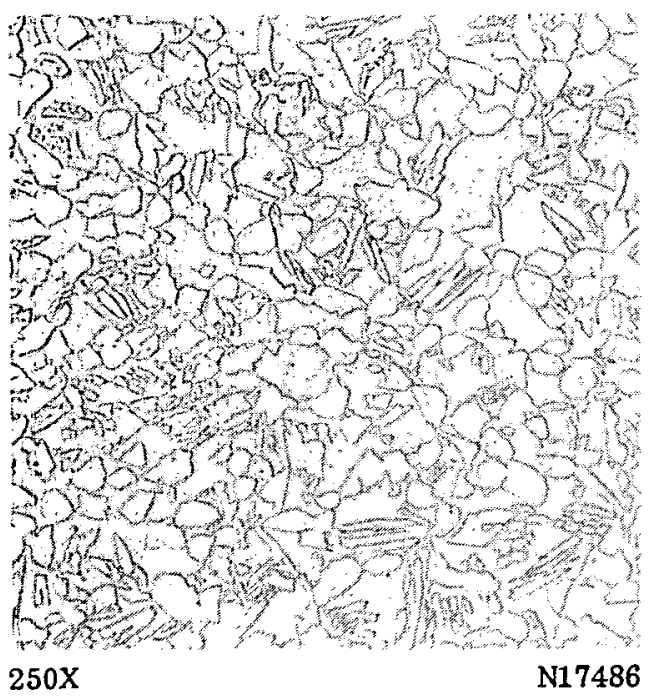

FIGURE 24. ZIRCONIUM-22 w/o. URANIUM; $36 \mathrm{HR}$ AT $840 \mathrm{C}(1550 \mathrm{~F}), 2 \mathrm{HR}$ A T $780 \mathrm{C}(1440 \mathrm{~F}), 5 \mathrm{HR}$ AT $700 \mathrm{C}(1300 \mathrm{~F})$, FURNACE COOLED; ALPHA ZIRCONIUM AND EPSILON

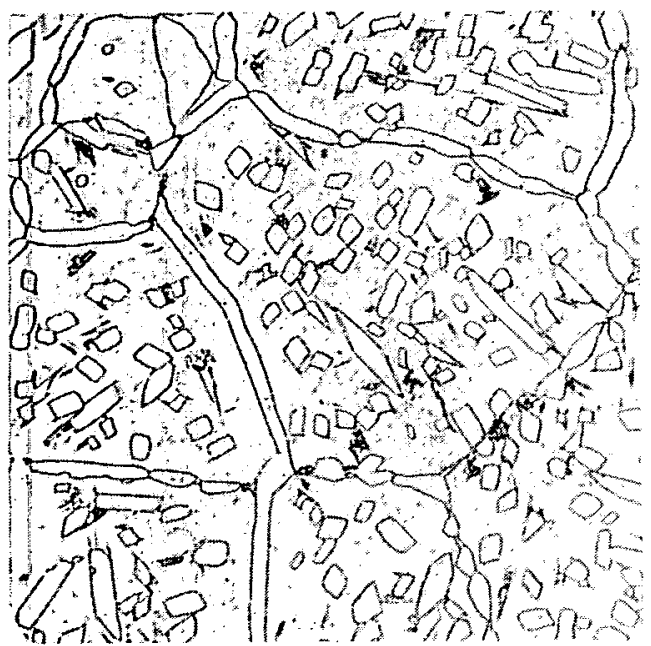
$250 \mathrm{X}$

N17347

FIGURE 26. ZIRCONIUM-22 w/o URANIUM; 36 HR AT 840 C (1550 F), WATER QUENCHED, REHEATED TO $760 \mathrm{C}$ (1400 F) FOR $100 \mathrm{HR}$, FURNACE COOLED; ALPHA ZIRCONIUM AND EPSILON 


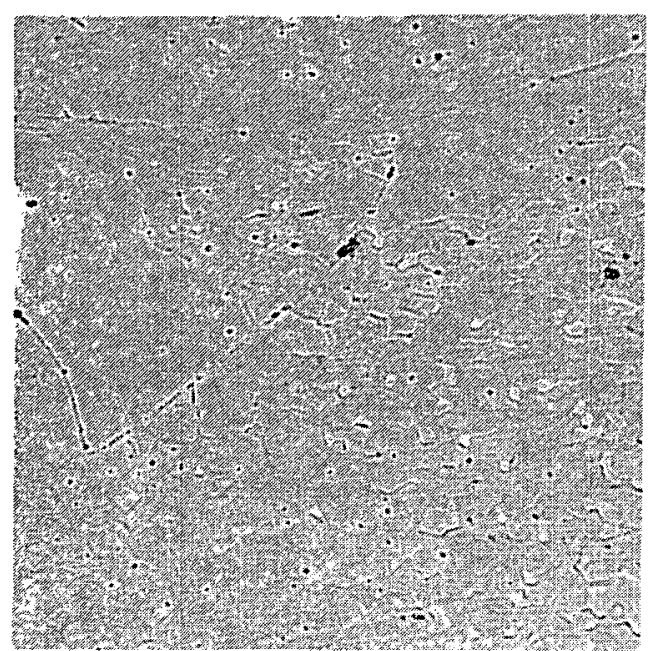

$500 \mathrm{X}$

N301
FIGURE 27. ZIRCONIUM-48 w/o URANIUM; 5 HR AT $1070 \mathrm{C}$ (1960 F). WATER QUENCHED, ANNEALED 32 DAYS AT 575 C (1070 F), FURNACE COOLED; EPSILON STRUCTURE

Large grain boundaries are former beta boundaries.

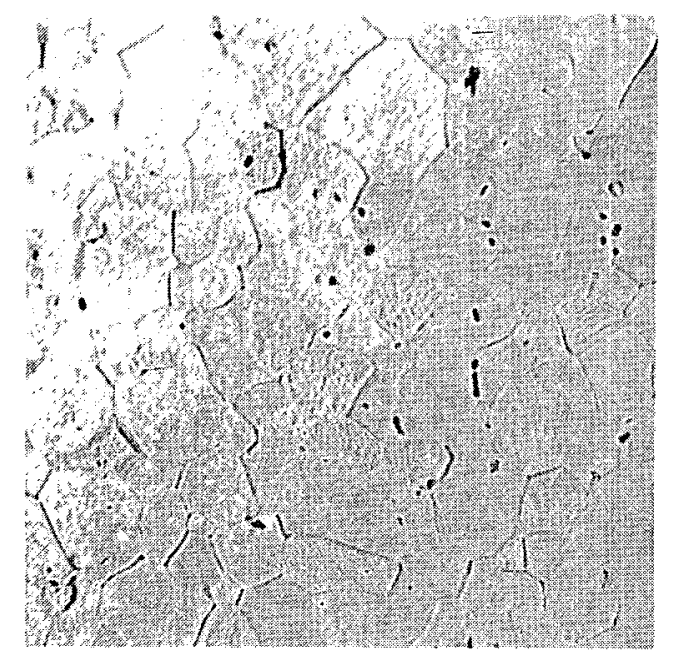

$500 \mathrm{X}$

N16912

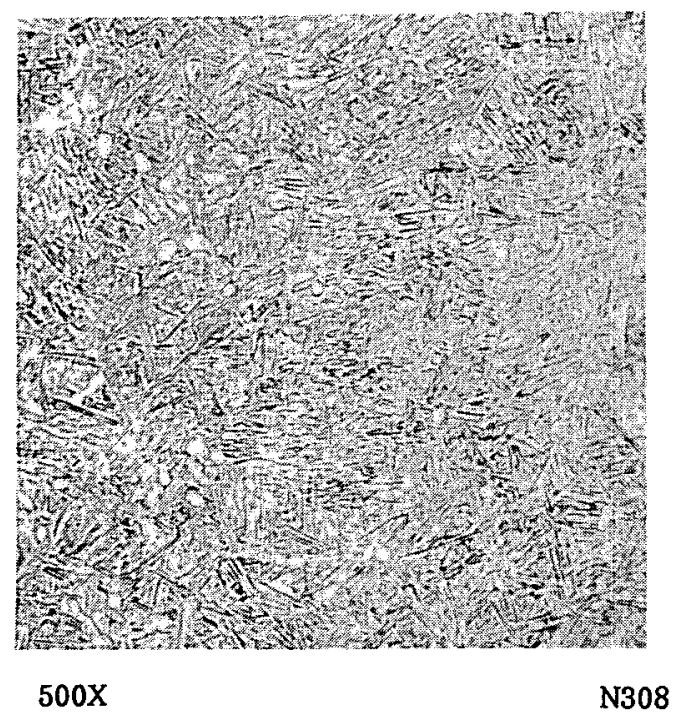

FIGURE 28. ZIRCONIUM-49 W/O URANIUM; 5 HR AT $1070 \mathrm{C}$ (1960 F). WA TER QUENCHED, COLD SWAGED, A NNEALED AT $550 \mathrm{C}(1020 \mathrm{~F})$, COLD SWAGED, ANNEALED AT $550 \mathrm{C}(1020 \mathrm{~F})$, COLD SWAGED, ANNEALED 7 DAYS AT 575 C (1070 F); EPSILON PHASE

FIGURE 29. ZIRCONIUM-78 W/o URANIUM; 5 HR AT $1070 \mathrm{C}$ (1960 F), 32 DAYS AT 535 C (1000 F), FURNACE COOLED; ACICULAR ALPHA URA NIUM AND EPSILON STRUCTURE 
By nucleating alpha zirconium in the grain boundaries, it is possible by further treatments to produce structures in which the epsilon phase is nearly completely surrounded by alpha zirconium. This has been done with the 22 w/o uranium alloy as illustrated in Figures 25 and 26(30). In these structures the alpha was nucleated at the grain boundaries by quenching and reheating. It would be worthwhile to determine whether similar or better results would be achieved by air cooling to give the structure shown in Figure 22 before reheating in the alpha-plus-beta region. Because of the necessity for producing many alpha nuclei in the beta boundaries, the resultant alpha network will always consist of a chain of several grains. All of the grain boundaries in the alpha phase cannot be seen in the microstructures of Figures 25 and 26.

Retained beta zirconium containing aboùt $48 \mathrm{w} / 0$ uranium has a hardness of about $230 \mathrm{DPH}$. On aging this material for a short time at 400 or $450 \mathrm{C}(750$ or $840 \mathrm{~F})$, the hardness increases to 400 or $420 \mathrm{DPH}(12)$. After aging for 32 days at $575 \mathrm{C}(1070 \mathrm{~F})$, the structure shown in Figure 27 is produced and the hardness is $250 \mathrm{DPH}$. The epsilon grains in this structure have formed within the old beta grains, and can be seen etched in relief in part of the structure. It is difficult to show clearly all of the epsilon grains in this type of structure.

If a $49 \mathrm{w} / \mathrm{o}$ uranium alloy is cold worked and annealed 7 days at $575 \mathrm{C}$ $(1070 \mathrm{~F})$, the recrystallized epsilon structure of Figure 28 is developed. Actually the specimen described was cold worked and annealed for 1 week at $575 \mathrm{C}(1070 \mathrm{~F})$ three times. No data are available on the effect of variables on the grain size of recrystallized epsilon.

It has been reported that the beta phase can be retained by quenching alloys containing up to $80 \mathrm{w} / \mathrm{o}$ uranium. When beta is not retained and alpha uranium forms in these uranium-rich alloys it precipitates in an acicular habit form $(31)$ much like that characterizing the precipitation of alpha zirconium in the zirconium-rich alloys. The microstructure produced by homogenizing a $78 \mathrm{w} / 0$ uranium alloy at $1070 \mathrm{C}(1960 \mathrm{~F})$, followed by quenching and heat treating 32 days at $535 \mathrm{C}(1000 \mathrm{~F})$ is shown in Figure 29.

\section{Discussion}

Although much heat treating has been done on zirconium-uranium alloys, additional studies are needed. It appears that the range up to $30 \mathrm{w} / \mathrm{o}$ uranium would be most benefitted by a study of the effect of heat-treatment variables on the shape and distribution of the alpha-zirconium phase. This has been done with a $22 \mathrm{w} / \mathrm{o}$ uranium alloy, but further study of this alloy and of other alloys would be worthwhile. 
The effects of heat-treatment variables on the epsilon structure also should be studied. While it is probable that heat treatment will be less effective in varying the microstructure of the alloys in the vicinity of the epsilon phase, attempts to vary the distribution of second-phase particles, whether alpha zirconium or alpha uranium, should prove worthwhile. A determination also of the effects of various transformation-type heat treatments, and of cold work and annealing to produce recrystallization, on the formation and grain size of epsilon is also needed. 


\title{
STRENGTH CHARACTERISTICS OF ZIRCONIUM-URANIUM ALLOYS
}

\author{
Lyle L. Marsh, Jr.
}

The mechanical strength of zirconium-base alloys, like the properties of other metal-base alloys, depends not only on composition, but also on the microstructure; that is, the type, amount, and distribution of phases. Impurity and alloy elements affect the beta (BCC) to alpha (HCP) transformation of zirconium and, therefore, affect not only the phases present at room temperature, but also the size and shape of the microconstituents. Thus, impurity elements such as oxygen, nitrogen, and carbon may exert a tremendous influence on the mechanical properties of zirconium.

Crystal-bar zirconium, processed to minimize contamination, is soft and ductile and will have a room-temperature tensile strength in the range 28,000 to $38,000 \mathrm{psi}$ with an elongation of about 50 per cent. A crystal-bar zirconium-0.1 w/o oxygen alloy will have a tensile strength of approximately 52, 000 psi at room temperature. The first sponge zirconium made had a high oxygen content, and possessed a tensile strength of 70, 000 to 90,000 psi at room temperature, with an elongation of only about 5 per cent. Sponge zirconium produced more recently has a lower oxygen content. It has a tensile strength of only about 52,000 psi, but an elongation of $25-30$ per cent. The latter values are comparable to those obtained from a zirconium- $0.1 \mathrm{w} / \mathrm{o}$ oxygen alloy made from crystal-bar zirconium. It is apparent from the above data that improved process control for sponge zirconium has resulted in roughly a 50 per cent decrease in strength with a severalfold increase in tensile ductility. Although the impurity content of zirconium alloys is very important, it has not been reported by many investigators. There has, however, been a gradual evolution toward higher purity. Because of these factors, it is frequently difficult to rationalize the results of early work with those of more recent studies.

Zirconium-uranium alloys have long been regarded as promising for reactor fuel, and much work has been done to develop various zirconiumuranium alloys. However, a detailed and systematic study of the binary system to evaluate the compositional dependence of heat-treatment characteristics and the effects on mechanical properties of corrosion and fabrication as directly related to heat treatment has not been undertaken. Recently, several studies have been made to bridge this gap in the knowledge of zirconium-uranium alloys $(22,38,39)$. Since much of the early mechanicalproperty data reported in the literature was determined on material of variable fabrication history and, nominally, in the alpha-annealed condition, it was not until these more recent studies of alloys richer in uranium were undertaken that the peculiarities of beta-phase decompositions were observed.

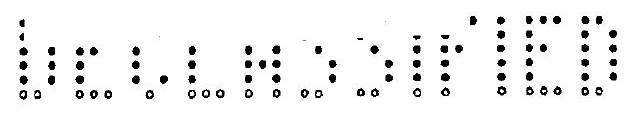


On the basis of the reported data, the mechanical properties of zirconium-uranium alloys have been divided into two groups for analysis: (1) data on alloys in the alpha-treated condition, and (2) data concerned primarily with beta-phase decomposition products. Before reviewing these data, a brief examination of the mechanical properties of the microconstituents is desirable.

The solid solubility of uranium in alpha zirconium is less than $1.0 \mathrm{w} / \mathrm{o}$ uranium(43). As a consequence, appreciable solid-solution strengthening of alpha is not to be expected, and the bulk of any strengthening will be dependent on the size and distribution of the beta-phase decomposition products, particularly of the epsilon phase. Experimental evidence obtained on alloys in the composition range where the volume per cent of the epsilon phase is large indicates that this phase is comparatively hard $(38,39)$ and of limited ductility. Therefore, the mechanical properties of zirconium-rich uranium alloys may be expected to be intermediate between the properties of alpha zirconium and epsilon.

The Effects of Composition on Mechanical Properties in the Annealed Condition

A fairly good picture of the properties of annealed zirconium-uranium alloys can be gained from hot-hardness data. Data for alloys across the system have been plotted on the constitutional diagram and are shown in Figure 30(39).

The early tensile data for various alloy compositions and temperatures are summarized in Figure 31 and Table 1. There is considerable scatter, but a trend of increasing strength with greater uranium content is shown. Much of the scatter can be attributed to variations in hot-rolling and annealing temperatures, as well as to variations in melting stock and melting practice. Contamination by carbon, oxygen, or nitrogen, in general, results in higher tensile strength and reduced tensile ductility for annealed alloys and contributes to the scatter also.

Figure 32 and Table 2 contains more recent tensile data obtained for alloys prepared by induction and by arc melting(38). The alloys were forged and rolled at temperatures, depending on composition, between $700 \mathrm{C}$ and $925 \mathrm{C}$ (1300 F and $1700 \mathrm{~F}$ ) and were vacuum annealed 24 hours at $575 \mathrm{C}$ (1065 F). Induction melting consistently resulted in lower tensile ductility, primarily because of carbon pickup from graphite crucibles. The tensile ductility at room temperature decreases continuously with increasing uranium and exhibits semibrittle behavior in the composition range 40 to $70 \mathrm{w} / \mathrm{o}$ uranium, presumably due to the epsilon phase. The effect of epsilon-phase formation on the dynamic modulus at various temperatures 

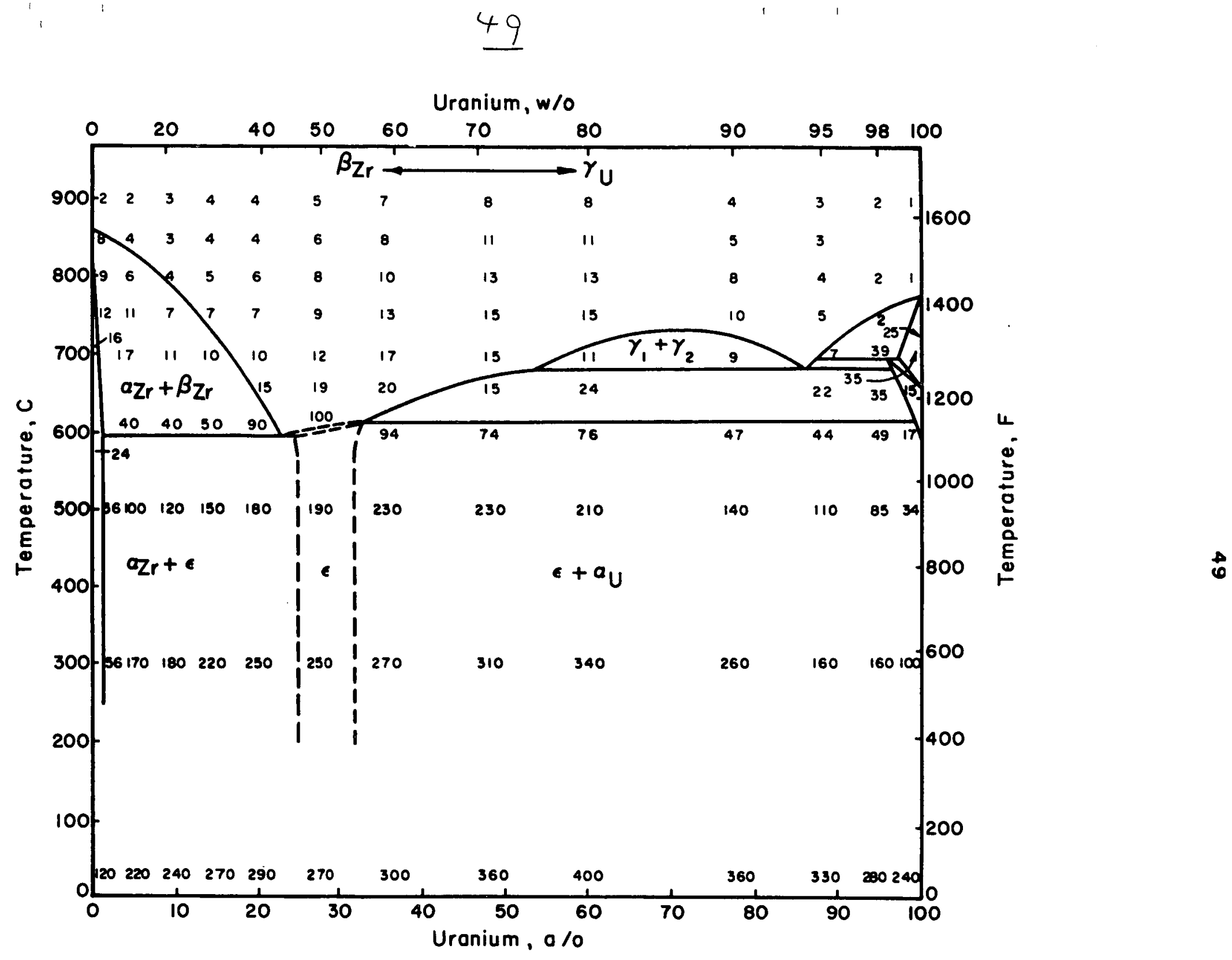

FIGURE 30. HARDNESS - TEMPERATURE RELATIONSHIPS IN THE ZIRCONIUM-URANIUM SYSTEM Hardness in DPH, $\mathrm{kg} / \mathrm{mm}^{2}$ 


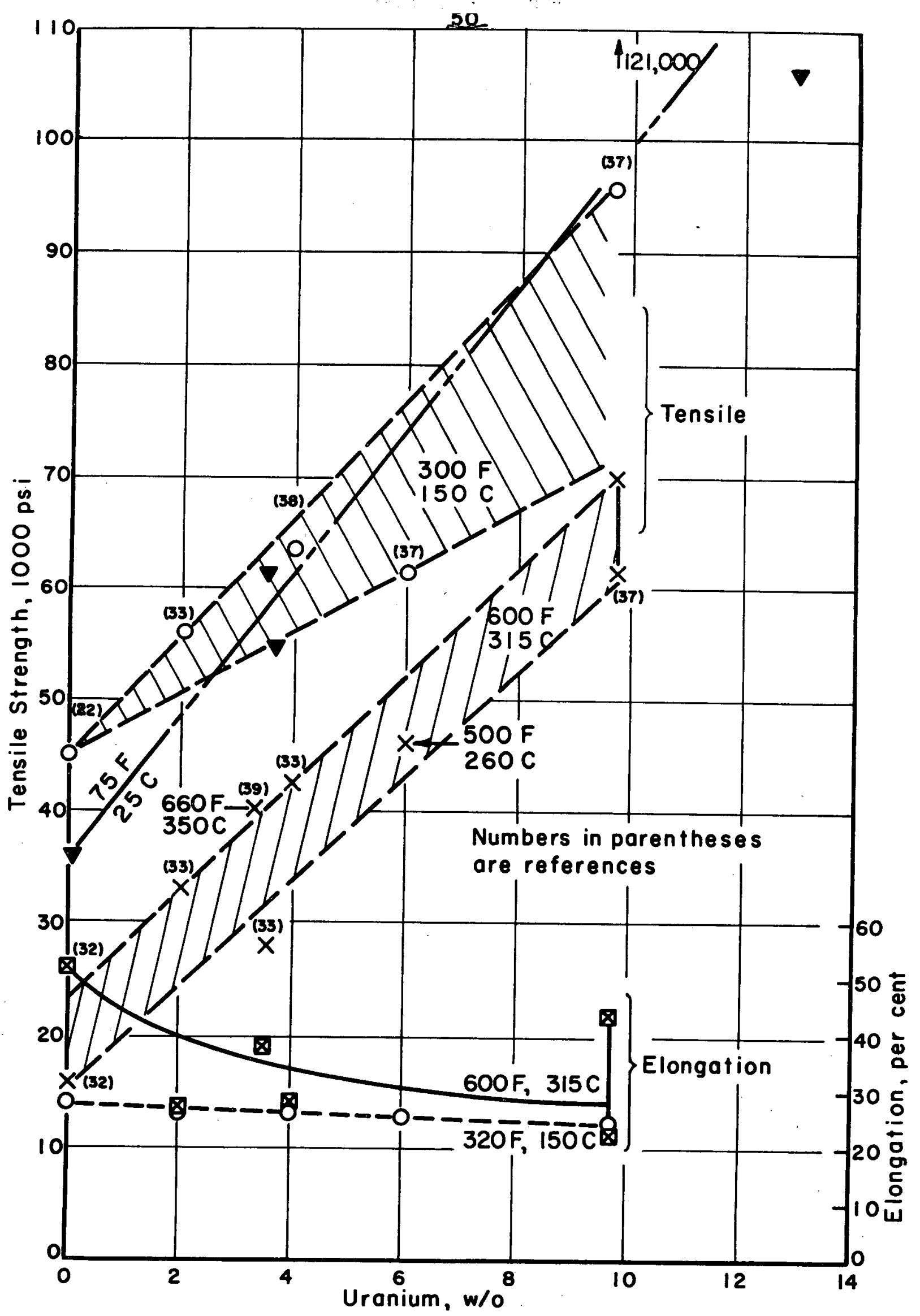

FIGURE 3I. TENSILE PROPERTIES OF ARC-MELTED ZIRCONIUMURANIUM ALLOYS PREPARED FROM CRYSTAL-BAR ZIRCONIUM CONFFIDENTIAL 
51

TABLE 1. RESULTS OF EARLY STUDIES OF TENSILE PROPERTIES OF ZIRCONIUM-URANIUM ALLOYS

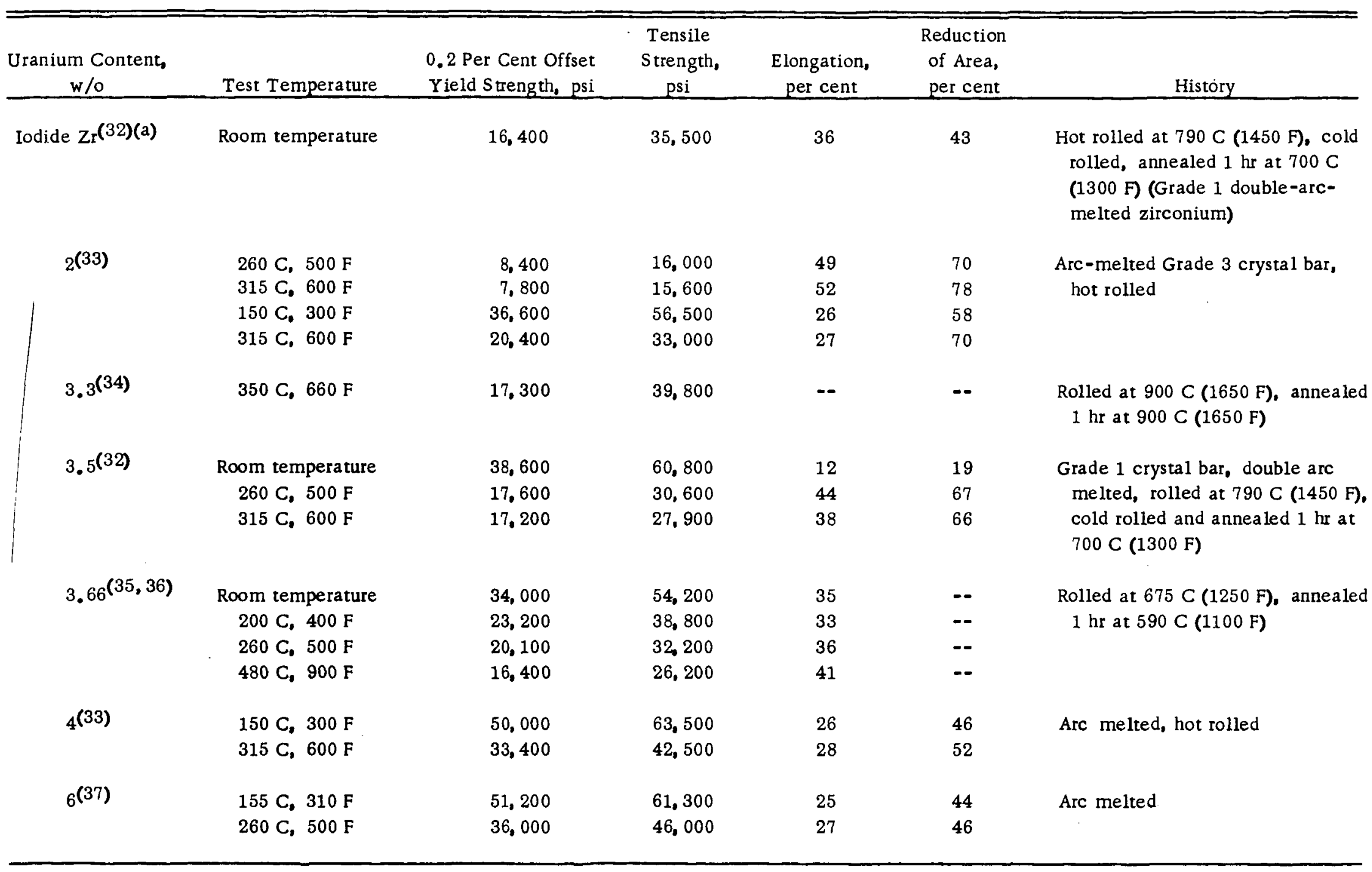


52

TABLE 1. (Continued)

\begin{tabular}{|c|c|c|c|c|c|c|}
\hline $\begin{array}{l}\text { Uranium Content, } \\
\text { w/o } \\
\end{array}$ & Test Temperature & $\begin{array}{l}0.2 \text { Per Cent Offset } \\
\text { Yield Strength, psi }\end{array}$ & $\begin{array}{l}\text { Tensile } \\
\text { Strength, } \\
\text { psi }\end{array}$ & $\begin{array}{c}\text { Elongation, } \\
\text { per cent }\end{array}$ & $\begin{array}{l}\text { Reduction } \\
\text { of Area, } \\
\text { per cent }\end{array}$ & History \\
\hline \multirow[t]{4}{*}{$9.7^{(37)}$} & Room temperature & $103,000-117,000$ & 121,000 & 18 & 37 & \multirow[t]{4}{*}{ Arc melted } \\
\hline & $150 \mathrm{C}, 300 \mathrm{~F}$ & $85,000-90,000$ & $\begin{array}{r}91,000- \\
96,000\end{array}$ & $25-34$ & $46-50$ & \\
\hline & $260 \mathrm{C}, 500 \mathrm{~F}$ & 58,500 & 74.700 & 24 & 48 & \\
\hline & $315 \mathrm{C}, 600 \mathrm{~F}$ & 57,500 & $\begin{array}{r}61,000- \\
70,000\end{array}$ & $22-43$ & $38-57$ & \\
\hline \multirow[t]{3}{*}{$12.9(34,36)$} & Room temperature & $81,300-92,500$ & $\begin{array}{r}106,000= \\
103,700\end{array}$ & 25 & $45 / 85$ & \multirow{3}{*}{$\begin{array}{l}\text { Rolled at } 900 \mathrm{C}(1650 \mathrm{~F}) \text {, annealed } \\
1 \mathrm{hr} \text { at } 900 \mathrm{C}(1650 \mathrm{~F}) \text {; Bur. } \\
\text { Mines } \mathrm{Zr}\end{array}$} \\
\hline & $100 \mathrm{C}, 212 \mathrm{~F}$ & 66,800 & 88,200 & 26 & $-\infty$ & \\
\hline & $100 \mathrm{C}, 212 \mathrm{~F}$ & 87,500 & 107,000 & -- & - & \\
\hline
\end{tabular}

(a) Superscript numbers refer to references at end of report. 


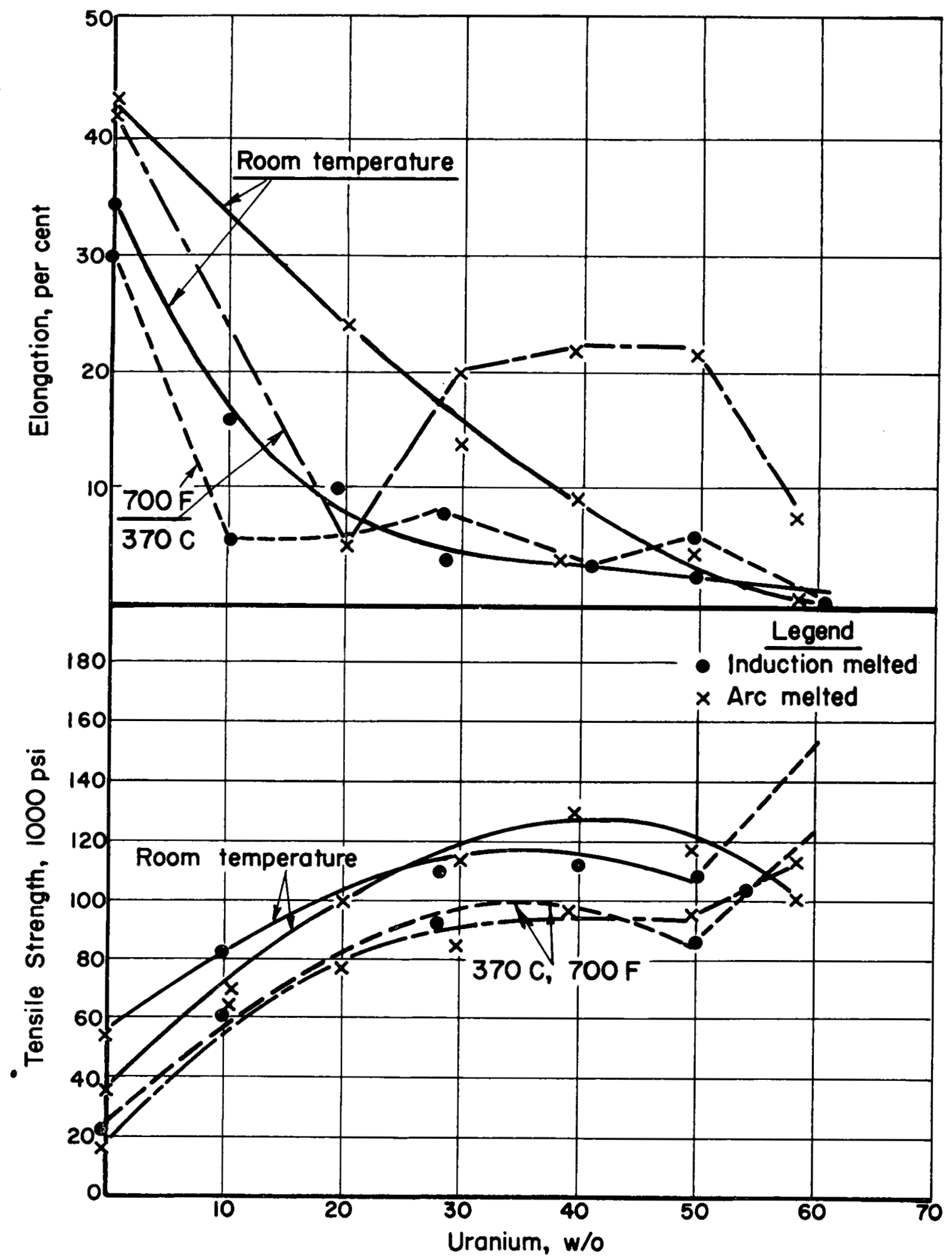

FIGURE 32. TENSILE BEHAVIOR OF ZIRCONIUM-URANIUM ALLOYS PREPARED BY INDUCTION AND ARC MELTING 
TABLE 2. TENSILE PROPERTIES OF ZIRCONIUM-URANIUM ALLOYS ANNEALED 24 HR AT $575 \mathrm{C}(1065 \mathrm{~F})$

\begin{tabular}{|c|c|c|c|c|c|c|c|c|c|c|}
\hline & & \multicolumn{5}{|c|}{ Room Temperaure } & \multicolumn{4}{|c|}{$370 \mathrm{C}(700 \mathrm{~F})$} \\
\hline \multicolumn{2}{|c|}{ Analysis, w/o } & $\begin{array}{l}0.2 \text { Per Cent } \\
\text { Offset Yield } \\
\text { Strength, psi }\end{array}$ & $\begin{array}{c}\text { Tensile } \\
\text { Strength. } \\
\text { psi }\end{array}$ & $\begin{array}{l}\text { Elongation } \\
\text { in } 2 \mathrm{In.,} \\
\text { per cent }\end{array}$ & $\begin{array}{l}\text { Reduction } \\
\text { in Area, } \\
\text { per cent }\end{array}$ & $\begin{array}{l}\text { Hardness } \\
\text { (DPHN) }\end{array}$ & $\begin{array}{l}0.2 \text { Per Cent } \\
\text { Offset Yield } \\
\text { Strength, psi }\end{array}$ & $\begin{array}{l}\text { Tensile } \\
\text { Strength, } \\
\text { psi } \\
\end{array}$ & $\begin{array}{c}\text { Elongation } \\
\text { in } 2 \mathrm{In} . \\
\text { per cent }\end{array}$ & $\begin{array}{l}\text { Reduction } \\
\text { in Area, } \\
\text { per cent } \\
\end{array}$ \\
\hline \multicolumn{11}{|c|}{ Induction-Melted Fernald Uranium } \\
\hline 100.0 & 0 & 26,700 & 53,800 & 34.0 & 27.0 & 138 & 10,500 & 22,400 & 30.0 & 55.0 \\
\hline 90.0 & 10.0 & 58,800 & 84,300 & 16.0 & 27.0 & 197 & 43,800 & 61,000 & 5.6 & 29.0 \\
\hline 80.8 & 19.2 & 85,500 & 103,900 & 10.0 & 8.0 & 252 & 69,300 & 80,100 & 5.7 & 9.0 \\
\hline 71.7 & 28.3 & 87,700 & 110,000 & 4.0 & 4.0 & 298 & 73,900 & 93,600 & 8.0 & 8.0 \\
\hline 59.5 & 40.5 & 80,700 & 116,500 & 3.6 & 6.2 & 302 & 60,100 & 94,100 & 3.5 & 1.1 \\
\hline 50.1 & 49.9 & 79,700 & 109,000 & 2.6 & 3.6 & 264 & 67,600 & 86,800 & 6.0 & 9.7 \\
\hline 39.7 & -- & 118,700 & 157,300 & 1.5 & 1.6 & 384 & 113,300 & 125,700 & 0.5 & 1.8 \\
\hline 29.9 & $-\infty$ & (a) & -- & $-\infty$ & - & 370 & 114,000 & 145,000 & 2.0 & - \\
\hline 21.9 & - & 140,000 & 179,000 & 4.0 & 5.8 & 291 & 116,700 & 137,200 & 4.3 & 9.3 \\
\hline 10.9 & $-\infty$ & 110,600 & 163,200 & 5.0 & 6.0 & 363 & 75,800 & 100,800 & 6.0 & 17.0 \\
\hline 5.8 & -- & 97.200 & 166,200 & 5.0 & 6.0 & 347 & 63,700 & 84,600 & 9.0 & 35.0 \\
\hline 0 & - & 65,900 & 117,300 & 3.5 & 4.9 & 265 & 27.100 & 34,550 & 16.0 & 37.0 \\
\hline \multicolumn{11}{|c|}{ Arc-Melted Derby Uranium } \\
\hline 100.0 & 0 & 18,000 & 36,700 & 43.0 & 56.0 & 113 & 8,500 & 17,300 & 42.0 & $\ldots$ \\
\hline 89.4 & 10.6 & 60,500 & 70,200 & $6.0(\mathrm{~b})$ & 19.0 (b) & 246 & 53,200 & 64,200 & 7. 0 (b) & 11.0 (b) \\
\hline 80.0 & 20.0 & 86,800 & 101,800 & 24.0 & 41.0 & 235 & 72,000 & 77.900 & 5.0 & 22.0 \\
\hline 70.4 & 29.6 & 71,300 & 115,000 & 14.0 & 16.0 & 243 & 64,800 & 86,400 & 20.0 & 27.0 \\
\hline 60.6 & 39.4 & 80,800 & 131,800 & 9.0 & 14.0 & 295 & 63,800 & 97,800 & 22.0 & 20.0 \\
\hline 50.5 & 49.5 & 84,300 & 118,000 & 4.5 & 8.0 & 272 & 68,100 & 96,100 & 22.0 & 28.0 \\
\hline 41.7 & 58.3 & 95,000 & 103,300 & 1.0 & -- & 279 & 97,000 & 115,300 & 8.0 & 13.0 \\
\hline 31.4 & $\cdots$ & 132,700 & 161,600 & 2.0 & 4.0 & 350 & 112,000 & 145,200 & 7.0 & 7.0 \\
\hline 20.5 & -- & (a) & -- & -- & -- & 411 & 124,000 & 135,200 & 8.0 & 18.0 \\
\hline 11.5 & -- & 145,000 & 199,000 & 9.0 & -- & 359 & 100,800 & 122,800 & 8.0 & 29.0 \\
\hline 5.5 & $-\infty$ & 88,000 & 162,000 & 6.0 & 7.5 & 307 & 50,500 & 77,000 & 10.0 & 25.0 \\
\hline 2.4 & -- & 47,300 & 133,000 & 18.0 & 21.0 & 283 & 35,100 & 48,400 & 17.0 & 49.0 \\
\hline 0 & -- & 48,400 & 123,000 & 11.0 & -- & 263 & 21,300 & 31,400 & 27.0 & 57.0 \\
\hline
\end{tabular}

(a) Specimens contained rolling defects.

(b) Specimens broke in what appeared to be rolling defects. 
is shown in Figures 33 and 34. The dynamic modulus of the inductionmelted alloys, Figure 33, is consistently greater than for the arc-melted alloys, Figure 34, again indicating the effect of contamination. It is possible that the role of contamination, aside from alloy strengthening, may be to alter the distribution and size of the microconstituents present after hot rolling followed by $24 \mathrm{hr}$ at $575 \mathrm{C}$ (1065 F).

The creep properties of dilute zirconium-uranium alloys have received limited attention. Creep data have been reported for a $3.66 \mathrm{w} / \mathrm{o}$ uranium alloy at $260 \mathrm{C}(500 \mathrm{~F})(35)$. These data are tabulated below.

\begin{tabular}{cccc}
$\begin{array}{c}\text { Stress, } \\
\text { psi }\end{array}$ & $\begin{array}{c}\text { Time, } \\
\text { hr }\end{array}$ & $\begin{array}{c}\text { Total Deformation, } \\
\text { per cent }\end{array}$ & $\begin{array}{c}\text { Secondary Creep Rate, } \\
\text { per cent per hr }\end{array}$ \\
\cline { 2 - 3 } 20,000 & 2,000 & 0.39 & $7 \times 10^{-6}$ \\
22,000 & 2,000 & 0.96 & $10 \times 10^{-6}$ \\
23,000 & 600 & 1.45 & $\mathrm{Nil}$ \\
27,000 & 600 & 2.60 & $\mathrm{Nil}$ \\
30,000 & 700 & 5.25 & $\mathrm{Nil}$
\end{tabular}

This alloy was prepared by double arc melting and was forged and rolled to sheet at $675 \mathrm{C}(1250 \mathrm{~F})$. The alloy was anneal straightened at $760 \mathrm{C}(1400 \mathrm{~F})$, cold rolled (25 per cent reduction) and annealed $1 \mathrm{hr}$ at $590 \mathrm{C}$ (1100 F).

These data reveal an interesting characteristic in that the strain obtained on loading is apparently sufficient to work harden the alloy such that negligible secondary creep results at stresses between 23,000 and 30,000 psi. These results are contrary to normal high-temperature creep behavior and would not be expected at temperatures above the recrystallization temperature.

Creep data have also been obtained on 22 and 41 w/o uranium alloys(22). These alloys were prepared from Foote Grade 1 low-hafnium iodide zirconium and biscuit uranium. The 22 w/o uranium alloy was arc melted by the consumable-electrode process, while the $41 \mathrm{w} / \mathrm{o}$ uranium alloy was prepared by arc melting in a water-cooled copper crucible. The creep data are summarized in the tabulations given on page 58. 


\section{6}

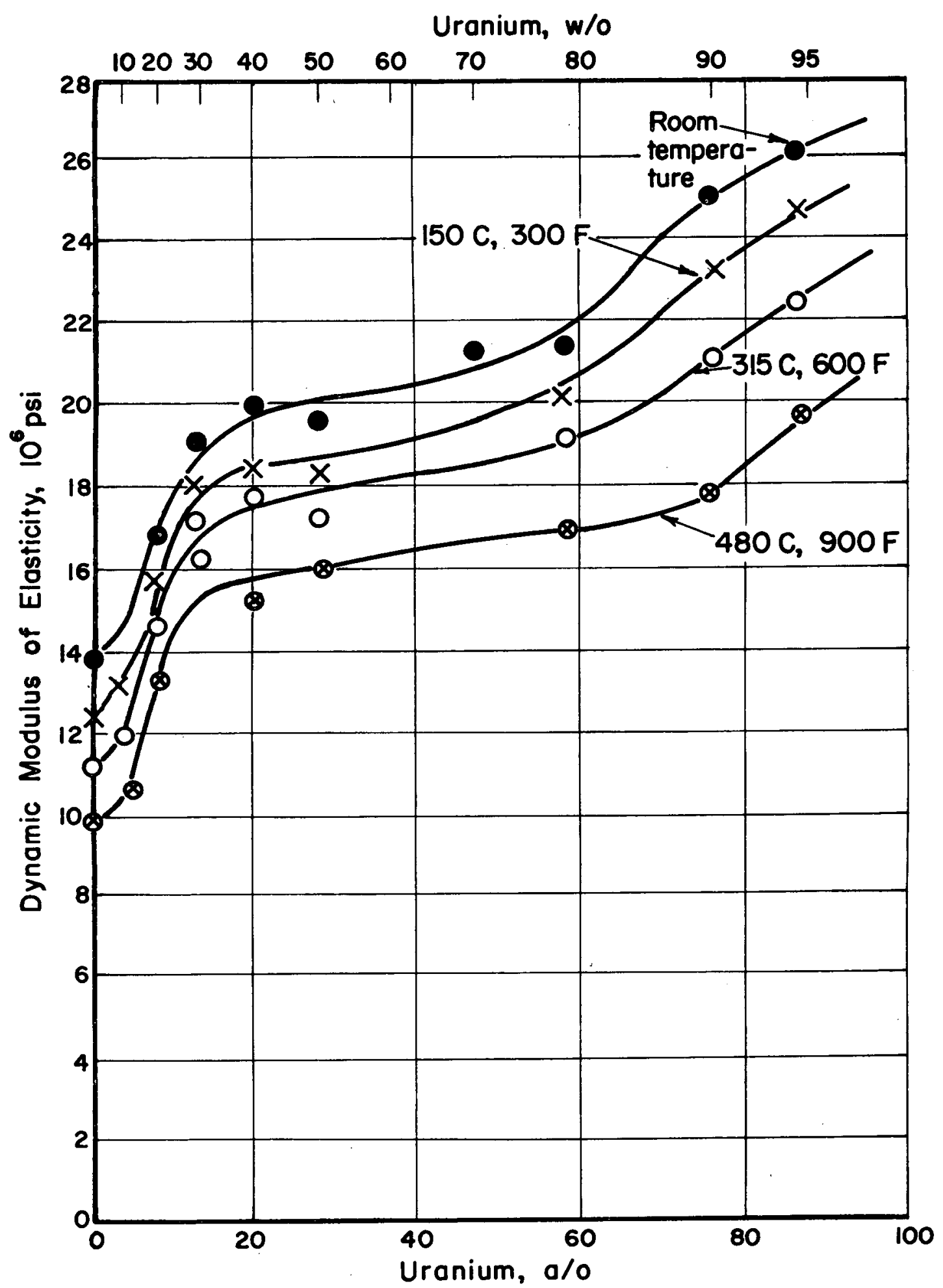

FIGURE 33. VARIATION OF DYNAMIC MODULUS OF ELASTICITY AT VARIOUS TEMPERATURES WITH URANIUM CONTENT IN INDUCTION-MELTED ZIRCONIUM-URANIUM ALLOYS 


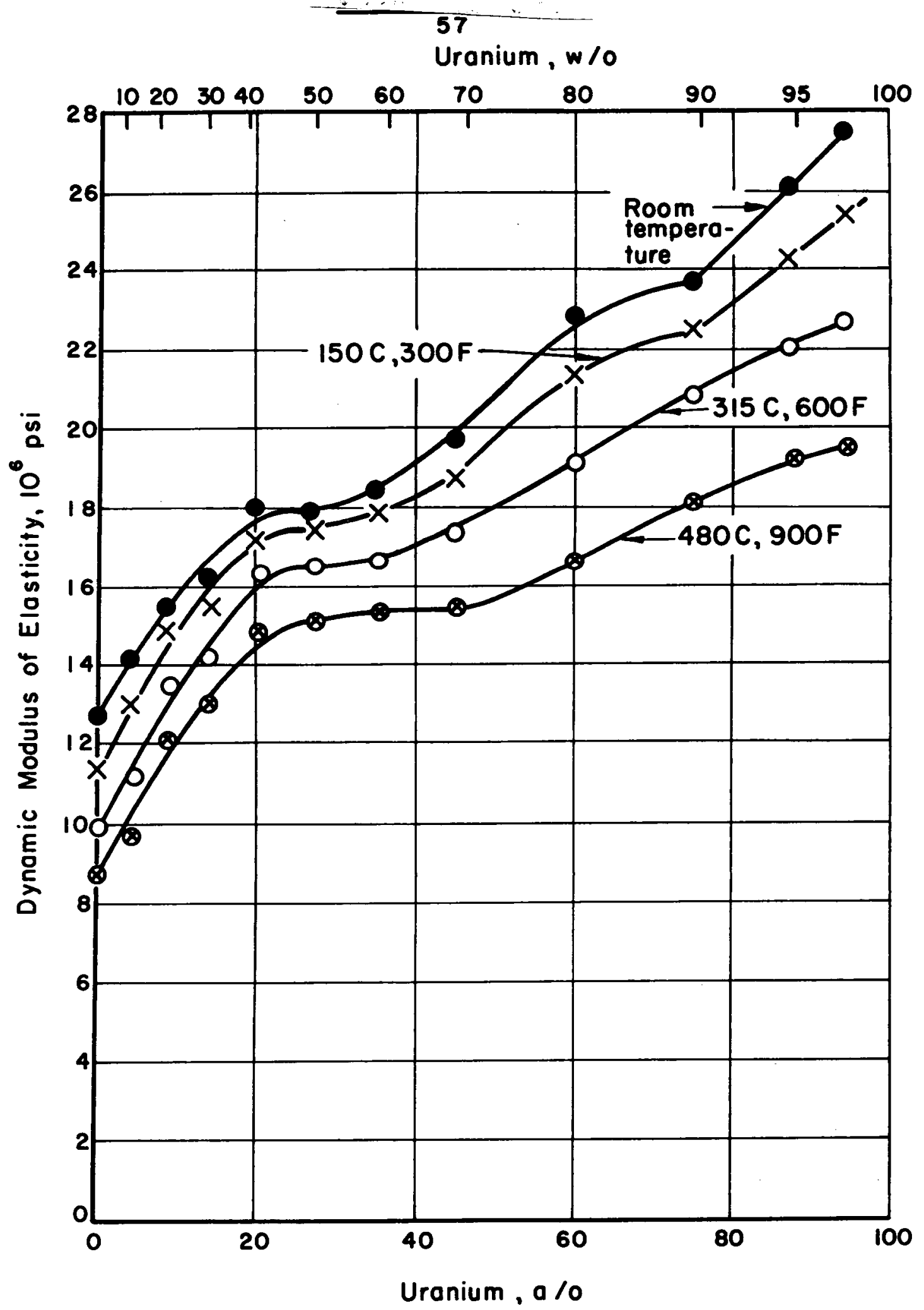

FIGURE 34. VARIATION OF DYNAMIC MODULUS OF ELASTICITY AT VARIOUS TEMPERATURES WITH URANIUM CONTENT IN ARC-MELTED ZIRCONIUM-URANIUM ALLOYS 


\section{8}

\begin{tabular}{|c|c|c|c|c|c|}
\hline \multirow[b]{2}{*}{$\begin{array}{c}\text { Fabrication } \\
\text { History } \\
\end{array}$} & \multirow[b]{2}{*}{$\begin{array}{c}\text { Test } \\
\text { Temperature } \\
\end{array}$} & \multicolumn{3}{|c|}{$\begin{array}{c}\text { Stress, psi, for } 1 \text { Per } \\
\text { Cent Deformation } \\
\end{array}$} & \multirow{2}{*}{$\begin{array}{c}\text { Minimum } \\
\text { Creep } \\
\text { Rate(a), } 10 \\
\text { in. /in. /hr } \\
\end{array}$} \\
\hline & & $\begin{array}{l}\text { In } \\
100 \mathrm{Hr}\end{array}$ & $10^{3} \mathrm{Hr}$ & $\begin{array}{l}\text { In } \\
10^{4} \mathrm{Hr} \\
\end{array}$ & \\
\hline \multicolumn{6}{|c|}{22 w/o Uranium Alloy(b) } \\
\hline $\begin{array}{l}\text { Hot rolled at } \\
675 \mathrm{C}(1245 \mathrm{~F}) \text {, } \\
\text { annealed at } \\
800 \mathrm{C}(1470 \mathrm{~F}), \\
\text { and furnace } \\
\text { cooled }\end{array}$ & $\begin{array}{l}400 \mathrm{C}, 750 \mathrm{~F} \\
450 \mathrm{C}, 840 \mathrm{~F} \\
500 \mathrm{C}, 930 \mathrm{~F}\end{array}$ & $\begin{array}{l}38,000 \\
19,000 \\
11,000\end{array}$ & $\begin{array}{r}30,000 \\
15,000 \\
8,400\end{array}$ & $\begin{array}{r}18,000 \\
8,400 \\
5,500\end{array}$ & $\begin{array}{c}0.8 \\
3 \\
100\end{array}$ \\
\hline \multicolumn{6}{|c|}{$41 \mathrm{w} / \mathrm{o}$ Uranium Alloy } \\
\hline 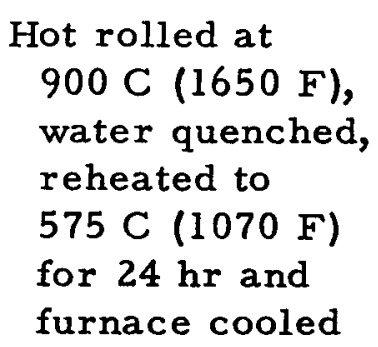 & $450 \mathrm{C}, 840 \mathrm{~F}$ & -- & 20,000 & 10,500 & 0.8 \\
\hline
\end{tabular}

(a) Minimum creep rate at a stress of 10,000 psi.

(b) Data obtained from graph in Reference 22.

The time to rupture of a $20 \mathrm{w} / 0$ uranium specimen at $540 \mathrm{C}(1000 \mathrm{~F})$ in sodium for various stresses has been determined(40). This alloy was double arc melted and rolled to sheet at $700 \mathrm{C}(1300 \mathrm{~F})$. Tests were run on the hot-rolled sheet. The data are given in the following tabulation:

\begin{tabular}{cc} 
Stress, psi & $\begin{array}{c}\text { Time to } \\
\text { Rupture(a), hr }\end{array}$ \\
\cline { 2 - 2 } 30,000 & 0.28 \\
5,000 & 12 \\
5,000 & 19 \\
4,000 & 33 \\
3,500 & 1,000
\end{tabular}

(a) Data taken from graph of Reference 40.

The data for the creep behavior of the 20 and $22 \mathrm{w} / \mathrm{o}$ uranium alloys are at first glance inconsistent, in that extrapolation of the data for the $22 \mathrm{w} / 0$ alloy to $540 \mathrm{C}(1000 \mathrm{~F})$ indicates that the stress for 1 per cent total deformation in $100 \mathrm{hr}$ should, if applied to the $20 \mathrm{w} / \mathrm{o}$ uranium alloy, result 
in rupture in less than $10 \mathrm{hr}$. While extrapolations should be viewed with caution, the range of extrapolation is only $40 \mathrm{C}(70 \mathrm{~F})$ and the alloy is already in the temperature range of rapid creep. The discrepancy might arise from the different thermal histories of the alloys or from a weakening influence of liquid sodium.

Creep data in the beta phase at $815 \mathrm{C}(1500 \mathrm{~F})$ and $980 \mathrm{C}(1800 \mathrm{~F})$ have been reported for 27.4 and 52.9 w/o uranium alloys(41). These alloys were double arc melted and forged and rolled at $790 \mathrm{C}(1450 \mathrm{~F})$. These data, along with data at $980 \mathrm{C}(1800 \mathrm{~F})$ for an induction-melted alloy containing $36.3 \mathrm{w} / \mathrm{o}$ uranium, are given in the following tabulation:

\begin{tabular}{|c|c|c|c|c|c|}
\hline $\begin{array}{c}\text { Uranium, } \\
\text { w/o } \\
\end{array}$ & $\begin{array}{c}\text { Stress, } \\
\text { psi } \\
\end{array}$ & $\begin{array}{c}\text { Time for } \\
1 \text { Per Cent } \\
\text { Deformation, } \\
\mathrm{hr} \\
\end{array}$ & $\begin{array}{c}\text { Minimum } \\
\text { Creep } \\
\text { Rate, } \\
\text { per cent } \\
\text { per hr } \\
\end{array}$ & $\begin{array}{c}\text { Test } \\
\text { Time, } \\
\text { hr } \\
\end{array}$ & $\begin{array}{c}\text { Elongation, } \\
\text { per cent } \\
\end{array}$ \\
\hline \multicolumn{6}{|c|}{$815 \mathrm{C}, 1500 \mathrm{~F}$} \\
\hline 27.4 & 500 & 40 & 0.021 & 162.7 & 12.3 \\
\hline 52.9 & 500 & 56 & 0.013 & 169 & 15.1 \\
\hline \multicolumn{6}{|c|}{$980 \mathrm{C}, 1800 \mathrm{~F}$} \\
\hline 27.7 & 500 & 0.57 & 1.7 & 7.5 & 36.2 \\
\hline $36.3^{(a)}$ & 500 & 0.5 & 2.0 & 21 & 65.3 \\
\hline 52.9 & 500 & 0.16 & 5.5 & 1.8 & 37 \\
\hline
\end{tabular}

(a) Induction melted, cast in copper crucible, rolled at $815 \mathrm{C}$ (1500 F).

These data demonstrate the weakness of the delta phase at these temperatures, but indicate that some solid-solution strengthening by uranium still occurs.

The Effects of Beta-Phase Decomposition on Mechanical Strength

Most of the information available on the relation between composition, heat treatment, and some strength parameter, such as tensile strength or hardness, has been of rather recent origin $(12,19,22,42)$.

Dilute zirconium-base alloys transform on rapid cooling from the beta phase by a mechanism very similar to the martensite reaction in iron-carbon 
and in many titanium-base alloys. Zirconium-uranium alloys, up to $10 \mathrm{w} / \mathrm{o}$, and probably up to $19 \mathrm{w} / \mathrm{o}$ uranium, appear to transform by a similar reaction. X-ray examination(22) revealed that the martensitic structure in a $10 \mathrm{w} / \mathrm{o}$ alloy is hexagonal-close-packed and is nearly indistinguishable from alpha zirconium. This suggests that the zirconium martensite is produced with little lattice straining due to the supersaturation of alpha zirconium and that it is formed at high temperatures where the shear strength of alpha and beta zirconium are not sufficient to support the high stresses associated with coherency hardening.

Typical mechanical properties of the $10 \mathrm{w} / \mathrm{o}$ uranium alloy, as affected by heat treatment, are summarized in Table 3. Based on the phase diagram, the microstructure of the $10 \mathrm{w} / 0$ uranium alloy at $700 \mathrm{C}(1300 \mathrm{~F})$ consists of alpha plus enriched beta. Hot working at this temperature will probably result in fine-grained alpha with regions of enriched beta dispersed through the structure. If a sufficiently rapid cooling is used from the two-phase field, the enriched beta phase undergoes a hardening reaction, and limited ductility would be expected as in Treatment 1, Table 3. Reheating to $700 \mathrm{C}$ (1300 F), Treatment 2, and soaking for $4 \mathrm{hr}$ probably resulted in alphaphase grain growth and, possibly, some coalescence of the enriched beta phase, thereby yielding somewhat greater ductility. The low ductility due to Treatment 3 is the result of a martensitic microstructure obtained on quenching from $900 \mathrm{C}(1650 \mathrm{~F})$. The increased ductility obtained by Treatment 4 may be associated with growth of the alpha phase at temperature and decomposition of the enriched beta phase to form a Widmanstätten structure of alpha and epsilon.

The heat-treatment response of the $19 \mathrm{w} / \mathrm{o}$ uranium alloy is strongly dependent on the quenching temperature(22). Water quenching from $900 \mathrm{C}$ $(1650 \mathrm{~F})$ results in a martensitic microstructure with a hardness of approximately $250 \mathrm{DPH}$, while quenching from $750 \mathrm{C}(1380 \mathrm{~F})$ can result in a hardness of $400 \mathrm{DPH}$, due to hardening of the enriched beta phase during quenching. Air cooling does not significantly affect the hardness of the $19 \mathrm{w} / 0$ uranium alloy.

Data from the same investigation(22), but for the $22 \mathrm{w} / \mathrm{o}$ uranium alloy, indicate that the martensitic reaction is suppressed and the beta phase is retained by water quenching. The hardness of the retained beta phase was about 425 to $450 \mathrm{DPH}$. It will be shown later from data on a $41 \mathrm{w} / \mathrm{o}$ uranium alloy that this hardness is not a characteristic of retained beta, but is the result of initiation of decomposition during quenching. The microstructure of a $22 \mathrm{w} / \mathrm{o}$ uranium specimen air cooled from $900 \mathrm{C}(1650 \mathrm{~F})$ contained an acicular product in a retained-beta-phase matrix. This evidence suggests that the high hardness of the beta phase retained on quenching could be the result of (a) local rearrangement which causes formation of a preprecipitation lattice of the low-temperature intermediate phase, or

(b) the result of coherency strains developed between the beta phase and 
TABLE 3. MECHANICAL PROPERTIES OF ZIRCONIUM-10 w/o URANIUM ALLOY(a)

\begin{tabular}{|c|c|c|c|c|c|c|c|}
\hline \multirow{3}{*}{$\begin{array}{c}\text { Heat } \\
\text { Treatment }\end{array}$} & \multicolumn{5}{|c|}{ Room-Temperature Tensile Properties } & & \\
\hline & 0.2 Per Cent Offset & $\begin{array}{l}\text { Ultimate } \\
\text { Strength, }\end{array}$ & $\begin{array}{l}\text { Elongation to } \\
\text { Maximum Load, }\end{array}$ & $\begin{array}{l}\text { Total Elongation } \\
\text { in } 1 \mathrm{In}_{\text {.. }}\end{array}$ & $\begin{array}{c}\text { Reduction } \\
\text { of Area, }\end{array}$ & \multicolumn{2}{|c|}{ Hardness } \\
\hline & Yield Strength, psi & $\mathrm{psi}$ & per cent & per cent & per cent & $\overline{\mathrm{DPH}}$ & $\overline{R_{A}}$ \\
\hline 1 & 77,800 & 109,200 & 4 & 8 & 13 & 221 & 59 \\
\hline 2 & 54,500 & 79,900 & 13 & 17 & 20 . & 203 & 56 \\
\hline 3 & 88,100 & 105,600 & 4 & 8 & 10 & 242 & 60 \\
\hline 4 & 40,800 & 71,800 & 19 & 32 & 32 & 180 & 51 \\
\hline
\end{tabular}

Treatment 1: Hot rolled at $700 \mathrm{C}(1300 \mathrm{~F})$ and air cooled.

Treatment 2: Hot rolled at $700 \mathrm{C}(1300 \mathrm{~F})$ and air cooled; reheated to $700 \mathrm{C}(1300 \mathrm{~F})$ for $4 \mathrm{hr}$ and furnace cooled.

Treatment 3: Hot rolled at $700 \mathrm{C}(1300 \mathrm{~F})$ and air cooled; reheated to $900 \mathrm{C}(1650 \mathrm{~F})$ for $1 \mathrm{hr}$ and water quenched. Treatment 4: Hot rolled at $700 \mathrm{C}(1300 \mathrm{~F})$ and air cooled; reheated to $800 \mathrm{C}(1470 \mathrm{~F})$ for $1 \mathrm{hr}$ and furnace cooled.

(a) From Reference 22 . 
the precipitating epsilon phase. A combination of these effects may actually be occurring. These interpretations are supported by X-ray studies(22) of the decomposition products obtained by quenching a Jominy bar of the 22 w/o alloy from $900 \mathrm{C}(1650 \mathrm{~F})$. No evidence was found of alpha zirconium even 1 in. from the quenched end, but retained beta and the epsilon phase were identified. Additional discussion of the hardening reaction is given in the section on "Kinetics of Transformation of Zirconium-Uranium Alloys".

Regardless of the hardening mechanism, its effect on the mechanical properties is, in many respects, pronounced. Mechanical properties of the 22 w/o uranium alloy, as determined in two separate investigations, are summarized in Tables 4 and 5 for various heat-treated conditions. One of the more important features shown by these data is the effect of hot-rolling temperature on the tensile ductility and, to a lesser degree, on the tensile strength. Hot rolling at $675 \mathrm{C}(1250 \mathrm{~F})$ in the alpha-plus-beta field (Table 4) resulted in a lower tensile strength and increased tensile ductility compared with rolling at $540 \mathrm{C}(1000 \mathrm{~F})$ (Table 5). These differences in properties may result from the distribution of the epsilon phase in the matrix, or to residual cold work. Another difference may be observed in the properties of the alloy in the beta-treated and furnace-cooled conditions. The specimen furnace cooled after $36 \mathrm{hr}$ at $845 \mathrm{C}(1550 \mathrm{~F})$, Treatment 2, Table 5, exhibited no ductility, while a $1-\mathrm{hr}$ treatment at $800 \mathrm{C}(1470 \mathrm{~F})$, Treatment 5, Table 4, resulted in excellent ductility. The specimen treated $36 \mathrm{hr}$ at $840 \mathrm{C}(1550 \mathrm{~F})$ may have been cooled more rapidly from the beta, and may also have picked up oxygen and nitrogen during the long heat treatment. Air cooling seems to embrittle the alloy, as shown by Treatment 4 , Table 4 .

The $41 \mathrm{w} / \mathrm{o}$ uranium alloy exhibits beta-decomposition behavior similar to the $22 \mathrm{w} / 0$ alloy, except that the reaction is slower. The beta phase can be fully retained in the $41 \mathrm{w} / 0$ alloy and is soft (260 DPH) and ductile. Jominy end-quench tests, Figure 35, produced a hardness maximum away from the quenched end of the specimen, indicating that the hardening reactions require time, or diffusion. $X$-ray studies also revealed that the Jominy bar contained only retained beta and the epsilon phase as far back as the middle of the bar. Unfortunately, these data still do not reveal the basic nature of the hardening reaction.

The mechanical properties of the $41 \mathrm{w} / \mathrm{o}$ uranium alloy after various heat treatments are given in Table 6. In general, the tensile strength has not been significantly affected by the increase in composition from 22 to $41 \mathrm{w} / \mathrm{o}$ nor by the heat treatments indicated. The tensile ductility has been generally decreased, as compared with the $22 \mathrm{w} / \mathrm{o}$ alloy. 
TABLE 4. MECHANICAL PROPERTIES OF ZIRCONIUM-22 W/o URANIUM ALLOY(a)

\begin{tabular}{|c|c|c|c|c|c|c|c|c|}
\hline \multirow{2}{*}{$\begin{array}{c}\text { Heat } \\
\text { Treatment }\end{array}$} & \multirow{2}{*}{$\begin{array}{c}\text { Test } \\
\text { Temperature }\end{array}$} & \multirow{2}{*}{$\begin{array}{l}0.2 \text { Per Cent Offset } \\
\text { Yield Strength, psi }\end{array}$} & \multirow{2}{*}{$\begin{array}{l}\text { Ultimate } \\
\text { Strength, } \\
\text { psi }\end{array}$} & \multirow{2}{*}{$\begin{array}{c}\text { Elongation to } \\
\text { Maximum Load, } \\
\text { per cent }\end{array}$} & \multirow{2}{*}{$\begin{array}{l}\text { Total Elongation } \\
\text { in } 1 \text { In.. } \\
\text { per cent }\end{array}$} & \multirow{2}{*}{$\begin{array}{l}\text { Reduction } \\
\text { of Area, } \\
\text { per cent }\end{array}$} & \multicolumn{2}{|c|}{ Hardness } \\
\hline & & & & & & & $\overline{\mathrm{DPH}}$ & $\overline{R_{A}}$ \\
\hline 1 & Room & 102,800 & 120,200 & 5 & 16 & 23 & 240 & 61 \\
\hline 2 & Room & 94,000 & 101,900 & 12 & 17 & 25 & 238 & 61 \\
\hline 3 & Room & (b) & 83,400 & (b) & 0 & 0 & 387 & 72 \\
\hline 4 & Room & 81,400 & 106,600 & 2 & 3 & 2 & 274 & 65 \\
\hline 5 & Room & 59,700 & 103,500 & 21 & 23 & 24 & 245 & 60 \\
\hline 5 & $400 \mathrm{C}, 750 \mathrm{~F}$ & 43,700 & 67,300 & 14 & 24 & 37 & -- & - \\
\hline 5 & $450 \mathrm{C}, 840 \mathrm{~F}$ & 41,000 & 59,200 & 10 & 29 & 34 & -- & - \\
\hline 5 & $500 \mathrm{C}, 930 \mathrm{~F}$ & 36,900 & 48,000 & 3 & 48 & 69 & -- &.- \\
\hline
\end{tabular}

Treatment 1: Hot rolled at $675 \mathrm{C}(1250 \mathrm{~F})$ and furnace cooled.

Treatment 2: Hot rolled at $675 \mathrm{C}(1250 \mathrm{~F})$ and furnace cooled; reheated to $575 \mathrm{C}(1065 \mathrm{~F})$ for 24 hr and furnace cooled.

Treatment 3: Hot rolled at $675 \mathrm{C}(1250 \mathrm{~F})$; heated to $800 \mathrm{C}(1470 \mathrm{~F})$ for $1 \mathrm{hr}$ and water quenched.

Treatment 4: Hot rolled at $675 \mathrm{C}(1250 \mathrm{~F})$; heated to $800 \mathrm{C}(1470 \mathrm{~F})$ for $1 \mathrm{hr}$ and air cooled in a Vycor capsule.

Treatment 5: Hot rolled at $675 \mathrm{C}(1250 \mathrm{~F})$; heated to $800 \mathrm{C}(1470 \mathrm{~F})$ for $1 \mathrm{hr}$ and furnace cooled at a rate of $100 \mathrm{C}(180 \mathrm{~F})$ per hr.

(a) From Reference 22 .

(b) Specimens failed in reduced section in brittle manner. 
T ABLE 5. TENSILE PROPERTIES OF HEAT-TREATED ZIRCONIUM-22 w/o URANIUM ALLOY(a)

\begin{tabular}{|c|c|c|c|c|c|c|}
\hline $\begin{array}{l}\text { Heat } \\
\text { Treatment }\end{array}$ & $\begin{array}{c}\text { Test } \\
\text { Temperature }\end{array}$ & $\begin{array}{l}0.2 \text { Per Cent Offset } \\
\text { Yield Strength, psi }\end{array}$ & $\begin{array}{l}\text { Ultimate } \\
\text { Strength, } \\
\text { psi }\end{array}$ & $\begin{array}{c}\text { Uniform } \\
\text { Elongation } \\
\text { per cent }\end{array}$ & $\begin{array}{l}\text { Total Elongation } \\
\text { in } 1 \text { In., } \\
\text { per cent }\end{array}$ & $\begin{array}{l}\text { Reduction } \\
\text { of Area, } \\
\text { per cent }\end{array}$ \\
\hline 1 & Room & 112,000 & 129,200 & 1.9 & 2 & 2 \\
\hline 2 & Room & (b) & 57.700 & 0.5 & 0 & 0 \\
\hline 3 & Room & 48,300 & 87,900 & 13 & 16 & 17 \\
\hline 4 & Room & (b) & 60,800 & 0.4 & 0 & 0 \\
\hline 5 & Room & (b) & 55,400 & 0.4 & 0 & 0 \\
\hline 6 & Room & 64,000 & 97,200 & 7.4 & 8 & 9 \\
\hline 1 & $500 \mathrm{C}, 930 \mathrm{~F}$ & 12,000 & 25,600 & 8.4 & 75 & 92 \\
\hline 2 & $500 \mathrm{C}, 930 \mathrm{~F}$ & 41,800 & 55,200 & 5.1 & 14 & 13 \\
\hline 3 & $500 \mathrm{C}, 930 \mathrm{~F}$ & 29,200 & 44,200 & 6.2 & 34 & 32 \\
\hline 4 & $500 \mathrm{C}, 930 \mathrm{~F}$ & 38,400 & 54,500 & 3.7 & 12 & 18 \\
\hline 5 & $500 \mathrm{C}, 930 \mathrm{~F}$ & 34,200 & 47,500 & 4.9 & 25 & 38 \\
\hline 6 & $500 \mathrm{C}, 930 \mathrm{~F}$ & 35,100 & 48,000 & 5.7 & 18 & 22 \\
\hline
\end{tabular}

Treatment 1: As rolled at $540 \mathrm{C}(1000 \mathrm{~F})$.

Treatment 2: $36 \mathrm{hr}$ at $840 \mathrm{C}(1550 \mathrm{~F})$, furnace cooled.

Treatment 3: $36 \mathrm{hr}$ at $840 \mathrm{C}(1550 \mathrm{~F})$, cooled $1 / 2 \mathrm{~F} / \mathrm{min}$ from $840 \mathrm{C}(1550 \mathrm{~F})$ to $650 \mathrm{C}(1200 \mathrm{~F})$, furnace cooled.

Treatment 4: $36 \mathrm{hr}$ at $840 \mathrm{C}(1550 \mathrm{~F})$, furnace cooled; reannealed $1 \mathrm{hr} 840 \mathrm{C}(1550 \mathrm{~F})$, quenched to $550 \mathrm{C}(1020 \mathrm{~F})$, held $1 / 2 \mathrm{hr}$, reheated to $700 \mathrm{C}$ $(1300 \mathrm{~F})$, held $10 \mathrm{hr}$, water quenched, annealed $1 \mathrm{hr} 550 \mathrm{C}(1020 \mathrm{~F})$, water quenched.

Treatment 5: $36 \mathrm{hr}$ at $840 \mathrm{C}(1550 \mathrm{~F})$, water quenched; annealed $1 / 2 \mathrm{hr}$ at $550 \mathrm{C}(1020 \mathrm{~F})$, water quenched; annealed $10 \mathrm{hr}$ at $760 \mathrm{C}(1400 \mathrm{~F})$. furnace cooled.

Treatment 6: $36 \mathrm{hr}$ at $840 \mathrm{C}(1550 \mathrm{~F})$, water quenched; annealed 22 days at $550 \mathrm{C}(1020 \mathrm{~F})$, furnace cooled.

(a) From Reference 19.

(b) Brittle fracture. 


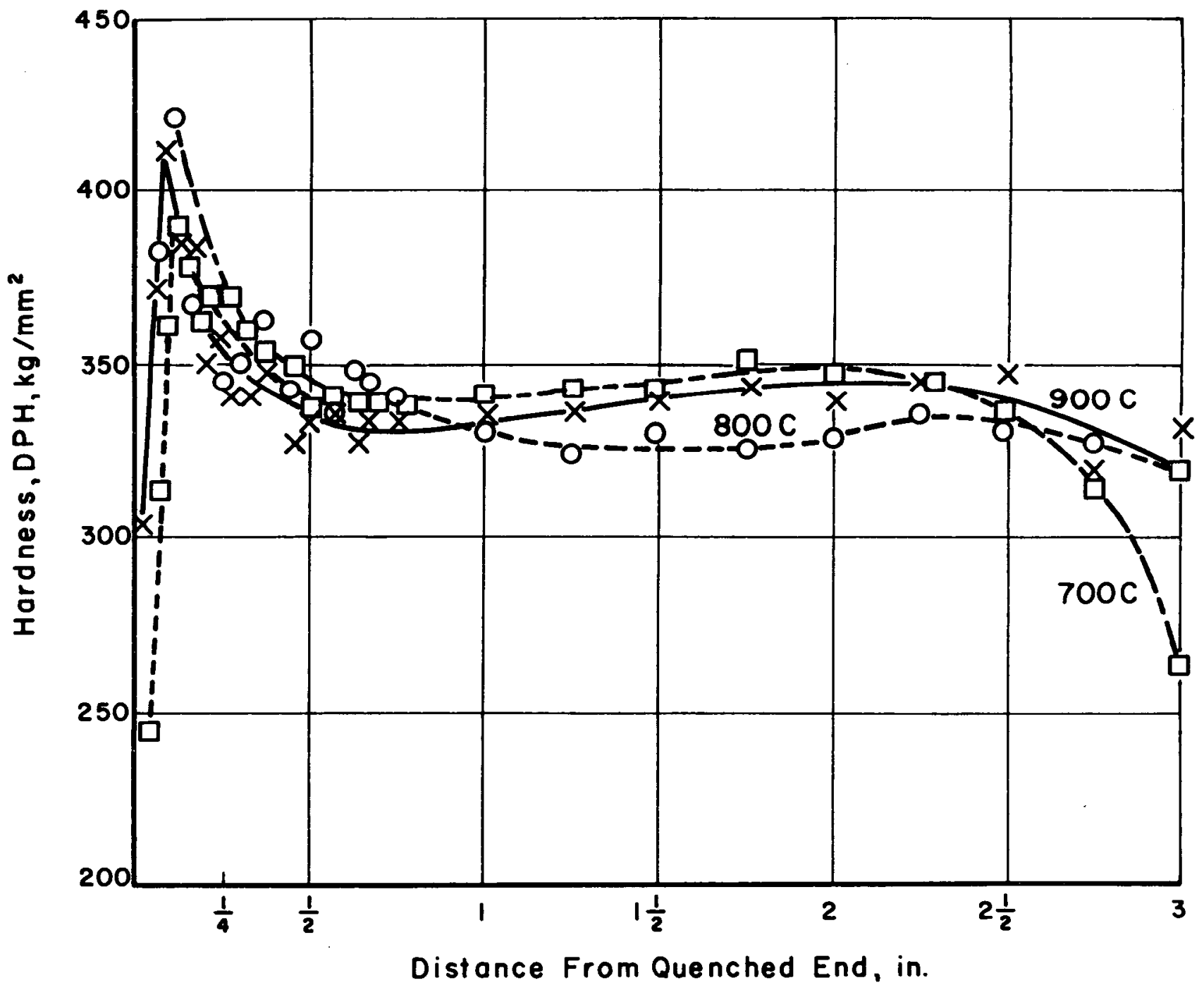

FIGURE 35. JOMINY END-QUENCH TESTS ON ZIRCONIUM-4I w/0 URANIUM ALLOY 


$$
66
$$

TABLE 6. MECHANICAL PROPERTIES OF ZIRCONIUM-41 w/o URANIUM ALLOY(a)

\begin{tabular}{|c|c|c|c|c|c|c|c|c|}
\hline \multirow{3}{*}{\multicolumn{2}{|c|}{$\begin{array}{ll}\therefore . . .: & \\
\vdots . . . .: & \\
\cdots \ldots . . & \text { Heat }\end{array}$}} & \multicolumn{5}{|c|}{ Room-Temperature Tensile Properties } & & \\
\hline & & 0.2 Per Cent Offset & $\begin{array}{l}\text { Ultimate } \\
\text { Strength, }\end{array}$ & $\begin{array}{l}\text { Elongation to } \\
\text { Maximum Load, }\end{array}$ & $\begin{array}{l}\text { Total Elongation } \\
\text { in } 1 \mathrm{In}_{\text {., }}\end{array}$ & $\begin{array}{l}\text { Reduction } \\
\text { of Area, }\end{array}$ & \multicolumn{2}{|c|}{ Hardness } \\
\hline & & Yield Strength, psi & psi & per cent & per cent & per cent & $\overline{\mathrm{DPH}}$ & $\mathrm{R}_{\mathrm{A}}$ \\
\hline & 1 & -- & 92,000 & -- & 0 & 0 & 227 & 61 \\
\hline & 2 & $111_{0} 600$ & 144,400 & 3 & 4 & 1 & 325 & 65 \\
\hline & 3 & 83,600 & 133,000 & 4 & 5 & 5 & 317 & 65 \\
\hline & 4 & 80,200 & 126,200 & 3 & 4 & 4 & 287 & 64 \\
\hline$\because \ldots$ & 5 & 53,600 & 73,400 & 1 & 2 & 5 & 243 & 60 \\
\hline
\end{tabular}

Treatment 1: Hot rolled at $760 \mathrm{C}(1400 \mathrm{~F})$ and furnace cooled; reheated to $700 \mathrm{C}(1300 \mathrm{~F})$ for $4 \mathrm{hr}$ and water quenched.

Treatment 2: Hot rolled at $760 \mathrm{C}(1400 \mathrm{~F})$ and furnace cooled; reheated to $700 \mathrm{C}(1300 \mathrm{~F})$ for $4 \mathrm{hr}$ and air cooled in a Vycor capsule.

Treatment 3; Hot rolled at $760 \mathrm{C}(1400 \mathrm{~F})$ and furnace cooled.

Treatment 4: Hot rolled at $760 \mathrm{C}(1400 \mathrm{~F})$ and furnace cooled; reheated to $575 \mathrm{C}(1070 \mathrm{~F})$ for $24 \mathrm{hr}$ and furnace cooled.

Treatment 5: Hot rolled at $900 \mathrm{C}(1650 \mathrm{~F})$ and water quenched from $900 \mathrm{C}$; reheated to $575(1070 \mathrm{~F})$ for $24 \mathrm{hr}$ and furnace cooled.

(a) From Reference 22. 
67 and 68

$\underline{\text { Discussion }}$

The foregoing description of data on the effects of uranium composition on the mechanical properties of zirconium-uranium alloys indicates that the system has been reasonably well studied in a general manner. Annealed alloys exhibit mechanical properties intermediate between those of the alpha zirconium and epsilon phases. The data also indicate that induction melting results in lower tensile ductility as compared with arc melting alloys. Presumably, this reduced ductility results from carbon contamination.

In the composition range up to $19 \mathrm{w} / 0$ uranium, alloys cooled from the beta phase transform to yield microstructures varying from a coarse Widmanstätten structure on slow cooling to a fine, acicular, martensitic structure on water quenching. As would be expected, the mechanical strength is sensitive to the size of the alpha-phase particles. There is, however, insufficient information on the relation between beta-phase transformation kinetics, and the resulting microstructure, and mechanical properties. With uranium contents in the range of 20 to $41 \mathrm{w} / \mathrm{o}$, the beta phase transforms by a reaction which results in considerable hardening with an accompanying loss in tensile ductility. In this intermediate composition range, the properties are greatly affected by heat treatment, with prolonged alpha-phase annealing restoring some of the ductility. Again, insufficient quantitative data are available to permit detailed conclusions concerning the dependency of mechanical properties on the various microstructures that may be obtained by thermal treatments. 
PHYSICAL PROPERTIES OF ZIRCONIUM-

URANIUM ALLOYS

Walston Chubb

Those physical properties of zirconium-uranium alloys which are available and which may be useful in the design of experiments, or for engineering applications, are included in this section. These properties include density, resistivity, thermal conductivity, thermal-expansion coefficients, and diffusion coefficients.

Various other properties which are known for uranium and for zirconium, but not for their alloys, have been omitted.

\section{Density}

The density of zirconium-uranium alloys is shown in Figure $36(44,45$, $46,47,48)$. Data for iodide and sponge zirconium-base alloys, regardless of heat treatment or history, fall approximately on the curve. Calculations show that the curve drawn corresponds closely with the law of mixtures.

\section{Resistivity}

The resistivity of zirconium-uranium alloys prepared by a variety of techniques is shown in Figure $37(16,36,46,49,50,51,52)$. The peak in resistivity corresponds with the epsilon phase. It can be seen by comparison of the curves for room temperature and $200 \mathrm{C}(390 \mathrm{~F})$ that the resistivity of alpha zirconium and of alpha uranium increases with temperature, while that of epsilon decreases with increasing temperature.

\section{Thermal Conductivity}

The thermal conductivity of alloys across the system zirconiumuranium have been determined. Part of the available data are shown in Figure $38(16,45,50,53,54)$. Data for intermediate temperatures were available, but were not included.

Based on electrical-conductivity and thermal-conductivity data for a series of specimens across the system, but for temperatures only up to 

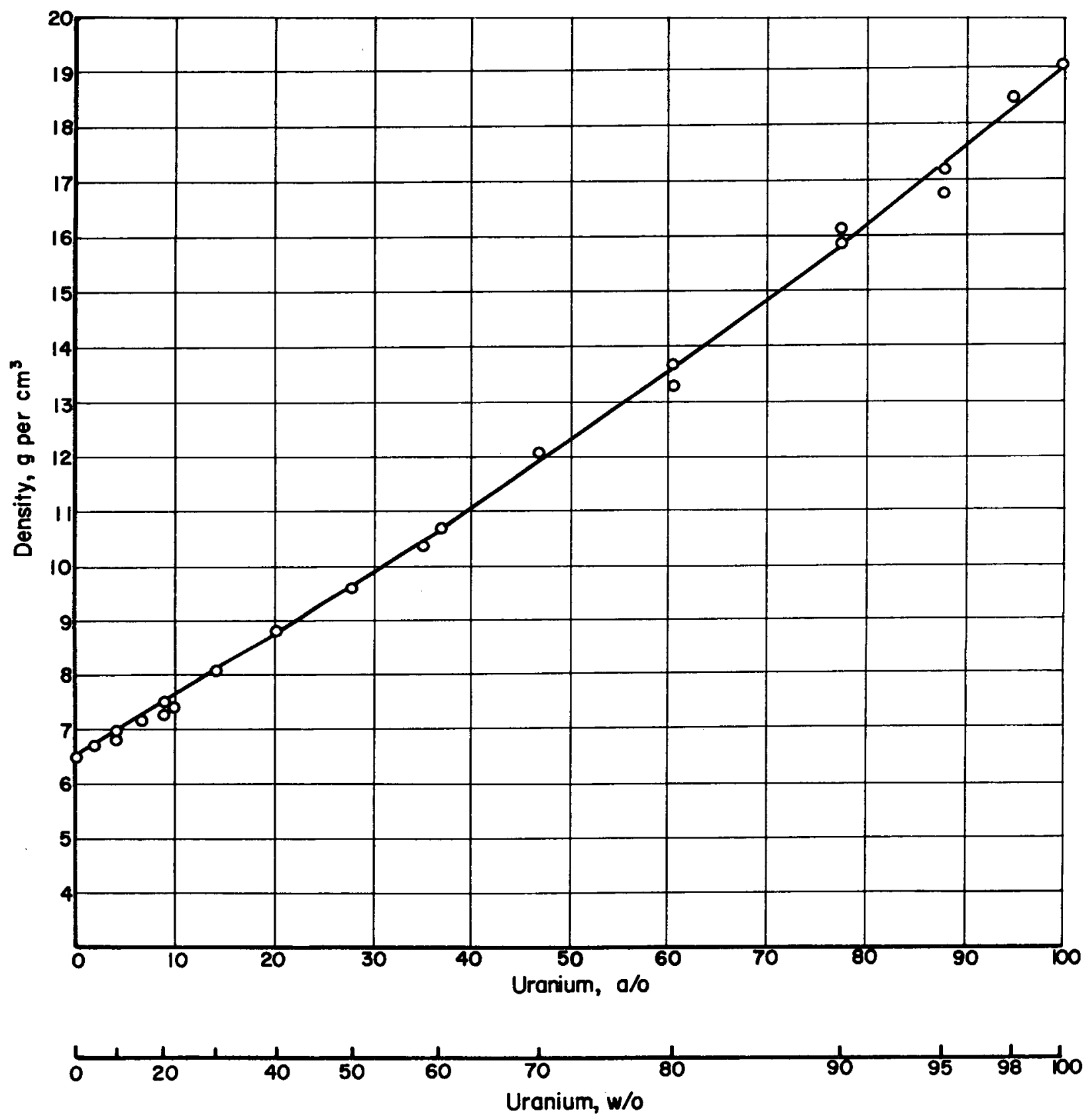

FIGURE 36. DENSITY OF ZIRCONIUM-URANIUM ALLOYS

萡 


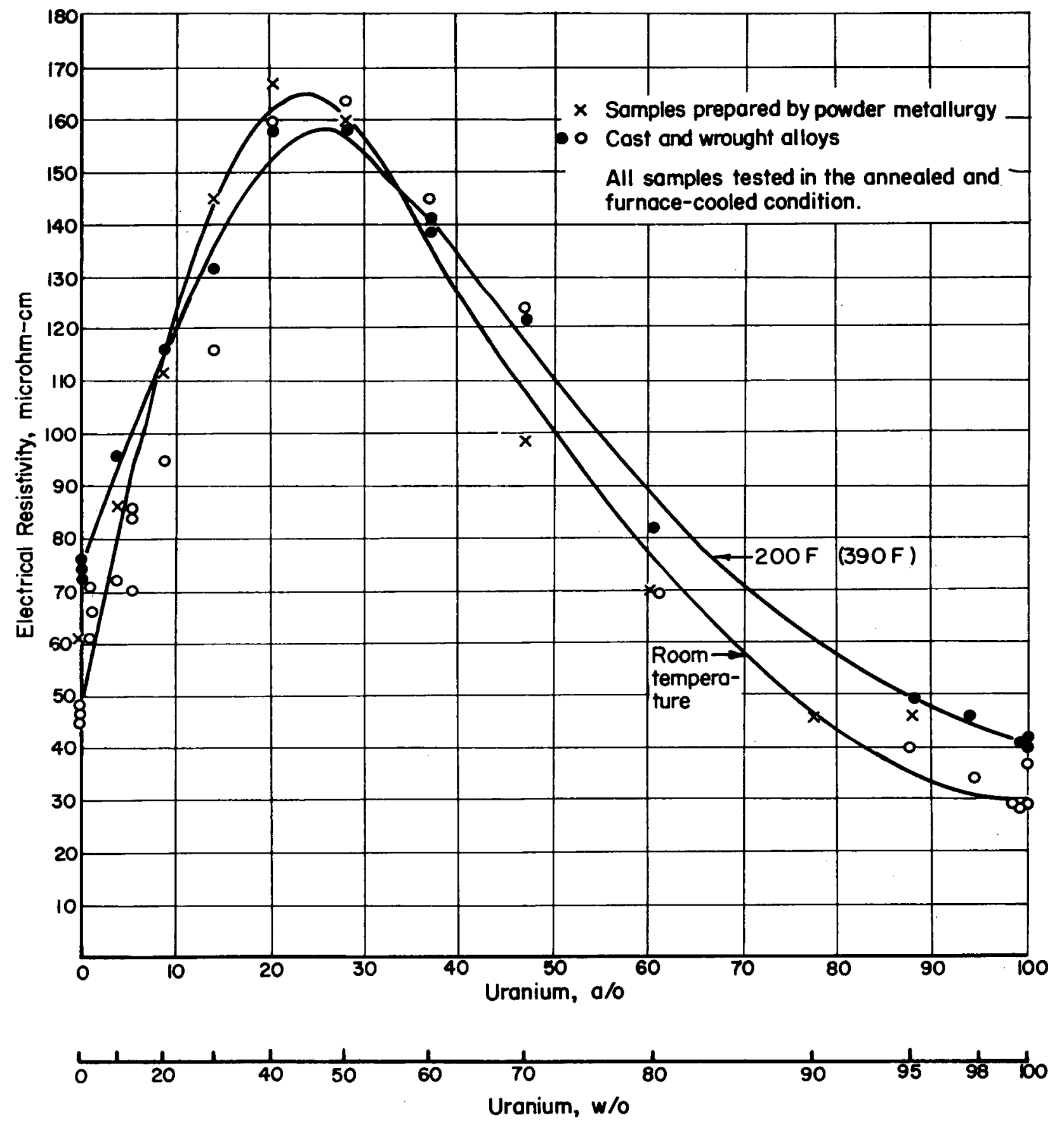

FIGURE 37. RESISTIVITY OF ZIRCONIUM-URANIUM ALLOYS 


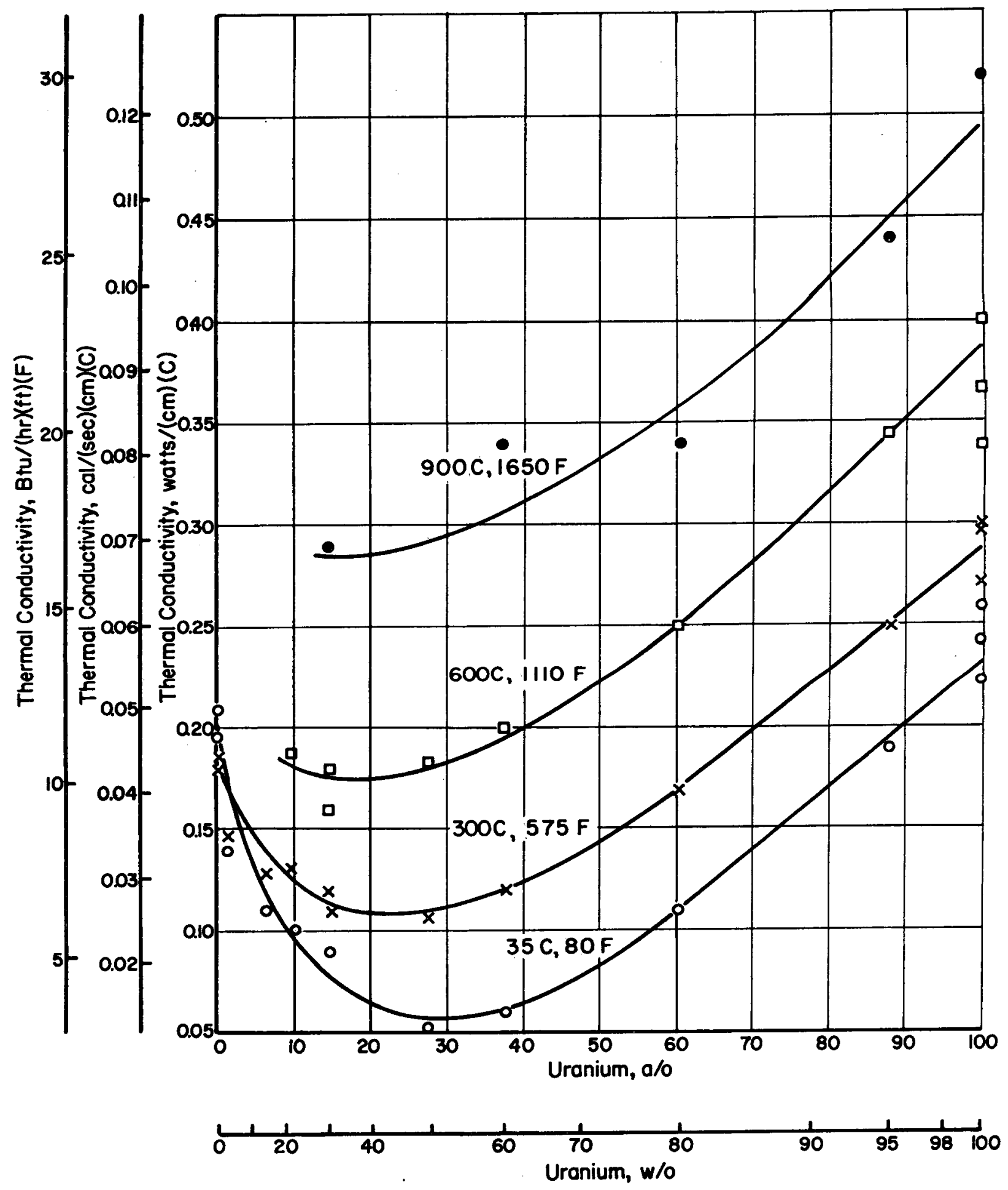

FIGURE 38. THERMAL CONDUCTIVITY OF ZIRCONIUM-URANIUM ALLOYS 


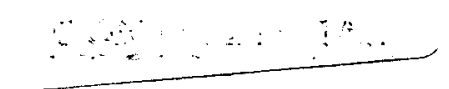

73

$200 \mathrm{C}(390 \mathrm{~F})$, an attempt was made to develop a relationship between the two properties. It was found that the Lorenz ratios calculated for the Wiedemann-Franz relation varied greatly with composition, and inadequate information was available to establish a relation for the system as a whole(63). An empirical relation has been established which applies to zirconium alloys containing up to $14 \mathrm{w} / 0$ uranium(62). Although it has not been done, a similar relation could be established for the uranium-rich alloys.

\section{Thermal Expansion}

The linear-thermal-expansion coefficients of uranium, of zirconium, and of alloys containing up to $41 \mathrm{w} / 0$ uranium have been determined, but there are no data on alloys directly in the epsilon phase region (about $50 \mathrm{w} / \mathrm{o}$ uranium).

The linear-thermal-expansion coefficients of uranium, and of zirconium to some extent, are affected by preferred orientations developed by working operations. Hence, when comparing data it is important to know the treatment and history of the specimens. Since the coefficients also increase rapidly with temperature, comparison should also be based on the same temperature ranges.

Thermal-expansion coefficients of zirconium, uranium, and alloys containing 22 and 41 w/o uranium are given in the following tabulation:

\begin{tabular}{|c|c|c|c|c|}
\hline Composition, w/o & $\begin{array}{c}\text { Temperature } \\
\text { Range, } \\
\text { C } \\
\end{array}$ & $\begin{array}{l}\text { Mean Thermal - } \\
\text { Expansion Coefficient, } \\
\mu \text { in./in./C } \\
\end{array}$ & Reference & History \\
\hline $100 \mathrm{Zr}$ & $20-200$ & 5.7 & 44 & Cold worked, and alpha annealed. \\
\hline $100 Z_{r}$ & 25 & 5.9 & 55 & Cold worked, and alpha annealed. \\
\hline $22 \mathrm{U}$ & $20-100$ & 7.5 & 50 & Rolled at $1250 \mathrm{~F}$, and beta annealed. \\
\hline $22 \mathrm{U}$ & $20-550$ & 8.2 & 50 & Rolled at $1250 \mathrm{~F}$, and beta annealed. \\
\hline $41 \mathrm{U}$ & $20-100$ & 9.4 & 50 & Rolled at $1450 \mathrm{~F}$, and beta annealed. \\
\hline $41 \mathrm{U}$ & $20-550$ & 10.9 & 50 & Rolled at $1450 \mathrm{~F}$, and beta annealed. \\
\hline $100 \mathrm{U}$ & $-170-25$ & 13 & 56 & Cast, and beta annealed. \\
\hline $100 \mathrm{U}$ & $25-125$ & 14.5 & 57 & $\begin{array}{l}\text { Average coefficient calculated from } \\
\mathrm{X} \text {-ray determination of lattice- } \\
\text { constant changes. }\end{array}$ \\
\hline
\end{tabular}

More complete information can be shown when thermal-expansion data are presented in graphical form. Heating and cooling curves for both the 22 and 41 w/o uranium alloys are shown in Figures 39 and 40. These curves 


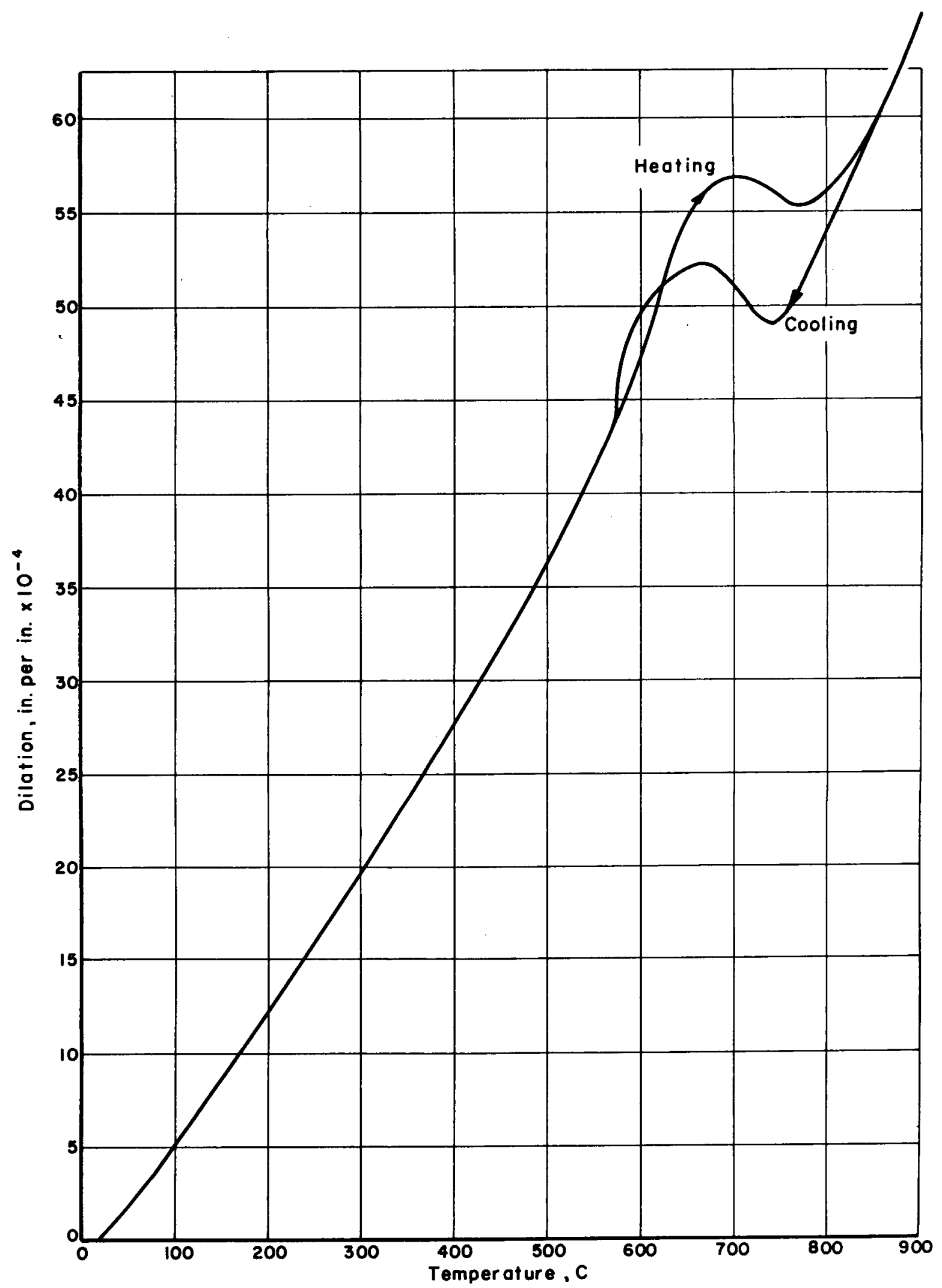

FIGURE 39. DILATION CURVE FOR ZIRCONIUM-22 w/o URANIUM ALLOY

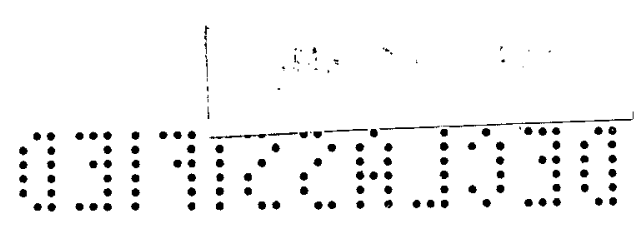




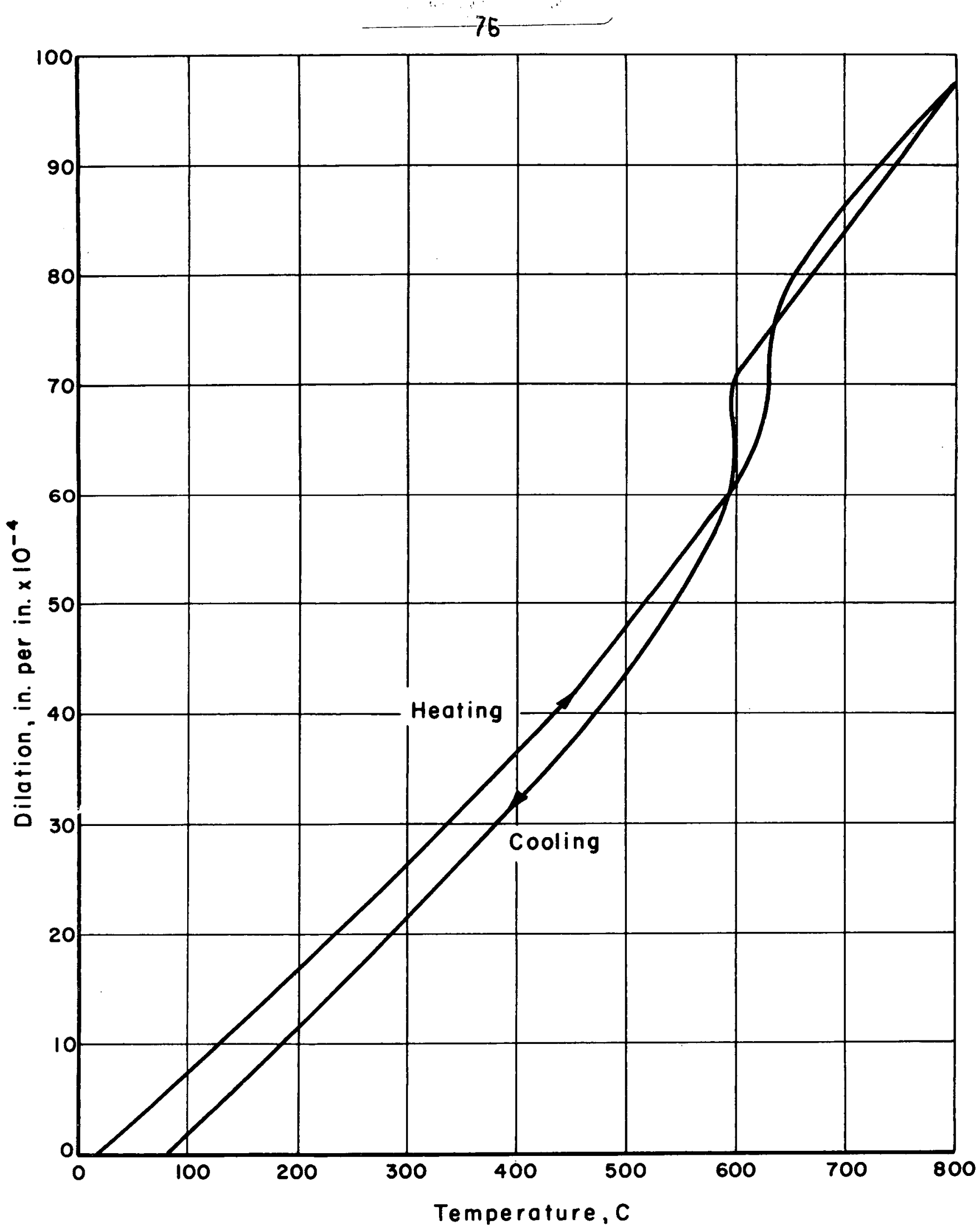

FIGURE 40. DILATION CURVE FOR ZIRCONIUM-4I W/O URANIUM ALLOY

A-15799

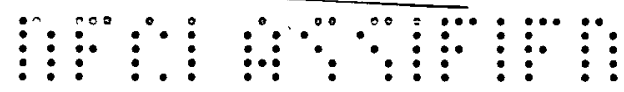


are for arc-melted sponge-base alloys which were fabricated at $675 \mathrm{C}$ $(1250 \mathrm{~F})$ and $815 \mathrm{C}(1500 \mathrm{~F})$, respectively. The samples were then randomized by heat treating in the beta-phase region $(50)$.

The same $22 \mathrm{w} / \mathrm{o}$ uranium sample, before randomization, gave very unusual results due to ratcheting which occurred when the sample was heated above the epsilon-to-beta phase change and into the alpha-plus-beta region. This ratcheting is probably the result of interaction of the alpha zirconium and uranium-rich phases which are present in some preferred orientation and have quite different thermal-expansion coefficients. In a $22 \mathrm{w} / \mathrm{o}$ uranium specimen, a linear shrinkage of 0.7 per cent was produced by one cycle between room temperature and $900 \mathrm{C}(1650 \mathrm{~F})$. Subsequent cycles had little effect and the alloy behaved as shown in Figure 39. Another specimen was cycled ten times between 350 and $750 \mathrm{C}(660$ and $1380 \mathrm{~F})$. A linear growth of about 0.6 per cent per cycle was produced. After heating to $900 \mathrm{C}$ (1650 F), however, the specimen was effectively randomized and again the alloy behaved as indicated in Figure 39.

Appreciable deformation was not observed during cycling of the $41 \mathrm{w} / \mathrm{o}$ uranium alloy, since the alloy was hot rolled and heat treated in the betaphase region ( $815 \mathrm{C}, 1500 \mathrm{~F}$ ) before cycling.

It is apparent that the thermal expansion of these alloys can be very greatly affected by preferred orientations and, probably, also by variables such as heat-treating temperatures and rates of heating and cooling.

\section{Diffusion Coefficients}

A number of investigations of the rate of interdiffusion of zirconium and uranium have been made. Included were investigations of the rate of interdiffusion of uranium from a sponge zirconium-14 w/o uranium alloy into sponge zirconium(58), of the rate of interface movement in diffusion couples of pure zirconium and pure uranium(59) and of the rate of interdiffusion of uranium from an iodide zirconium-4l w/o uranium alloy into pure zirconium $(60)$ and into Zircaloy 2(61). All investigators agree that the rate of interdiffusion of uranium in the beta zirconium phase is many times faster than the rate in the alpha zirconium phase, but the activation energy for diffusion is about the same in both the alpha and beta phases. Based on the latest data $(60,61)$, the following expressions for the rate of interdiffusion of uranium and zirconium have been derived (see Figure 41):

In beta zirconium (780 to $1030 \mathrm{C}$ ),

$$
\mathrm{D}=3.54 \times 10^{-4} \mathrm{e}^{-30,600 / \mathrm{RT}}
$$




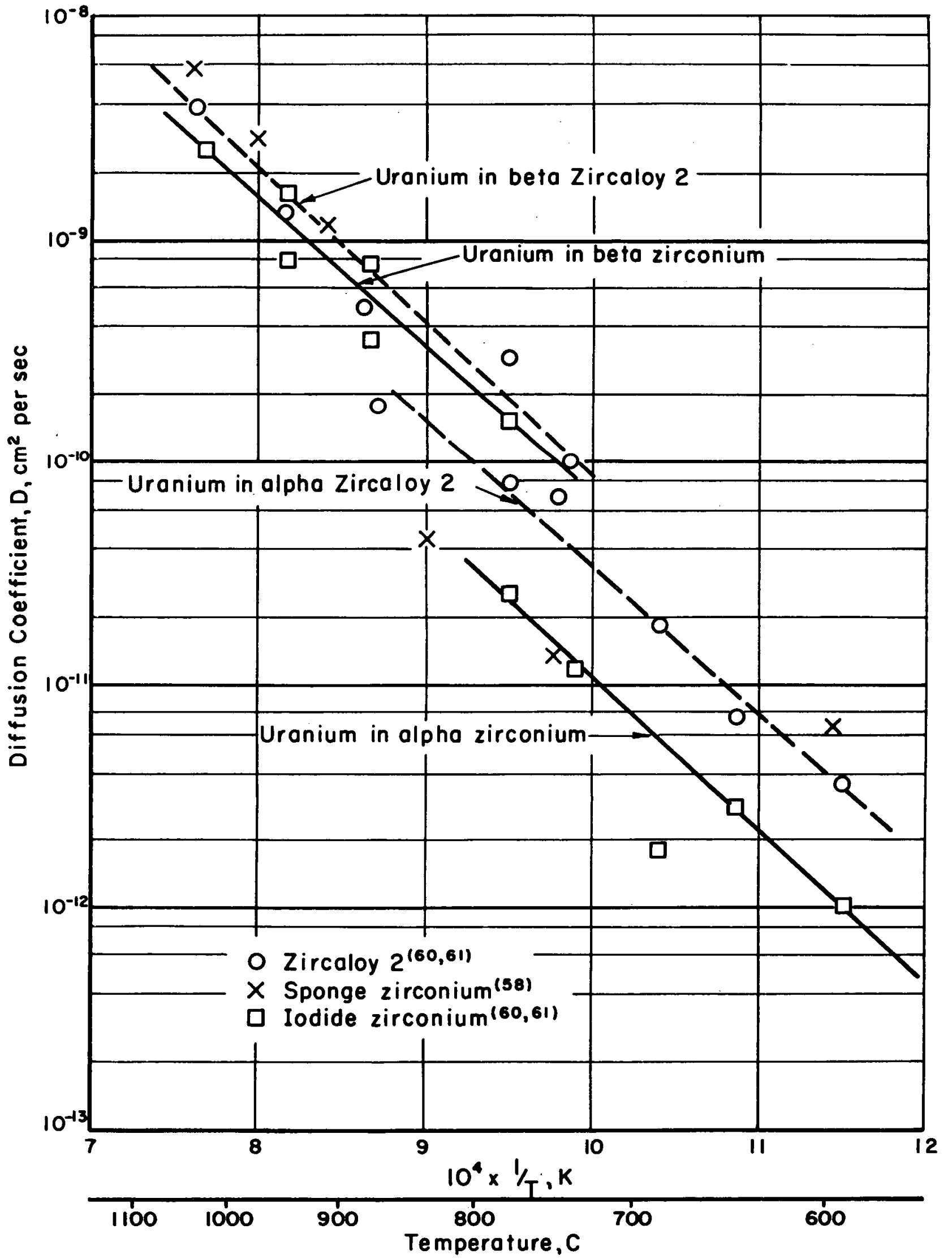

FIGURE 4I. DIFFUSION OF URANIUM IN ALPHA AND BETA ZIRCONIUM 
78

In beta Zircaloy 2 (740 to $1030 \mathrm{C}$ ),

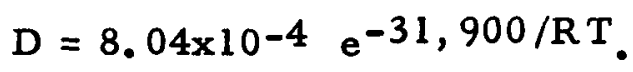

In alpha zirconium (594 to $780 \mathrm{C}$ ),

$$
D=1.08 \times 10^{-4} e^{-32,000 / R T} \text {. }
$$

In alpha Zircaloy 2 (594 to $885 \mathrm{C})$,

$$
\mathrm{D}=1.61 \times 10^{-4} \mathrm{e}^{-29,800 / \mathrm{RT}} \text {. }
$$

$D$ is the interdiffusion coefficient in $\mathrm{cm}^{2}$ per sec

$R$ is the gas constant ( $1.986 \mathrm{cal}$ per deg $C$ per mole)

$\mathrm{T}$ is the absolute temperature in $\mathrm{deg} \mathrm{K}$.

The alloying and impurity elements in Zircaloy 2 evidently cause an increase in the rate of interdiffusion of uranium and zirconium. 
CONTAINING UP TO $50 \mathrm{w} / \mathrm{O}$ URANIUM

\section{Stan J. Paprocki}

Zirconium and uranium form a complete series of solid solutions at elevated temperatures. All the alloys of such a system should be both fabricable and heat treatable. This system is no exception; however, the heat treatment and working of these alloys is complicated by the presence of the epsilon phase which occurs at about $50 \mathrm{w} / \mathrm{o}$ uranium and at temperatures below about $600 \mathrm{C}(1110 \mathrm{~F})$. The epsilon phase is metallic in nature, but forms by a process which causes hardening during the transformation from beta to epsilon. As a result, alloys involving epsilon are very sensitive to heat treatment.

For purposes of discussion, the alloys have been divided into two groups: (1) alloys containing up to $20 \mathrm{w} / \mathrm{o}$ uranium, and (2) alloys containing 20 to $50 \mathrm{w} / 0$ uranium. This division is based largely on differences in heat-treating characteristics of the two groups, but, as will be seen, some of the fabricating characteristics of the two groups are also quite different.

Alloys Containing up to $20 \mathrm{w} / \mathrm{o}$ Uranium

Zirconium is a ductile metal that can be fabricated hot or cold with little concern about heat treatment. Alloys containing up to $20 \mathrm{w} / \mathrm{o}$ uranium are progressively less ductile, and use of the proper heat treatment is essential, especially for cold-fabrication operations.

When beta treated and quenched, these alloys form martensitic structures. This martensite is relatively soft and, in the $10 \mathrm{w} / 0$ uranium alloy, can be cold worked small amounts. Perhaps the best simple heat treatment for the production of a ductile structure in the $10 \mathrm{w} / 0$ alloy is a slow furnace cool from $815 \mathrm{C}(1500 \mathrm{~F})$ or above $(64)$. In this condition, the $10 \mathrm{w} / \mathrm{o}$ uranium alloy can be cold worked over 50 per cent by rolling.

Most heat treatments of the $19 \mathrm{w} / 0$ uranium alloy result in some ductility, but the best results are obtained by heat treating in the beta phase and furnace cooling or isothermally transforming in the alpha-plus-beta phase at $675 \mathrm{C}(1250 \mathrm{~F})$, and by transforming just below the beta-to-epsilon transformation $(22,24)$.

When the 10 and $19 \mathrm{w} / \mathrm{o}$ uranium alloys are cooled at some intermediate rate between quenching and furnace cooling, such as air cooling, acicular alpha structures are formed. Little information is available on the ductility 
of these structures, but generally they are considered to be inferior to the treatments described above.

The 10 and 19 w/o uranium alloys can be cold worked and recrystallized at temperatures in the epsilon region, or about $540 \mathrm{C}(1000 \mathrm{~F})$. However, this treatment is generally inferior to the beta treatments which were described earlier.

At about $19 \mathrm{w} / \mathrm{o}$ uranium, difficulty is encountered in cold working, regardless of heat treatment, because of increased hardness and lower ductility.

The 10 and $19 \mathrm{w} / 0$ uranium alloys can be hot fabricated most readily in the alpha-plus-beta region, or about $675 \mathrm{C}(1250 \mathrm{~F})$. Hot fabrication of the $19 \mathrm{w} / \mathrm{o}$ alloy was actually successful over a range of temperatures from 540 to $730 \mathrm{C}(1000 \mathrm{~F}$ to $1350 \mathrm{~F})$. This range includes both the alpha-plusepsilon and alpha-plus-beta regions. The $10 \mathrm{w} / 0$ uranium alloy has also been fabricated in the beta at $815 \mathrm{C}(1500 \mathrm{~F})$ with no difficulty, but the $19 \mathrm{w} / \mathrm{o}$ alloy is sensitive to surface chilling, which causes cracking during fabrication in the beta. This sensitivity to surface chilling may be the result of the formation of a martensitic structure on the surface. The behavior may be further complicated by surface age hardening similar to the $22 \mathrm{w} / 0$ uranium alloy. This effect will be discussed below.

Important factors in the hot fabrication of the $19 \mathrm{w} / 0$ alloy are the size of the piece and the fabrication method. Since ingots of less than $10 \mathrm{lb}$ were used in the work described above, surface chilling occurred. With larger ingots, or jacketed assemblies, used in cladding and extrusion operations, surface temperatures will not drop so rapidly, and the problem of surface chilling will be largely avoided.

\section{Alloys Containing 20 to $50 \mathrm{w} / \mathrm{o}$ Uranium}

While alloys across the zirconium-uranium system have been forged and hot rolled, detailed fabrication studies have not been made beyond about $50 \mathrm{w} / \mathrm{o}$ uranium, except for uranium-rich alloys. Discussion in this section is, therefore, largely confined to alloys containing $22,30,40,41$, and $50 \mathrm{w} / \mathrm{o}$ uranium.

Alloys of 20 to $80 \mathrm{w} / \mathrm{o}$ uranium will retain beta when quenched rapidly from the beta region. When fully retained, beta is a soft, ductile phase. In the $22 \mathrm{w} / \mathrm{o}$ uranium alloy, however, initiation of decomposition occurs during quenching and the alloy is very hard and brittle. The best heat treatment for cold working this alloy was found to be a slow furnace cool [ 50 to $100 \mathrm{C}(100$ to $200 \mathrm{~F})$ per $\mathrm{hr}]$ from about $800 \mathrm{C}(1475 \mathrm{~F})$. The alloy can be

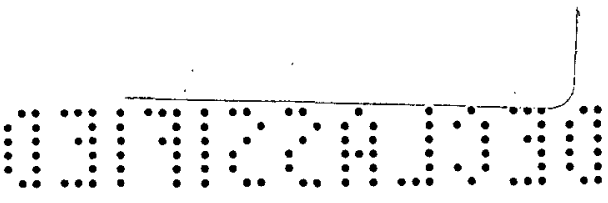


recrystallized by annealing at about $540 \mathrm{C}(1000 \mathrm{~F})$, but furnace cooling from $800 \mathrm{C}(1475 \mathrm{~F})$ is more effective $(47,60)$. An isothermal treatment used for the $19 \mathrm{w} / \mathrm{o}$ alloy was unsatisfactory for the $22 \mathrm{w} / \mathrm{o}$ alloy and produced brittle structures $(24,47)$. A slightly different treatment consisting of annealing at $800 \mathrm{C}(1475 \mathrm{~F})$ and isothermally transforming at $620 \mathrm{C}$ $(1150 \mathrm{~F})$ gives fair results in less time, but is inferior to the furnace-cooling treatment. In a $30 \mathrm{w} / 0$ uranium alloy the best cold fabricability was obtained by treating $1 \mathrm{hr}$ at $650 \mathrm{C}(1200 \mathrm{~F})$ and furnace cooling. This treatment was more satisfactory than furnace cooling from the beta, but the reason is not apparent.

In alloys of 40 to $60 \mathrm{w} / \mathrm{o}$ uranium, beta can be fully retained, but only in thin sections. As a result, beta-quenched $40 \mathrm{w} / 0$ uranium alloy specimens can be cold worked up to 50 per cent, but this applies only to specimens up to about $3 / 16-$ in. thickness, or diameter $(22,67)$. Thin sections of the $50 \mathrm{w} / \mathrm{o}$ uranium alloy have been treated in a similar fashion, but no data are available on the thickness of sections that can be effectively quenched.

Perhaps the most experience in fabrication has been obtained with the $22 \mathrm{w} / \mathrm{o}$ uranium alloy. It has been extruded successfully in the beta range. In this work, it was necessary to heat treat at $900 \mathrm{C}(1650 \mathrm{~F})$, or hot work, before extrusion in order to get smooth surfaces. The purpose of heat treating, or hot working, was to homogenize the cast structure. A steel can, instead of copper, also aided in the production of smooth, extruded surfaces. Friction during extrusion was minimized by the use of a stainless steel nose. Using the se techniques, billets were extruded with a reduction ratio of 30 to $1(28)$. This alloy has also been successfully hammer forged at temperatures of 750 to $815 \mathrm{C}(1375 \text { to } 1500 \mathrm{~F})^{(28)}$, but when it was hot rolled in the beta, it was very sensitive to surface chilling, which caused cracking. This is probably the result of the start of decomposition of the beta phase which, as indicated already, can produce a very hard, brittle structure. However, there is no real proof that the cracking is caused by this effect. The best hot-rolling temperature for the $22 \mathrm{w} / \mathrm{o}$ uranium alloy is in the alpha-plus-beta region at about $675 \mathrm{C}(1250 \mathrm{~F})$, where surface chilling is not a problem. The $30 \mathrm{w} / 0$ alloy has been fabricated in a similar fashion (70).

As the alloy content increases from $22 \mathrm{w} / \mathrm{o}$ uranium, the temperature at which beta is stable is progressively lower. This seems to correlate with the observation that the 40 and $50 \mathrm{w} / 0$ uranium alloys are insensitive to the effects of surface chilling. 
The 40 and $50 \mathrm{w} / 0$ alloys have been hot fabricated by a variety of techniques. The $40 \mathrm{w} / 0$ alloy has been hot rolled in the beta, 815 to $870 \mathrm{C}$ $(1500 \text { to } 1600 \mathrm{~F})^{(16,67,69)}$, and has also been extruded satisfactorily in the beta range with a reduction ratio of 15 to $1^{(69)}$. The $50 \mathrm{w} / \mathrm{o}$ alloy has been beta fabricated at $675 \mathrm{C}(1250 \mathrm{~F})$, and has been coextruded with a Zircaloy 2 cladding to give reductions of 40 to 50 per cent at 700 to $925 \mathrm{C}$ (1300 to $1700 \mathrm{~F})$.

\section{Discussion}

The data presented indicate that all of the alloys discussed can be fabricated by a variety of techniques. The best conditions of fabrication are determined not only by the constitutional diagram and heat-treating characteristics, but also by the type of fabrication, such as extrusion, forging, and rolling, and by the size and geometry of the piece to be fabricated.

The hot-hardness data presented in the section on "Strength Characteristics of Zirconium-Uranium Alloys" can be a useful aid in understanding and selecting fabrication procedures. However, these data should be used in conjunction with available data on the heat treatment and transformation of the se alloys. Similarly, in roll-cladding studies, roll-pressure data may be particularly useful in determining temperatures where the fabrication characteristics of the core and clad materials are compatible, but the temperature selected must be one where good bonding will occur.

Many of the fabrication studies discussed have been directed toward the production of pin-type fuel elements. For most of the alloys, extrusion is the most desirable process for making pins. Generally, there is less danger of failure during extrusion due to improper heat treatment, or to chilling, as compared with a process involving rolling, swaging, and drawing.

An attempt was made to correlate the heat-treating characteristics of the se alloys with their fabrication. It is likely that the interpretation is superficial in some cases. It also seems probable that the best heat treatments for cold fabrication have not been developed for all of the alloys. The fabrication procedures can, then, probably be improved when more is known about heat treatment, rates of transformation, and mechanical properties. 
THE EFFECTS OF COMPOSITION AND HEAT TREATMENT ON CORROSION OF ZIRCONIUM-URANIUM ALLOYS

Edward W. Cawthorne, James E. Reynolds, and Warren E. Berry

This section is devoted to a review and evaluation of the corrosion data in the literature. Particular emphasis has been placed on the corrosion behavior of zirconium-5 through $-100 \mathrm{w} / \mathrm{o}$ uranium alloys in $315 \mathrm{C}$ (600 F) and higher temperature water. Where possible, data from several sources have been compared and the effects of composition, heat treatment, and microstructure on corrosion resistance have been interpreted.

Corrosion Behavior of Uranium

Unalloyed uranium has poor corrosion resistance and tarnishes readily in humid air at room temperature. It corrodes rapidly in water at $100 \mathrm{C}$ $(212 \mathrm{~F})$ to for $\mathrm{m}$ a nonprotective coating of uranium dioxide $(71,72)$. Corrosion rates have been reported ranging from -2.5 to $-4.9 \mathrm{mg} /\left(\mathrm{cm}^{2}\right)(\mathrm{hr})^{(72)}$, depending upon metal purity and heat treatment. Corrosion rates have been found to decrease as the general quality of the metal improves (72). Corrosion resistance appears to be improved somewhat by gamma quenching (73) with rates of $-3.3 \mathrm{mg} /\left(\mathrm{cm}^{2}\right)(\mathrm{hr})$ reported, as compared with $-4.9 \mathrm{mg} /\left(\mathrm{cm}^{2}\right)$ (hr) for alpha-annealed uranium.

The corrosion resistance of unalloyed uranium is sensitive to dissolved gases in the test water (72). Dissolved hydrogen increases corrosion rates at test temperatures ranging from 50 to $225 \mathrm{C}$ (120 to $440 \mathrm{~F}$ ). Corrosion rates in aerated water are initially much lower because of the formation of a protective oxide film. However, at temperatures above $70 \mathrm{C}(160 \mathrm{~F})$, or after extended exposures, corrosion rates approach those obtained in hydrogen-saturated water.

Very little data are available on the water corrosion of uranium above $100 \mathrm{C}(212 \mathrm{~F})$. However, a corrosion rate of approximately $-6260 \mathrm{mg} /\left(\mathrm{cm}^{2}\right)$ $(\mathrm{hr})$ in $315 \mathrm{C}(600 \mathrm{~F})$ water has been reported $(74)$.

Corrosion Behavior of Zirconium

The corrosion resistance of zirconium and several of its alloys in water at temperatures up to $360 \mathrm{C}(680 \mathrm{~F})$ has been well established and reported in the minutes of meetings of the Zirconium Corrosion Committee. Good-quality zirconium corrodes in $315 \mathrm{C}(600 \mathrm{~F})$ water at a rate of about

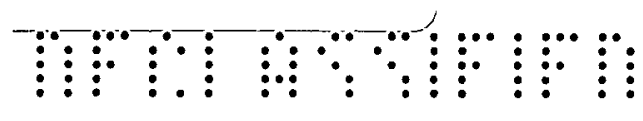


$10^{-5} \mathrm{mg} /\left(\mathrm{cm}^{2}\right)(\mathrm{hr})$ to form an adherent protective film of $\mathrm{ZrO}_{2}(75)$. It has been found that after the film reaches a certain thickness it is no longer protective and the resulting sharp increase in corrosion rate is generally known as "breakaway"(75). This occurs well in excess of a 1-year exposure with crystal-bar zirconium in $315 \mathrm{C}(600 \mathrm{~F})$ water.

Minor compositional variables greatly influence the corrosion behavior of zirconium. More than $50 \mathrm{ppm}$ nitrogen, titanium, or aluminium, or more than several hundred ppm carbon, result in early failure(73). On the other hand, it is believed that zirconium corrodes rather rapidly unless small amounts (approximately $500 \mathrm{ppm}$ ) of iron, or nickel, are present. The impurity content of sponge zirconium has been reduced to the extent that the corrosion behavior of the latest Bureau of Mines sponge approaches that of crystal-bar zirconium.

The effect of heat treatment on the corrosion behavior of zirconium has not been well established. However, it has been shown that, although rapidly quenching from, or annealing, above the transformation temperature does not retain the beta phase, it does result in poorer corrosion resistance than annealing in the alpha-phase field $(76)$.

The principal corrosion-resistant alloy of zirconium is Zircaloy 2 which contains $1.5 \mathrm{w} / \mathrm{o}$ tin, $0.12 \mathrm{w} / \mathrm{o}$ iron, $0.10 \mathrm{w} / \mathrm{o}$ chromium and $0.05 \mathrm{w} / \mathrm{o}$ nickel. This alloy is corrosion resistant in water up to $360 \mathrm{C}(680 \mathrm{~F})$ and is an excellent cladding material which can be hot fabricated in air.

\section{Corrosion of Binary Alloys in $100 \mathrm{C}(212 \mathrm{~F})$ Water}

Most investigations of high-uranium low-zirconium alloys have been directed toward applications in low-temperature water-cooled reactors. Numerous sites have studied the $100 \mathrm{C}(212 \mathrm{~F})$ water corrosion of zirconiumuranium alloys $(16,42,67,71,77,78,79,80,81,82)$.

It has been shown that alloys containing as much as 94 to 96 w/o uranium are resistant and form a tarnish film with little or no weight change when exposed to $100 \mathrm{C}(212 \mathrm{~F})$ water, after water quenching from near $800 \mathrm{C}(1470 \mathrm{~F})^{(71,72,73,77)}$. On the other hand, only alloys containing less than $80 \mathrm{w} / \mathrm{o}$ uranium are resistant in the alpha-annealed condition(77). Table 7 summarizes these data. 
TABLE 7. SURVEY OF CORROSION DATA ON ZIRCONIUMURANIUM ALLOYS TESTED IN $100 \mathrm{C}(212 \mathrm{~F})$ WATER

\begin{tabular}{|c|c|c|c|}
\hline \multirow[b]{2}{*}{ Heat Treatment } & \multicolumn{3}{|c|}{$\begin{array}{l}\text { Uranium, w/o, in Alloys That } \\
\text { Resist Corrosion for Time Shown }\end{array}$} \\
\hline & $\begin{array}{l}\text { Less Than } \\
24 \mathrm{Hr}\end{array}$ & $\begin{array}{l}\text { Less Than } \\
\text { l Week }\end{array}$ & $\begin{array}{c}10 \\
\text { Months }\end{array}$ \\
\hline $1 \mathrm{hr} 600 \mathrm{C}(1110 \mathrm{~F})$, furnace cooled & $91-100$ & $82-89$ & $0-80$ \\
\hline $1 \mathrm{hr} 800 \mathrm{C}(1470 \mathrm{~F})$, water quenched & $96-100$ & -- & $0-94$ \\
\hline $\begin{array}{l}1 \mathrm{hr} 800 \mathrm{C}(1470 \mathrm{~F}) \text {, water quenched } \\
\text { and } 1 \mathrm{hr} 600 \mathrm{C}(1110 \mathrm{~F}) \text {, furnace } \\
\text { cooled }\end{array}$ & $96-100$ & $89-94$ & $0-82$ \\
\hline $1 \mathrm{hr} 700 \mathrm{C}(1300 \mathrm{~F})$, water quenched & $96-100$ & -- & $0-94$ \\
\hline
\end{tabular}

Alloys containing up to about $20 \mathrm{w} / \mathrm{o}$ uranium and more than about $80 \mathrm{w} / \mathrm{o}$ uranium transform by a martensitic type of reaction when quenched from the beta-zirconium-phase field. X-ray diffraction studies of water and oil quenched 94 to 96 w/o uranium alloys showed no lines that could not be assigned to alpha uranium(73). Subsequent annealing yielded a fine precipitate, presumably epsilon(73). The first few per cent $(0-10 \mathrm{w} / \mathrm{o})$ of zirconium are evidently the most potent in improving the $100 \mathrm{C}(212 \mathrm{~F})$ corrosion resistance of uranium. The best corrosion resistance for veryhigh-uranium alloys is obtained by a beta-quench heat treatment which produces a supersaturated alpha-uranium matrix.

The poor corrosion resistance of alpha-annealed high-uranium alloys can be attributed to the presence of alpha uranium. In alloys containing less than $80 \mathrm{w} / 0$ uranium the alpha uranium apparently is dispersed in and surrounded by the epsilon phase so that it is no longer a major factor in the corrosion process. If this is true, it may be possible by proper heat treatment to produce the same distribution in alloys containing more than $80 \mathrm{w} / \mathrm{o}$ uranium and, thereby, obtain improved corrosion resistance in $100 \mathrm{C}$ $(212 \mathrm{~F})$ water without resorting to a rapid quench. 
Corrosion rates of alloys prepared at several sites are compared in Figure $42(71,80,81)$. The variance in results can be accounted for in part by the difference in heat treatment employed by the several laboratories. Quality of melting stock may be a factor, although the effect of impurities on corrosion behavior has not been established. Another possible explanation is the control of dissolved gases in the test water. The corrosion resistance of a beta-quenched $95 \mathrm{w} / \mathrm{o}$ uranium alloy was found to be dependent upon the amount of dissolved oxygen in the test water. Small amounts of dissolved oxygen apparently maintained a protective oxide film (77). Dissolved oxygen could well affect the corrosion behavior of other zirconium-uranium alloys.

Corrosion of Binary Alloys in High-Temperature Water

A considerable amount of corrosion data on zirconium-uranium alloys has been reported(83). It was found that alloys containing more than $60 \mathrm{w} / 0$ uranium were completely oxidized after a 24-hr exposure in $315 \mathrm{C}$ (600 F) water while those containing less than $60 \mathrm{w} / \mathrm{o}$ uranium generally exhibited corrosion life in excess of 1 year. A plot of the corrosion rates in $315 \mathrm{C}$ $(600 \mathrm{~F})$ water for induction, double-arc-and triple-arc-melted alloys is presented in Figure 43. Points are plotted without respect to heat treatment, since no given treatment resulted in consistent behavior at the various composition levels. It can be seen that a considerable spread in corrosion rates exists up to about $20 \mathrm{w} / \mathrm{o}$ uranium. This effect must be attributed to heat treatment, because, at any given composition, heat treatments were performed on duplicate samples from a given melt.

For the 10 and $20 \mathrm{w} / 0$ uranium alloys, beta quenching gave lower corrosion rates than other heat treatments. From a structural viewpoint, the 0-20 w/o uranium alloys undergo a martensitic transformation on quenching from the beta phase, and the increased scatter appearing in this range may be due to the increased sensitivity to cooling rates. The poorer corrosion behavior of alloys in this range heat treated below the transformation temperature can be attributed to the two-phase character of the alloys.

In the range of 30 through $60 \mathrm{w} / 0$ uranium the effect of heat treatment on corrosion rates is less pronounced and more consistent for any given heat treatment. In general, beta-quenched alloys fail by cracking or rupture in localized areas. The theory has been advanced that this cracking is due to untransformed beta(84). In recent work ${ }^{(85)}$ metallographic examination has revealed no localized or intergranular type attack such as is observed in hydriding of the gamma uranium phase in the uranium-12 w/o molybdenum alloy (86). Instead, it is believed that cracking may have resulted from 


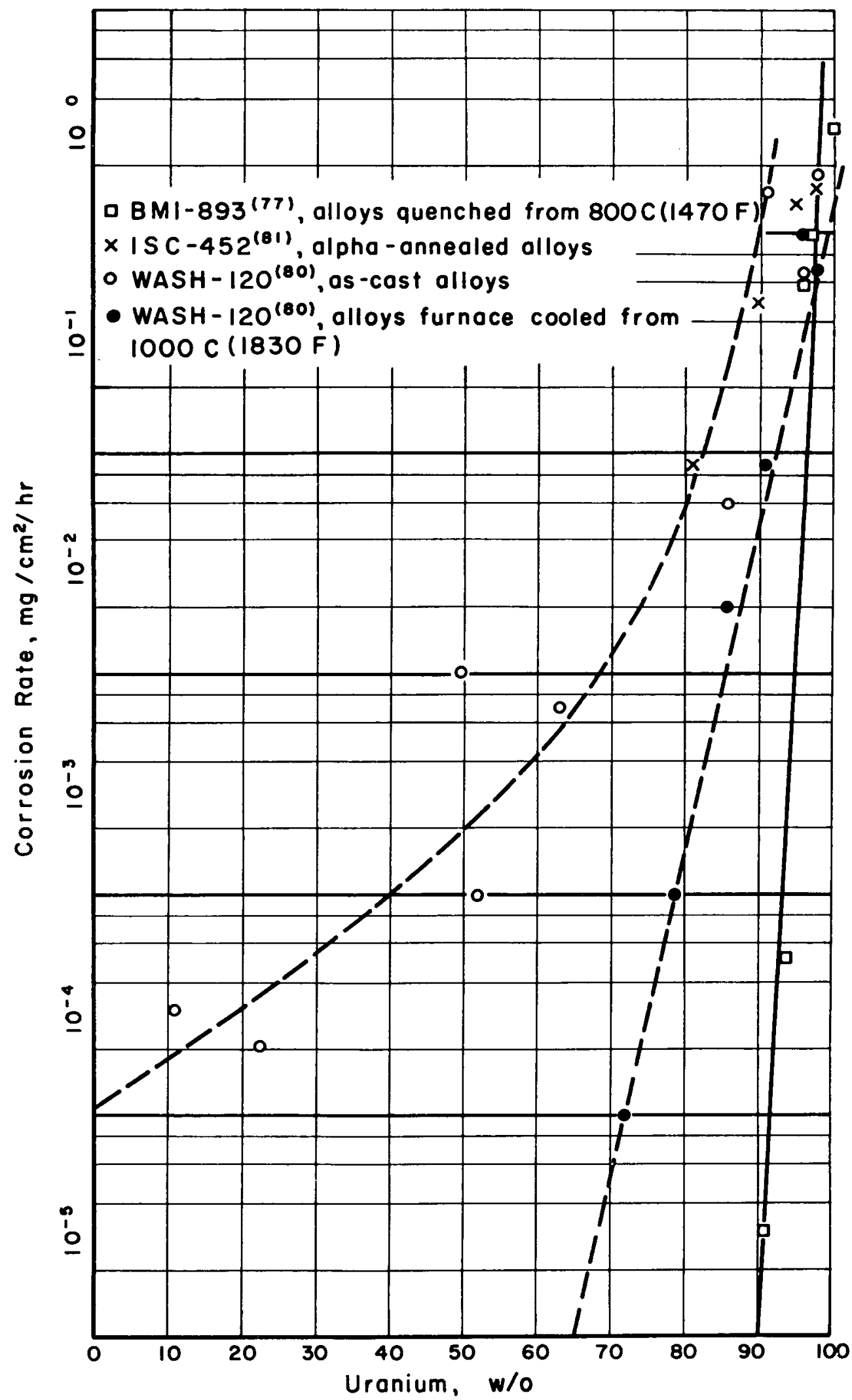

FIGURE 42. CORROSION RATES OF ZIRCONIUM-URANIUM ALLOYS IN $100 \mathrm{C}(212 \mathrm{~F})$ WATER 


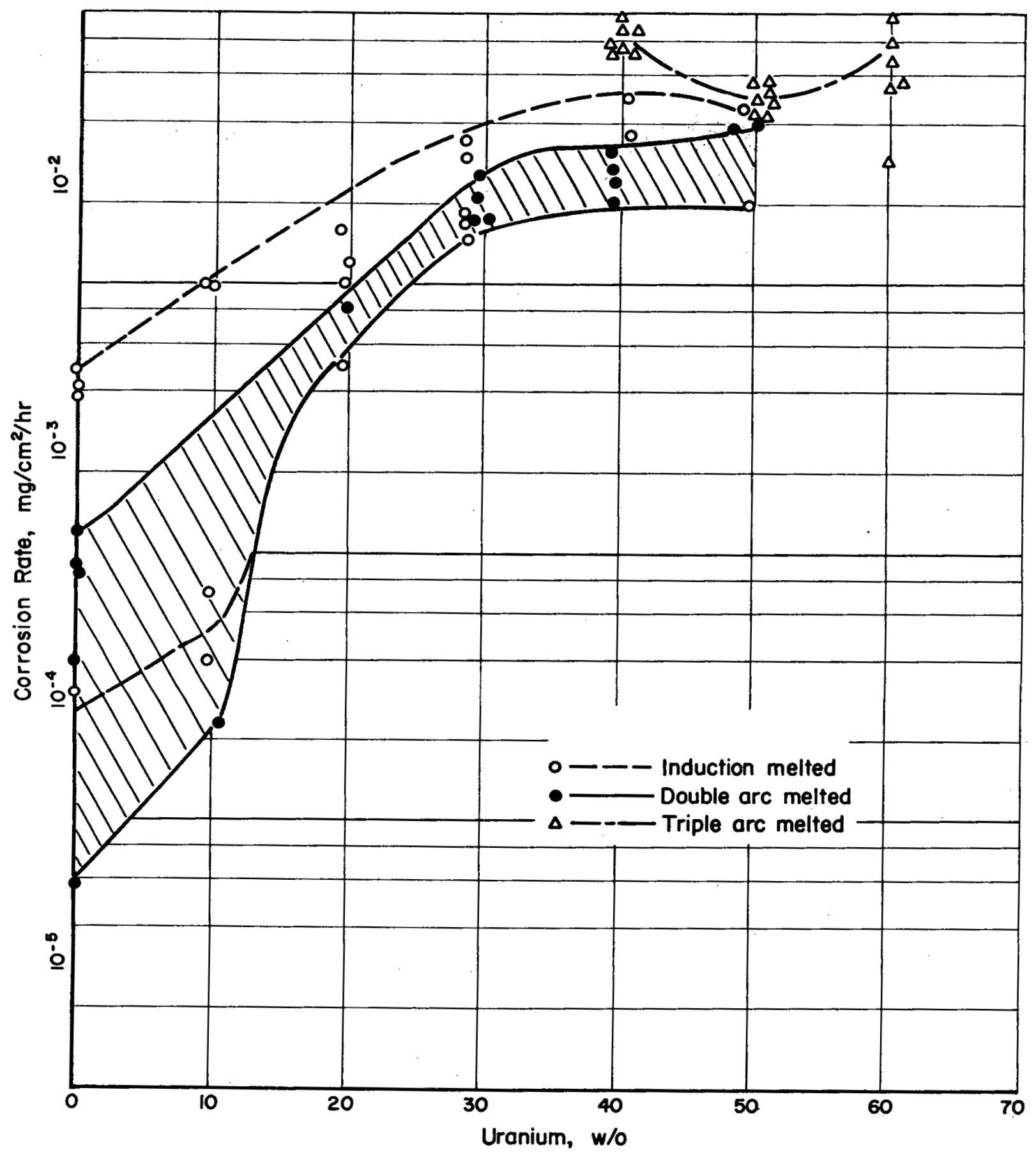

FIGURE 43. CORROSION RATES OF ZIRCONIUM-URANIUM ALLOYS IN 315 C (600 F) WATER ${ }^{(83)}$

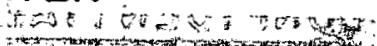

CONFIDENTIA:

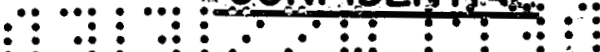

؛ 
internal stresses or stresses from stamping numbers or from drilling support holes in specimens. Rupturing may also have been the result of alloy segregation during melting.

The effect of compositional variables on corrosion behavior has not been established. It can be seen from Figure 43 that alloys induction melted and cast in graphite generally corroded at a more rapid rate than did doublearc-melted alloys. This increased rate can probably be attributed to the carbon picked up during melting (carbon content ranged from 0.24 to 0.96 w/o). There is also some indication that 40, 50, and $60 \mathrm{w} / 0$ uranium alloys prepared from sponge zirconium corrode at slightly higher rates than do similar melts prepared from crystal bar (83).

As shown in Figure 43, the corrosion rates in $315 \mathrm{C}(600 \mathrm{~F})$ water of the $50 \mathrm{w} / 0 \mathrm{triple-arc-melted}$ alloy samples are lower than those for either the 40 or $60 \mathrm{w} / 0$ uranium alloy. When tested in $260 \mathrm{C}(500 \mathrm{~F})$ water, duplicate samples also exhibited a minimum rate at $50 \mathrm{w} / 0$ as illustrated in Figure $44^{(83)}$.

A minimum in corrosion rate at approximately $50 \mathrm{w} / \mathrm{o}$ uranium can be explained in terms of microstructure since the epsilon structure is believed to exist over the range of 46 to $56 \mathrm{w} / 0$ uranium. The single-phase epsilon structure would be expected to have considerable corrosion resistance. Corrosion resistance would decrease with the appearance of a second phase.

The data plotted in Figure 44 not only revealed lower rates in $315 \mathrm{C}$ $(600 \mathrm{~F})$ water, but indicated a minimum rate at less than $50 \mathrm{w} / 0$ uranium $(80)$. This apparent inconsistency may be real since neither the existence range nor the effect of variations in composition on extending the existence range of epsilon have yet been fully established.

All alloys containing more than $60 \mathrm{w} / 0$ uranium completely oxidized within a 24-hr exposure in $315 \mathrm{C}(600 \mathrm{~F})$ water (83). Alloys annealed below the transformation temperature probably contained a considerable amount of alpha uranium, which would account for the poor corrosion behavior. As mentioned earlier, 80 and $90 \mathrm{w} / 0$ uranium alloys do not retain beta when water quenched and, therefore, disintegrate because of the poor corrosion resistance of the alpha uranium. However, it is believed that $70 \mathrm{w} / 0 \mathrm{ura-}$ nium alloys retain beta on rapid quenching, and might, therefore, have fair corrosion resistance. A possible explanation of their failure may be that, at this composition, beta transforms to alpha uranium plus epsilon at the corrosion-test temperature of $315 \mathrm{C}(600 \mathrm{~F})$. 


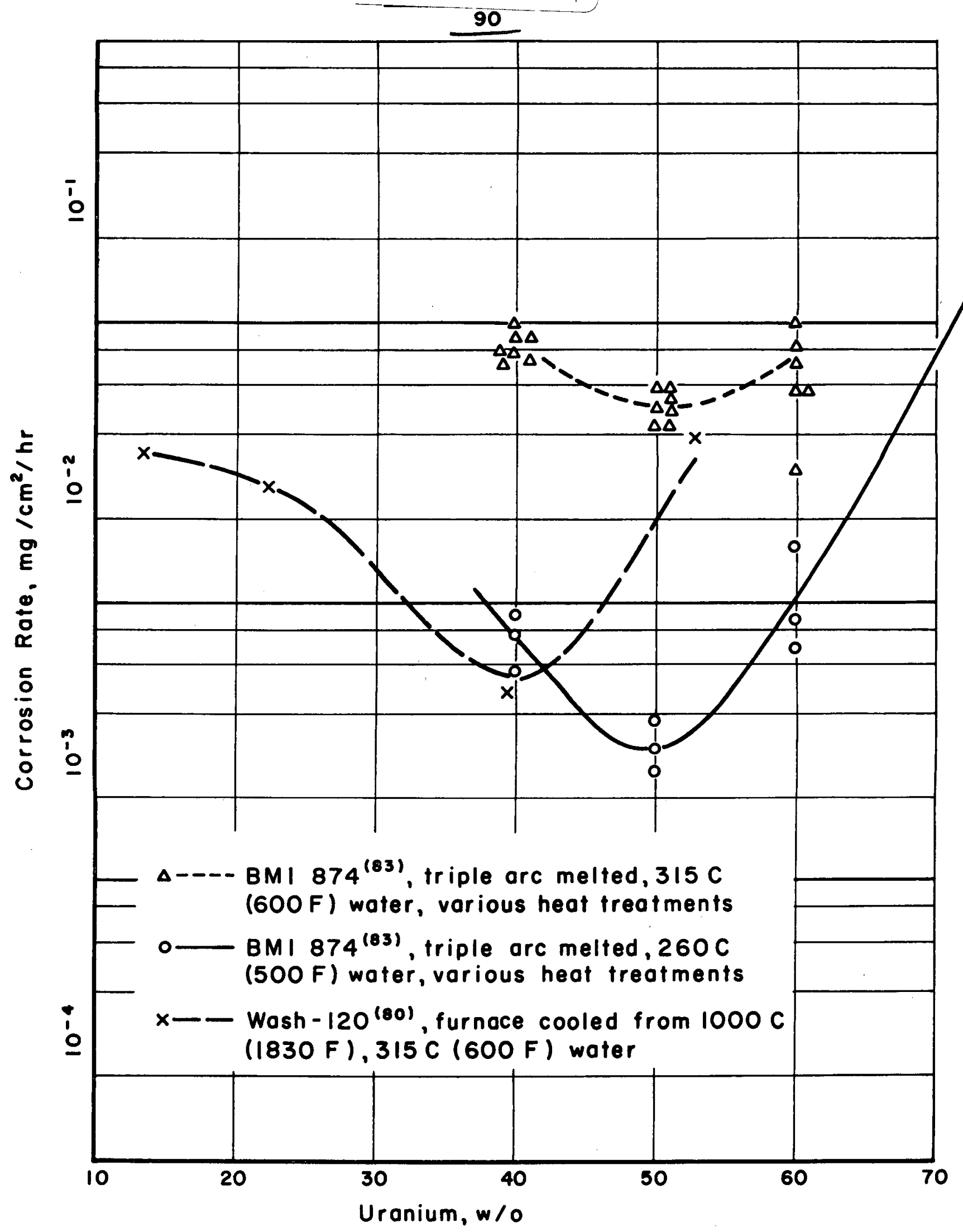

FIGURE 44. CORROSION RATE OF URANIUM-ZIRCONIUM ALLOYS IN 260 AND 315 C (500 AND 600 F) WATER 
Corrosion of Zirconium-Uranium-Base Ternary Alloys

A large number of ternary systems have been studied in attempts to develop corrosion resistant $z$ irconium-uranium alloys. The major part of this work has been devoted to alloys containing more than $70 \mathrm{w} / 0$ or less than $10 \mathrm{w} / 0$ uranium. Only a minor amount of work has been reported for alloys of intermediate uranium content. The work reported in the literature includes somewhat detailed studies of the effect of additions such as molybdenum, niobium, thorium, tin, and titanium. Data are also reported for fifteen other ternary additions.

Zirconium-Uranium-Niobium Alloys

The addition of up to $10 \mathrm{w} / 0$ niobium to alloys containing 80 to $98 \mathrm{w} / \mathrm{o}$ uranium has been found to markedly increase their corrosion resistance in water at temperatures up to $315 \mathrm{C}(600 \mathrm{~F})$ if the alloys are rapidly quenched

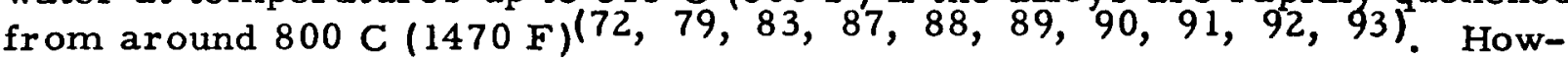
ever, additions of up to $3 \mathrm{w} / 0$ niobium to $70 \mathrm{w} / 0$ uranium alloys did not result in any improvement in corrosion resistance ${ }^{(83)}$. It should be pointed out that the uranium -3 to $6 \mathrm{w} / 0$ niobium alloy is in itself fairly resistant to $315 \mathrm{C}(600 \mathrm{~F})$ water if rapidly quenched from about $800 \mathrm{C}(1470 \mathrm{~F})^{(82,94)}$. The structure of uranium-niobium alloys so treated is martensitic and apparently ages at the corrosion-test temperature to equilibrium alpha uranium. This results in a corrosion life of approximately 2 weeks in $315 \mathrm{C}$ (600 F) water, and gives longer life in $260 \mathrm{C}(500 \mathrm{~F})$ and $300 \mathrm{C}(570 \mathrm{~F})$ water $(94)$. From the corrosion results, it appears that the martensitic structure is formed in uranium-zirconium-niobium alloys containing more than $80 \mathrm{w} / \mathrm{o}$ uranium, but not at $70 \mathrm{w} / \mathrm{o}$ uranium.

The effect of niobium additions on the corrosion behavior of the epsilonphase $50 \mathrm{w} / 0$ alloys apparently has not been investigated.

Zirconium-Uranium-Molybdenum Alloys

The effect of molybdenum additions on the corrosion resistance of zirconium-uranium alloys in $315 \mathrm{C}(600 \mathrm{~F})$ water has been investigated for alloys containing 50 to $90 \mathrm{w} / 0$ uranium plus 1 to $5 \mathrm{w} / 0$ molybdenum and for alloys containing 94 to $98 \mathrm{w} / 0$ uranium plus 2 to $6 \mathrm{w} / 0$ molybdenum(82).

No improvement in corrosion resistance was noted with the addition of molybdenum to $50 \mathrm{thr}$ ough $90 \mathrm{w} / 0$ uranium alloys. Molybdenum additions in the range of 2 to $6 \mathrm{w} / 0$ to 94 to $98 \mathrm{w} / 0$ uranium alloys did result in some improvement in corrosion resistance. Higher molybdenum additions should further improve corrosion resistance, since the gamma-quenched uranium-9 
to $15 \mathrm{w} / 0$ molybdenum binary alloys are themselves corrosion resistant, with corrosion rates of -0.1 to $-0.2 \mathrm{mg} /\left(\mathrm{cm}^{2}\right)(\mathrm{hr})$ and corrosion life of $4-6$ weeks in $340 \mathrm{C}(650 \mathrm{~F})$ water reported for the $12 \mathrm{w} / \mathrm{o}$ molybdenum alloy $(86)$.

\section{Zirconium-Uranium-Tin Alloys}

Additions of 1 to $2 \mathrm{w} / \mathrm{o}$ tin do not improve the corrosion resistance of $80 \mathrm{w} / \mathrm{o}$ uranium alloys in $315 \mathrm{C}(600 \mathrm{~F})$ water $(83)$.

However, it has been reported that additions of 2 and 5 w/o tin to 1.5 through $9 \mathrm{w} / 0$ uranium alloys result in increased resistance $(71)$. This result could be expected, since the principal phase present in the se alloys would be alpha zirconium, and it has been shown that tin is instrumental in overcoming adverse effect of certain impurities and contaminants in zirconium(76).

\section{Other Ternary Alloys}

Only a limited amount of work has been reported for other ternary alloys. The alloy compositions investigated and the source of information are summarized in Table 8.

The alloys containing $30 \mathrm{w} / \mathrm{o}$ zirconium were tested in $315 \mathrm{C}(600 \mathrm{~F})$ water in the following heat-treated conditions:

(1) Heated to $800 \mathrm{C}(1470 \mathrm{~F})$ and water quenched

(2) Heated $24 \mathrm{hr}$ at $575 \mathrm{C}(1070 \mathrm{~F})$ and furnace cooled

(3) Heated $1 \mathrm{hr}$ at $800 \mathrm{C}(1470 \mathrm{~F})$, quenched to $550 \mathrm{C}$ $(1020 \mathrm{~F}), 10 \mathrm{~min}$ at $550 \mathrm{C}(1020 \mathrm{~F})$, and air cooled

In general, alloys in the isothermally annealed condition, Heat Treatment (3), exhibited the best corrosion resistance. The annealed alloys, Heat Treatment (2), had the least corrosion resistance. Only one alloy, that containing $30 \mathrm{w} / \mathrm{o}$ zirconium and $5.6 \mathrm{w} / \mathrm{o}$ tantalum, was considered to merit further investigation (83). It is possible the tantalum may have altered the structure of this alloy so as to extend the existence range of epsilon, or it may be that $64 \mathrm{w} / \mathrm{o}$ uranium is just below the borderline composition where alpha uranium is present in sufficient quantity to cause rapid failure. 
TABLE 8. COMPOSITION OF ADDITIONAL TERNARY ALLOYS TESTED

\begin{tabular}{|c|c|c|c|}
\hline \multicolumn{3}{|c|}{ Alloy Composition, w/o } & \multirow[b]{2}{*}{ Source of Information } \\
\hline Zirconium & Uranium & Ternary Addition & \\
\hline 20 & Balance & Th $1-30$ & Reference 83 \\
\hline 30 & Balance & Th $1-10$ & Reference 83 \\
\hline 20 & Balance & Ti 1,2 & Reference 83 \\
\hline 30 & Balance & Ti $0.3,1.5$ & Reference 83 \\
\hline 30 & Balance & $\operatorname{Cr} 0.32,1.6$ & Reference 83 \\
\hline 30 & Balance & $\mathrm{Fe} 0.35,1.72$ & Reference 83 \\
\hline 30 & Balance & Co- $0.36,1.8$ & Reference 83 \\
\hline 30 & Balance & $\mathrm{Ni}-0.36,1.8$ & Reference 83 \\
\hline 30 & Balance & $\mathrm{Sb}-0.75,3.74$ & Reference 83 \\
\hline 30 & Balance & $\mathrm{Ce}-0.86$ & Reference 83 \\
\hline 30 & Balance & $\mathrm{Ta}-1.12,5.6$ & Reference 83 \\
\hline 30 & Balance & $W-1.12,5.66$ & Reference 83 \\
\hline 30 & Balance & $\mathrm{Pb}-1.26,2.52$ & Reference 83 \\
\hline 30 & Balance & $\mathrm{Bi}-1.27,6.4$ & Reference 83 \\
\hline
\end{tabular}

Analysis of Data

Adherent protective oxide films are formed in $315 \mathrm{C}(600 \mathrm{~F})$ water on alloys containing up to approximately $20 \mathrm{w} / 0$ uranium, providing they are rapidly quenched from $800 \mathrm{C}(1470 \mathrm{~F})^{(83)}$. Above $20 \mathrm{w} / \mathrm{o}$ uranium, the film may be adherent in initial exposure but eventually begins to flake, or spall, and is no longer protective(83). This decrease in corrosion resistance can be attributed to the various phases encountered in the zirconium-uranium system as the uranium content is increased. The $315 \mathrm{C}(600 \mathrm{~F})$ water corrosion behavior of the phases appears to be as follows: alpha zirconium $>$ epsilon $>$ beta (of same composition as epsilon) > alpha uranium. The beta phase may actually corrode at a lower rate than epsilon, but because of cracking associated with this phase, its corrosion life is shorter. It appears that corrosion resistance of zirconium-uranium alloys can be improved by (1) heat treatment or alloy additions that affect retention, existence range, or dispersion of the phases, and (2) changes in the corrosion environment so that its action is less drastic. 
Effects of Heat Treatment

and Microstructure

Heat treating to improve corrosion resistance of zirconium-uranium alloys offers promising possibilities. It has been demonstrated that rapidly quenching 5 to $15 \mathrm{w} / 0$ uranium alloys from $800 \mathrm{C}(1470 \mathrm{~F})$ results in a martensitic structure with corrosion behavior approaching that of unalloyed zirconium (83). Since the zirconium-uranium alloys would normally be clad with zirconium or Zircaloy 2 , beta quenching may impair corrosion resistance of the cladding itself. Therefore, it seems advisable to investigate effects of quenching from a lower temperature but still from the two-phase region (alpha-beta). Although not too likely, it may be possible by isothermal treatments to obtain the desired corrosion resistance in the core without affecting that of the cladding.

Heat treatments which eliminate internal stresses may improve the corrosion resistance of alloys that have a retained-beta structure.

Heat treating to form the epsilon phase may be desirable, since it has been shown that two-phase alloys containing epsilon and alpha zirconium, or epsilon and alpha uranium, are less corrosion resistant than the singlephase epsilon alloy.

The variation of microstructure of a $22 \mathrm{w} / \mathrm{o}$ uranium alloy with heat treatment has received considerable study(95). This work indicates that it is possible to exercise considerable control over the size and the distribution of the alpha zirconium phase in the epsilon matrix. It is highly significant that the distribution of the alpha zirconium as a network phase can be effected by beta quenching then reheating for long periods of time in the alpha-beta-phase field and furnace cooling. It may thus be possible to obtain increased corrosion resistance by encompassing each epsilon grain in the more corrosion-resistant zirconium phase. This may be considered as analogous to cladding each grain with a corrosion-resistant material.

Other work with high-uranium alloys indicates that, through heat treatment, it is possible to produce the epsilon phase as a continuous network surrounding the alpha uranium phase(95). If this type of microstructure can be obtained consistently, it may be possible to markedly increase the corrosion resistance of higher uranium alloys.

Effects of Composition

The effects of composition variables, either as impurities or ternary additions, in zirconium-uranium alloys are not well defined. In highzirconium alloys, it could be expected that those elements which affect the corrosion behavior of zirconium itself would have an effect on the alloys.

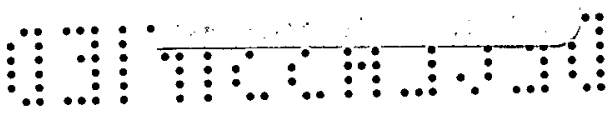


Therefore, impurities and contaminants such as aluminum, carbon, nitrogen, and titanium should be avoided. On the other hand, additions of iron, nickel, or tin may improve corrosion resistance. Because of its extremely poor corrosion resistance in high-temperature water, it is very doubtful that minor impurity variations in production-quality uranium would have any marked effect on improving resistance of high-uranium alloys. However, impurities may affect the existence range of the epsilon phase, and this in turn could affect corrosion behavior. A minor addition of a third element might increase the existence range of epsilon, with respect to uranium content. If so, it may be possible to obtain corrosion resistance in alloys containing more than $60 \mathrm{w} / \mathrm{o}$ uranium.

\section{Effects of Test Conditions}

Another possible avenue of approach to improve corrosion behavior and prolong corrosion life is to vary the test conditions. If it is found that 60 plus w/o uranium alloys fail rapidly because of hydrogen pickup, as reported for aluminum(96) and the uranium-12 w/o molybdenum alloy $(86)$, an additive to the test water such as nickel sulfate may show beneficial effects. Another alternative would be to alloy with an element which depolarizes hydrogen, as demonstrated by nickel additions to aluminum(96), or platinum additions to uranium-12 w/o molybdenum(86). Certainly, the effects of dissolved hydrogen or oxygen in the water should be investigated. The effect of raising the $\mathrm{pH}$ with additions of $\mathrm{LiOH}$ might also be beneficial.

It should be noted that water temperatures up to $360 \mathrm{C}(680 \mathrm{~F})$ are being considered for future reactors. It has been shown that increasing the test temperature from 260 to $315 \mathrm{C}(500 \mathrm{~F}$ to $600 \mathrm{~F})$ results in at least tenfold increase in corrosion rates and early failure of high-uranium alloys (83). Increasing the test temperature from 315 to $360 \mathrm{C}(600 \mathrm{~F}$ to $680 \mathrm{~F}) \mathrm{might}$ well produce the same effect and eliminate still more alloys from consideration. Therefore, it is imperative that the effect of all contributing factor $s$ be determined so that optimum corrosion behavior can be obtained. 
THE EFFECT OF COMPOSITION AND HEAT TREATMENT ON

THE IRRADIATION PERFORMANCE OF ZIRCONIUM-URANIUM ALLOYS

Alfred E. Austin

Introduction

Zirconium-uranium alloys are subject to damage during irradiation by both fast neutrons and by fission products. The principal effects on properties, of course, will be dependent upon the accumulation of fission products.

The irradiation of enriched alloys may be expressed as per cent burnup of uranium-235 or of total alloy atoms. The latter is more useful in considering effects related to concentration of fission atoms and will be used in the following discussion. From the concentration of fission atoms, estimates can be made of volume changes. For 1 a/o burnup there will be produced 2 a/o fission atoms. The mean atomic volume, $\bar{v}$, of fission atoms, calculated from the fission yield and the metallic radii of the atoms, is $25.6 \mathrm{~A}^{3}$. For zirconium-uranium alloys the per cent volume increase per 1 a/o burnup may be represented by $\left(2 \bar{V}-V_{U}\right) / \bar{V}_{U}, Z$ for additive volumes, where

$$
\begin{aligned}
\bar{V} & =\text { mean atomic volume of fission products, } \\
\mathrm{V}_{\mathrm{U}}= & \text { atomic volume of uranium, and } \\
\overline{\mathrm{V}}_{\mathrm{U}, \mathrm{Zr}}= & \begin{array}{l}
\text { mean atomic volume of the alloy of uranium and } \\
\text { zirconium atoms. }
\end{array}
\end{aligned}
$$

It is apparent that the composition of the alloy will affect $\bar{V}_{U, Z r}$ and, therefore, will affect the calculated volume change. The calculated changes for 100 per cent uranium, 25 a/o uranium, and 5 a/o uranium alloys are approximately $2.60,2.25$, and 2.20 , respectively. These values are in good agreement with calculated values based on densities of the elements $(97)$. The volume increase may also be estimated on the basis of impurity atoms being centers of pressure in an isotropic elastic medium $(98,99)$. For substitution of impurity atoms in solid solution, the linear expansion is equal to the product of the fractional mismatch of atomic radii and the atomic per cent of impurity. For 1 a/o burnup the average volume expansion on this basis would be 1.08 per cent(97). However, it has been indicated that expansions calculated on an elastic basis do not hold at concentrations greater than about $1 \mathrm{a} / \mathrm{o}(99)$. Impurity atoms may also be dispersed as interstitials, and for this case the linear expansion would be about equal to the atomic concentration, and volume expansion would be three times the atomic concentration. Since for 1 a/o burnup there are 2 a/o fission atoms formed, it 


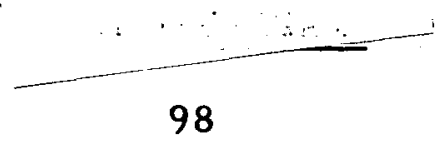

appears more reasonable to consider the presence of both substitutional and interstitial atoms. On this basis, the estimated volume increase would be about 3.5 per cent.

The results of the various methods of estimating the volume changes produced by fission products from 1 a/o burnup are summarized in the following tabulation.

\section{Assumption}

Additive volumes

Substitution positions

Interstitial and substitutional positions.

\author{
Calculated Volume \\ Increase, per cent \\ 2.20 to $2.60(\mathrm{a})$
}

1.08

3. $5^{(b)}$

(a) Depends on composition.

(b) Calculated for 50-50 distribution of fission products.

For irradiations at low temperatures the concept of fission atoms dispersed substitutionally in an elastic medium may be valid. However, at elevated temperatures, where diffusion becomes appreciable, part of the fission atoms may be rejected from solid solution, and then the volume expansion would move toward the value of 2.5 per cent per 1 a/o burnup calculated from atomic volumes.

In comparing volume changes with theoretical causes, it should be remembered that some ratio of interstitial and substitutional atoms other than the 50-50 ratio could give volume increases similar to those predicted on the basis of the assumption of additive volumes. Since some of the fissionproduct atoms will be soluble, there will always be some of them in substitutional positions. As a result, correlations of predicted and observed volume changes may not be entirely valid.

In the zirconium-uranium system most alloys consist of two phases in which irradiation effects may be markedly different. Compositions below $600 \mathrm{C}(1110 \mathrm{~F})$ may be either alpha zirconium or alpha uranium and epsilon, or just epsilon for the narrow region shown on the constitutional diagram. At temperatures above $600 \mathrm{C}(1110 \mathrm{~F})$, alloys may be alpha zirconium and beta, or beta phase, or beta phase and uranium. For ease of interpretation, the alloys can be divided into three groups: (1) alloys containing less than $20 \mathrm{w} / \mathrm{o}$ uranium, (2) 20 to $80 \mathrm{w} / \mathrm{o}$ uranium, and (3) more than $80 \mathrm{w} / \mathrm{o}$ uranium. The alloys of less than $20 \mathrm{w} / \mathrm{o}$ uranium form alpha zirconium and epsilon upon cooling. Beta phase can be retained in alloys with 20 to $80 \mathrm{w} / \mathrm{o}$ uranium by quenching, but they will form epsilon and alpha zirconium, or 
epsilon, or epsilon and alpha uranium with heat treatment. The alloys of greater than $80 \mathrm{w} / 0$ uranium transform during cooling from the beta phase.

For two-phase alloys of alpha zirconium and epsilon, the uranium is concentrated in the epsilon phase. Thus, there is the possibility that the distribution of fission atoms may not be uniform in the alloy. As indicated in the section on heat treatment, the microstructure can be varied from a fine acicular alpha-zirconium dispersion, or a fine alpha zirconium and epsilon of about $5-\mu$ grain size to a large-grained structure in which alpha zirconium surrounds epsilon regions of about $50 \mu$. Taking the average range of fission products to be $8 \mu$, then damage of the finer phase dispersions would be essentially homogeneous, but in coarser structures the concentration of fission atoms may be greater in epsilon and less in alpha zirconium than the average. The accumulation of fission atoms in the grain boundaries of a fine-grained structure should occur more rapidly than for coarse structures.

\section{Alloys Containing Less than $20 \mathrm{w} / \mathrm{o}$ Uranium}

Alpha zirconium has relatively little change in its properties after irradiation. Data available for irradiation to $3 \times 10^{19} \mathrm{nvt}$ at temperatures up to $280 \mathrm{C}(540 \mathrm{~F})$ show hardness increases of 10 to 30 per cent, depending upon the degree of initial cold working( 100$)$. The yield strength is about doubled with an accompanying decrease in ductility(20). Creep experiments $(101)$ during irradiation at $260 \mathrm{C}(500 \mathrm{~F})$ indicate a decrease in creep rate of 13 to 20 times during irradiation. This lower creep rate increased about by a factor of 15 after irradiation.

Data have been accumulated on STR elements having compositions up to $14 \mathrm{w} / \mathrm{o}$ uranium. Irradiations have been made up to $1.75 \mathrm{a} / \mathrm{o}$ burnup of the alloy atoms and at temperatures up to $280 \mathrm{C}(540 \mathrm{~F})$. The main outward effect was a density decrease, or volume increase, which was about 0.6 per cent per 1 a/o burnup $(34,102,103,104,105,106)$. This volume increase is considerably less than the 2.5 per cent calculated from the average volume increase of fission products $(97)$. However, it approximates the 1.06 per cent expansion calculated from the assumption of substitution in solid solution and elastic deformation around fission atoms $(97,98)$. These alloys were hot rolled and annealed at $900 \mathrm{C}(1650 \mathrm{~F})$ and, presumably, all had an acicular alpha structure. The low-volume increase indicates that retention of fission products occurred as dispersed atoms with only local deformation.

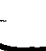


Alloys that have been examined in this composition range are mainly 22 and $41 \mathrm{w} / \mathrm{o}$ uranium, but a few intermediate compositions were studied $(40,107)$. The $22 \mathrm{w} / \mathrm{o}$ uranium alloys were clad with zirconium. The $41 \mathrm{w} / \mathrm{o}$ uranium alloys were mainly unclad wire, but a few experiments were performed on stainless steel-clad elements. In general, specimens which remained below about $600 \mathrm{C}(1110 \mathrm{~F})$, had an average volume increase of 2 per cent per 1 a/o burnup. For such specimens, the core temperatures were between 400 and $600 \mathrm{C}$ (750 and $1110 \mathrm{~F}$ ). Cycling of the $22 \mathrm{w} / \mathrm{o}$ uranium alloy below the $600 \mathrm{C}(1110 \mathrm{~F})$ temperature did not appear to increase this volume-expansion rate. In the case of the unclad $41 \mathrm{w} / 0$ uranium alloy, there were some specimens that had volume-expansion rates of 5 to 6 per cent per 1 a/o burnup. These specimens had been cold swaged after water quenching from $840 \mathrm{C}(1550 \mathrm{~F})$ and may have had initial longitudinal cracks which propagated to give an apparent large volume increase. The structure of the $41 \mathrm{w} / \mathrm{o}$ uranium alloy was probably a fine-grained, oriented structure of epsilon and alpha zirconium.

The average volume increase of 2 per cent per 1 a/o burnup agrees well with the calculated value of 2.5 per cent, based on additive atomic volumes. The specimens with 5 to 6 per cent volume expansion may possibly have had some core temperatures exceeding $600 \mathrm{C}(1110 \mathrm{~F})$ which would tend to produce deformation due to transformation of the core. However, some cracking of the epsilon phase may have occurred to give the additional volume expansion.

Irradiation of $22 \mathrm{w} / \mathrm{o}$ uranium specimens in the alpha-plus-beta region caused volume expansions. of about 11 -per cent per 1 a/o burnup. This large expansion may be the result of the transformation to the weaker bodycentered solid solution causing cracking, swelling, and release of fission products. The rate of diffusion of fission atoms in the body-centered solid solution would increase due to the higher temperature and thus enable the fission products to form clusters, or migrate into grain boundaries.

Cycling of $22 \mathrm{w} / \mathrm{o}$ uranium specimens through the epsilon transformation produced marked volume increases of from 15 to 20 per cent per 1 a/o burnup with some cracking, swelling, and release of fission products. These specimens had a greater thermal gradient around them than did specimens at lower temperatures. The resulting stresses may have caused cracking. The cycling through the transformation may also have produced cracking because of the transformation expansion and, possibly, grain reorientation. The prior fabrication and treatment of irradiated $22 \mathrm{w} / 0$ uranium specimens varied from coextrusion around $800 \mathrm{C}(1470 \mathrm{~F})$ and cold swaging, to mechanical bonding and diffusion bonding. The extrusion and cold swaging would give a fine-grained oriented structure. Diffusion bonding in the beta phase and 
cooling would probably yield a randomized dispersion of alpha zirconium in epsilon. Further data are needed about the relation of microstructure to irradiation deformation. Of interest would be alloys where the alpha zirconium is the matrix phase containing epsilon. Here the alpha zirconium may serve to contain the deformation of the epsilon, or beta phase, depending upon the temperature.

In order to interpret the deformation of specimens cycled through the epsilon transformation, the concept of fission-gas release by grain-boundary movement has been advanced. This theory proposes that the grain boundaries move during transformation and sweep fission-gas atoms into the grain boundaries where the gas can accumulate and expand. The expansion to free gas would cause the observed swelling and cracking. However, there are no data available on the extent of grain-boundary movements in zirconiumuranium alloys. In general, if the cycling temperature does not exceed the temperature of prior heat treatment in the beta-plus-alpha field, there should not be much grain growth of beta, or epsilon, but the boundaries would move as the amounts of the phases changed during cycling.

The bulk diffusion of rare gases is low in metals, being of the order of self-diffusion. Data on uranium-aluminum, uranium-lithium, and on uranium $(109)$ indicate that fission gases start to be released significantly only when the temperature approaches within about $100 \mathrm{C}(200 \mathrm{~F})$ of the melting point. It has been demonstrated that temperature cycling of uranium irradiated to $0.004 \mathrm{a} / \mathrm{o}$ burnup causes a momentary increase in the release of krypton(109). However, the cycling is effective only when the upper temperature is 1050 to $1075 \mathrm{C}(1920$ to $1965 \mathrm{~F})$. It was also reported that both cycling and holding at constant temperature required an induction period before the release of krypton started. Two tentative explanations were advanced. The first is that grain-boundary diffusion is greater than bulk diffusion and the concentration gradient is high at grain boundaries. Then grain-boundary diffusion would produce local depletion, and the movement of boundaries during transformation would restore the initial conditions of concentration and diffusion. The second possibility is that bulk diffusion causes local gas concentrations, hydrostatic stressing, and the formation of microcracks. Cycling would produce boundary movement sweeping out some of the gas pockets. Neither of these explanations accounts completely for the data on the rate of release of krypton(109).

It has been reported that at Harwell uranium irradiated to $0.4 \mathrm{a} / \mathrm{o}$ burnup has xenon escaping at $600 \mathrm{C}(1110 \mathrm{~F})(109)$. Also, for gamma-quenched uranium, the rate of escape of gas during irradiation becomes rapid after 2 a/o burnup (110). On this basis, it appears that with longer irradiations and greater burnup of uranium-235, there may be sufficient bulk diffusion and agglomeration of fission-product gases to produce microcracks. 


\section{Alloys of 80 to $98 \mathrm{w} / \mathrm{o}$ Uranium}

One series of wire specimens with compositions from 74 to $91 \mathrm{w} / \mathrm{o}$ uranium was irradiated to burnups of between 0.33 and $0.48 \mathrm{a} / \mathrm{o}$, depending upon the uranium content (98). These specimens were not clad, but were dimensionally stable at temperatures apparently not over $450 \mathrm{C}(840 \mathrm{~F})$.

A comparison has been made of natural uranium, beta-uranium treated uranium-235, and a $90 \mathrm{w} / \mathrm{o}$ uranium-235 alloy annealed at $575 \mathrm{C}$ (1070 F), after irradiation at $\left.50 \mathrm{C}(120 \mathrm{~F})^{(1111)}\right)$. The beta-uranium-treated uranium235 had an 0.7 a/o burnup and showed marked surface deformation, while there was no surface change for the $90 \mathrm{w} / \mathrm{o}$ uranium alloy with $0.55 \mathrm{a} / \mathrm{o}$ burnup and the natural uranium with $0.005 \mathrm{a} / \mathrm{o}$ burnup. The annealed alloy specimen was presumably two phase, consisting of alpha uranium and epsilon and did not undergo appreciable distortion other than surface effects.

Small pin samples of 80,90 , and $94 \mathrm{w} / 0$ uranium have been examined as cast and after annealing at temperatures comparable to beta uranium treatment of uranium (about $735 \mathrm{C})(80)$. Irradiations of as-cast material to 1.9 to 2.7 a/o burnup, depending upon uranium content, showed the $80 \mathrm{w} / \mathrm{o}$ uranium sample had a length increase of less than 1 per cent per 1 a/o burnup, while the 90 and $94 \mathrm{w} / 0$ alloys had about 2.5 per cent increase per 1 a/o burnup. However, irradiation of beta-uranium-treated alloys to burnups of 0.37 to 0.52 a/o produced 33 to 54 per cent length increases per 1 a/o burnup for 90 and $94 \mathrm{w} / \mathrm{o}$ uranium, while the alloy of $80 \mathrm{w} / \mathrm{o}$ uranium was comparable to the as-cast material. The heat treatment of the 90 and $94 \mathrm{w} / 0$ uranium alloy may well have been in a two-phase region and produced a different microstructure from the as-cast material. The $80 \mathrm{w} / \mathrm{o}$ alloy may have been heat treated in the beta-zirconium solid-solution region, and thus formed a microstructure similar to alloys richer in zirconium. Similarly, comparison of 80 and $96 \mathrm{w} / 0$ uranium alloys $(102)$ has been made for three conditions: (1) alpha rolled and beta-uranium quenched, (2) alpha rolled and beta-uranium annealed, and (3) alpha rolled and alpha annealed. Irradiations to 0.37 and $0.55 \mathrm{a} / \mathrm{o}$ burnup indicated much better dimensional stability for the $80 \mathrm{w} / \mathrm{o}$ alloy. One intermediate composition of $60 \mathrm{w} / 0$ uranium(20) irradiated at Hanford-process water temperatures had a volume increase of less than 1 per cent per 1 a/o burnup.

It is apparent that the stability of alloys containing more than $80 \mathrm{w} / \mathrm{o}$ uranium is markedly dependent upon heat treatment and the resultant distribution of the anisotropic alpha uranium.
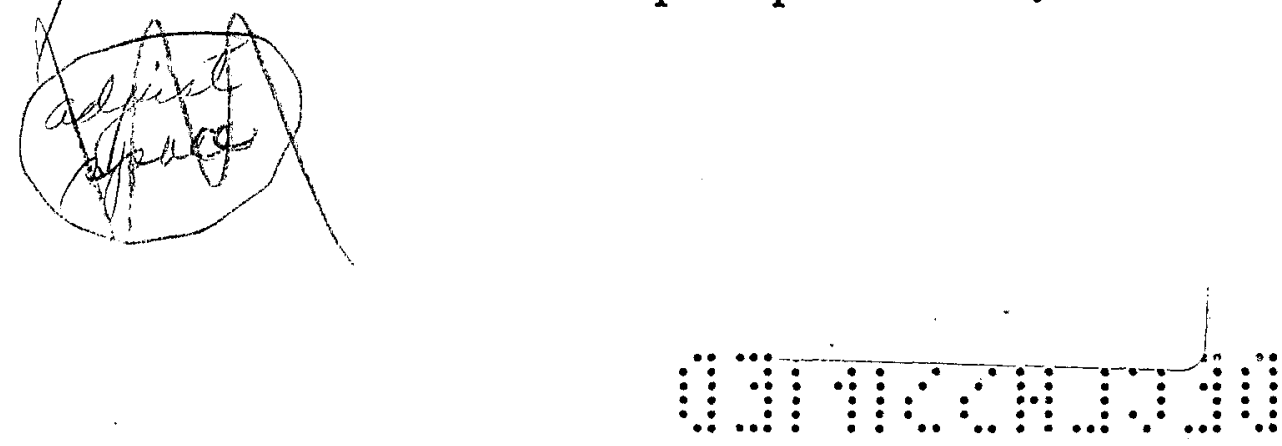


\section{3 and 104}

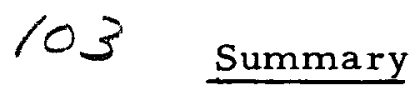

The literature data indicate that, for alloys from 0 to $80 \mathrm{w} / \mathrm{o}$ uranium, irradiation at low temperatures produces volume increases of from about 1 to less than 2.5 per cent per 1 a/o burnup. Irradiations at temperatures in the range of 400 to $600 \mathrm{C}(750$ to $1110 \mathrm{~F})$ can produce volume increases of 2.5 per cent per $1 \mathrm{a} / 0$ burnup, or greater. These volume changes are about the change required to account for the volume of fission-product atoms. In the beta phase, or above the epsilon transformation, the alloys undergo deformations much greater than the 2.5 per cent volume increase per $1 \mathrm{a} / \mathrm{o}$ burnup.

The dependence of irradiation deformation upon microstructure is not clear. For alloys below $600 \mathrm{C}(1110 \mathrm{~F})$ possible variations may be the grain size of epsilon, and the distribution of alpha zirconium or alpha uranium. Data are needed on alloys with single-phase epsilon structures. Epsilon may deform anisotropically, and, in such a case, the control of grain size and randomization would be beneficial for irradiation at temperatures below $600 \mathrm{C}(1110 \mathrm{~F})$. The deformation of alloys at higher temperatures by the agglomeration of fission-product gases may be a problem of resistance of the beta phase to deformation from thermal stresses, as well as from strains produced by dispersion of fission-product atoms.

Transformation of epsilon to beta produces a considerable volume expansion. Fluctuating thermal gradients which produce local transformation may, therefore, produce sufficient stress to cause microcracks. The extent of such possibilities should be dependent upon the grain size, orientation of phases, and, also, on the relative amounts and distribution of epsilon and alpha zirconium or alpha uranium, as well as the conditions of irradiation. Thus, the increased deformation observed for cycled alloys may be caused by several factors which need further investigation. 


\section{REFERENCES}

(1) Peterson, D., and Wilhelm, H. A., "Phase Studies of UraniumZirconium Alloys", ISC-139 (December, 1950).

(2) Kaufmann, A. R., Arnold, S. V., Titorchook, W. H. , Russell, R. B., and Paynton, W. C. , "Status of Zirconium-Uranium Phase Diagram", MIT-1078 (April, 1952).

(3) Saller, H. A., Rough, F. A., and Bauer, A. A., "The UraniumZirconium Constitutional Diagram", BMI-824 (April, 1953).

(4) Summers-Smith, D., "Constitution of Uranium-Zirconium Alloy System", J. Inst. Metals, 83 (February, 1955).

(5) Buzzard, R. W., Liss, R. B., and Fickle, D. P., "The UraniumZirconium Binary System", Journal of Reactor Science and Technology, 2 (2), TID-2002 (August, 1952).

(6) McGeary, R. K., "Dilatometric Investigation of Zirconium, ZirconiumUranium, Zirconium-Oxygen, and Zirconium-Nitrogen Alloys", W APD36 (July, 1951).

(7) "Minutes of the Conference of Zirconium-Uranium Alloys held at WAPD, May 6, 1955", W APD-LSR (MM) (May, 1955).

(8) Epremian, Edward, "Uranium Alloy Newsletter No. 10", WASH-197 (May, 1955).

(9) Cashin, W. M., and Holden, A. N., "Metallurgy Report of the Technical Department", KAPL-1305 (February, 1955).

(10) Frost, P. D., Parris, W. M., Hirsch, L. L., Doig, J. R., and Schwartz, C. M. , "Isothermal Transformation of Titanium-Manganese Alloys", Trans. ASM, 46 (1954).

(11) Jaffee, L. D., "Heat Treatment of Titanium Alloys", Metal Progress (February, 1955).

(12) Lillie, D. W., "Uranium Alloy Newsletter No. 8", W ASH-155 (August, 1954).

(13) Dayton, R. W., and Tipton, C. R., Jr., "Progress Report for July, $1955^{\prime \prime}, \mathrm{BMI}-1025$ (August, 1955). 


\section{6}

(14) Dayton, R. W., and Tipton, C. R., Jr., "Progress Report for May, 1955", BMI-1005 (June, 1955).

(15) Saller, H. A., Rough, F. A., Fackelmann, J. M. , Bauer, A. A., "Phase Relations in the Uranium-Zirconium-Oxygen System Involving Zirconium and Uranium Dioxide", BMI-1023 (July, 1955).

(16) Nelson, H. R., and Dayton, R. W., "Progress Report for January, 1954", BMI- 902 (February, 1954).

(17) Austin, A. E., "Report of Trip to KAPL and Discussions with A. Holden", Unpublished Information (May 26, 1955).

(18) Bauer, A. A., Unpublished Information.

(19) Epremian, Edward, "Uranium Alloy Newsletter No. 11", W ASH-198 (May, 1955).

(20) Cashin, W. M., and Holden, A. N., "Metallurgy Report of the Technical Department", KAPL-1256 (November, 1954).

(21) Lukesh, J. K., Private Communication (1955).

(22) Chubb, W., Muehlenkamp, G. T., and Manning, G. K., "The Properties and Heat Treatment of Zirconium-Uranium Alloys", BMI-973 (January, 1955).

(23) White, J. F., "Uranium Alloy Newsletter No. 9", W ASH-156 (November, 1954).

(24) Nelson, H. R. and Dayton, R. W., "Progress Report for February, 1954", BMI-905 (March, 1954).

(25) Bauer, A. A., "Report of Trip to KAPL", Unpublished Information (July, 1955).

(26) Haýes, E. E., and Kaufmann, A. R., "Observations on the AlphaBeta Transformation in Zirconium", Zirconium and Zirconium Alloys, American Society for Metals, Cleveland, Ohio (1953), p 241.

(27) "Large Ship Reactor Program Technical Progress Report", WAPDMRL-5 (May, 1955).

(28) Van Tassel, K. R., White, D. W., Holden, A. N., and Cashin, W. M., "Report of the Metallurgy Section", KAPL-1196 (August, 1954).

(29) "Large Ship Reactor Program Technical Progress Report", WAPDMRL-4 (March 20, 1955).

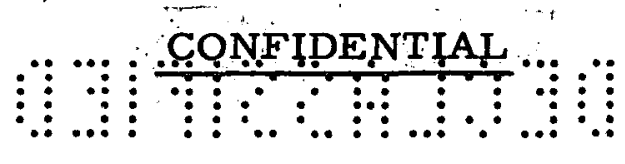


(30) Saller, H. A., Rough, F. A., Bauer, A. A., "Heat Treatment and Alloy Study of the Zirconium-22 w/o Uranium Alloy", BMI-1011 (June, 1955).

(31) Saller, H. A., Rough, F. A., and Bauer, A. A., "The UraniumZirconium Constitutional Diagram", TID-5151 (January, 1954).

(32) Schwope, A. D., Mueblenkamp, G. T., and Chubb, W., "Mechanical Properties of Zirconium and Zirconium-Uranium Alloys Containing Tin", BMI-770 (September, 1952).

(33) "Monthly Technical Progress Report", WAPD-MR-14 (February, 1951 ).

(34) Layman, D. C., and Naymark, S., "Interim Evaluation of Irradiation of Naval Reactor Fuel Element Prototype Subassemblies in Chalk River Reactor", ANL-4634 (May, 1951).

(35) Schwope, A. D., and Muehlenkamp, G. T., "Tensile-Creep Properties at $500^{\circ} \mathrm{F}$ of Zirconium and a 3.66 Per Cent Uranium Alloy of Zirconium", BMI- 779 (November, 1952).

(36) Udy, M. C., and Boulger, F. M., "The Properties of Zirconium Alloys, Part IV", BMI-T-50 (June, 1951).

(37) "Monthly Technical Progress Report", WAPD-MR-13 (January, 1951 ).

(38) Muehlenkamp, G. T., Chubb, W., and Schwope, A. D., "Mechanical Properties of Alloys of the Uranium-Zirconium System", BMI-879 (October, 1953).

(39) Chubb, W., Muehlenkamp, G. T. and Schwope, A. D., "A HotHardness Survey of the Zirconium-Uranium System", BMI-833 (May, 1953).

(40) "SIR Program Progress Report", KAPL-1171 (July, 1954).

(41) Saller, H. A., Stacy, J. T., Eddy, N. S., and Klebanow, H. L., "Creep Strength of Uranium Alloys at 1500 and 1800 F", BMI-834 (May, 1953).

(42) Lillie, D. W., "Uranium Alloy Newsletter No. 4", W ASH-125.

(43) Saller, H. A. and Rough, F. A., "Compilation of U.S. and U. K. Uranium and Thorium Constitutional Diagrams", BMI-100 (June, 1955).

(44) Adenstedt, H. K., "Physical Properties of Zirconium", Trans. ASM, 44 (1952). 


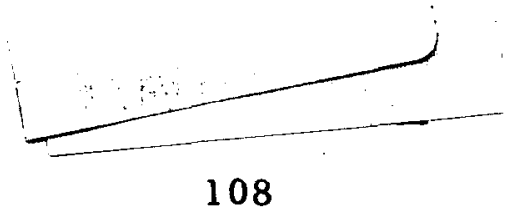

(45) Smith, K. F., "Physical Properties of Zirconium and ZirconiumUranium Alloys", ANL-4464 (April, 1951).

(46) Kalish, H. S., and Hausner, H. H., "The Structures and Properties of Zirconium-Uranium Alloys", TID-5084 (June, 1952).

(47) "Metallurgy Section Progress Report", KAPL-1 149 (May, 1954).

(48) Saller, H. A., and Rough, F. A., "Microstructure and Properties of Uranium Alloys", BMI-878 (October, 1953).

(49) Cook, L. A., Castleman, L. S., and Johnson, W. E., "The Electrical Resistivity of Zirconium", WAPD-25 (December, 1950).

(50) Deem, H. W., Private Communication, BMI.

(51) Balz, G., "Electrical Behavior and Allotropy of Uranium", Metallforschung, 2 (May, 1947).

(52) Ebert, H., and Schulze, A., "Electrical and Thermal Properties of Uranium", Metallforschung, 2 (February, 1947).

(53) Droher, J. J., "Thermal Conductivity of Uranium", TID-5185, Proceedings of the Metallurgy Information Meeting held at Argonne National Laboratory, April 19-21, 1954) (December, 1954).

(54) McCreight, L. R., "Thermal Conductivity Data of Some Nuclear Fuels", KAPL-822 (October, 1952).

(55) Russell, R. B., "Coefficients of Thermal Expansion for Zirconium", Trans. AIME, 200 (September, 1954).

(56) Schuch, A. F., and Lacquer, H. L., "Low Temperature Thermal Expansion of Uranium", Physical Review, 86 (June, 1952).

(57) "Reactor Materials Handbook", 3 (1953).

(58) Schwope, A. D., and Jackson, L. R., "Diffusion'Studies of the Zirconium-Uranium System", BMI-T-24 (April, 1950).

(59) Mash, D. R. and Disselhorst, B. F., "Uranium-Zirconium Diffusion Studies", LRL-143 (June, 1954).

(60) Dayton, R. W., and Tipton, C. R., Jr., "Progress Report for July, 1954", BMI-937 (July, 1954).

(61) Dayton, R. W., and Tipton, C. R., Jr., "Progress Report for June, 1954', BMI-925 (June, 1954).

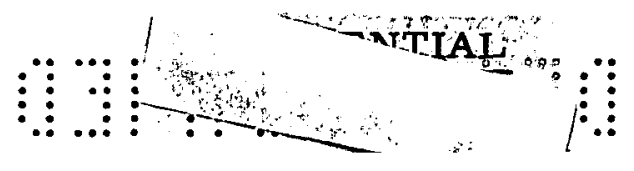


(62) Bing, G., Fink, F. W., and Thompson, H. B., "The Thermal and Electrical Conductivities of Zirconium and Its Alloys", BMI-65 (April, 1951).

(63) Baroody, E., Unpublished Information (1954).

(64) Dayton, R. W., and Tipton, C. R., Jr., "Progress Report for September, 1954", BMI- 953 (October, 1954).

(65) Dayton, R. W., and Tipton, C. R., Jr., "Progress Report for May, 1954", BMI-920 (June, 1954).

(66) Roll Experience at Battelle and KAPL.

(67) Burke, J. E., and White, D. W., "Report of the Metallurgy Section", KAPL- 1039 (November, 1953).

(68) Nelson, H. R., and Dayton, R. W., "Progress Report for December, 1953", BMI-896 (January, 1954).

(69) Van Tassel, K. R., White, D. W., Holden, A. N., and Cashin, W. M., "Report of the Metallurgy Section", KAPL-1093 (February, 1954).

(70) Dayton, R. W., and Tipton, C. R., Jr., "Progress Report for December, 1954", BMI- 972 (January, 1955).

(71) Waber, James T., "A Review of the Corrosion of Uranium and Its Alloys", LA-1524 (November 7, 1952).

(72) McWhirter, J. W., and Draley, J. E., "Aqueous Corrosion of Uranium and Alloys: Survey of Project Literature", ANL-4862 (May 14, 1952).

(73) Foote, F. G., and Schumar, J. F., "The Metallurgy Division Quarterly Report for July, August, and September, 1952", ANL-4923 September 30, 1952).

(74) Greiser, D. R., and Simons, E. M. , "Apparatus for Visual Study of Corrosion by Hot Water", BMI- 998 (May 4, 1955).

(75) Goldman, K. M., "Minutes of Meeting on the Corrosion of Zirconium Alloys", W APD-MM- 127 (July 18, 1952).

(76) Kass, S., "Report of the May, 1954, Meeting of the Zirconium Alloy Corrosion Committee", W APD-MM-448 (June 1, 1954). 
(77) Pray, H. A., and Berry, W. E., "Corrosion of Uranium-Zirconium Alloys in Water at Temperatures up to $100 \mathrm{C"}$, BMI-893 (December 16, 1953).

(78) Lillie, D. W., "Uranium Alloy Newsletter No. 3", WASH-124 (May 27, 1953).

(79) "Reactor Engineering Division Quarterly Report for December 1, 1953 through March 30, 1954", ANL-5260 (April 15, 1954).

(80) Lillie, David W., "Uranium Alloy Newsletter No. 1", WASH-120 (January 29, 1953).

(81) Chiotti, P., and Carlson, O. N., "Hanford Slug Program Quarterly Report for October, November, and December, 1953", ISC-452 (February 15, 1954).

(82) Lillie, D. W., "Uranium Alloy Newsletter No. 2", WASH-123 (n. d.).

(83) Pray, H. A., and Berry, W. E., "Corrosion of Uranium Alloys in High-Temperature Water", BMI-874 (October 5, 1953).

(84) Thomas, D. E., "Corrosion of Zirconium-Uranium Alloys", W APDMDM-24 (December 29, 1954).

(85) Dayton, R. W., and Tipton, C. R., Jr., "Progress Report for June, 1955", BMI- 1012 (July 1, 1955).

(86) Lustman, B., "Résumé of Uranium Alloy Data - VIII", W APD- PMM- 15 (February 25, 1954).

(87) "Progress (A-1) Report for Month of June, 1945", MIT, CT-3194 (July 10, 1945).

(88) Foote, Frank, "Summary Report for Month of June, 1945 - Metallurgy Division", University of Chicago, CT-3071 (July 9, 1945).

(89) Foote, Frank, "Summary Report for Month of May, 1945 - Metallurgy Division", University of Chicago, CT-3011 (June 5, 1945).

(90) Greninger, A. B., "Report for Month of April, 1945 - Metallurgy Division", University of Chicago, CT-2925 (May 8, 1945).

(91) Greninger, A. B., "Report for Month of March, 1945 - Metallurgy Division", University of Chicago, CT-2794 (April 12, 1945). 
(92) Dwight, A. E., and Roebuck, A. H., "Preliminary Report on Corrosion of Uranium-Base Alloys Containing Niobium and Zirconium", ANL-5376 (December 19, 1954).

(93) McGeary, R. K., and Justusson, W. M., "Corrosion Resistant Uranium Alloys", WAPD-MM-227 (June, 1953).

(94) Draley, J. E., "Status of the Development of Corrosion Resistant Uranium Alloys", ANL-EF-409b (November 12, 1953).

(95) Bauer, A. A., Private Communication.

(96) "Quarterly Progress Report on Reactor Development (4, 000 Program)", ANL-5398 (January 31, 1955).

(97) Howe, J. P., and Weher, C. E., "Reactor Science and Technology", $\underline{4}$ (1), TID-2012 (March, 1954).

(98) Burke, J. E., Koenig, R. F., Low, J. R., White, D. W., and Weber, C. E., "Metallurgy Section Report for December 1952, January and February 1953", KAPL-894 (April, 1953).

(99) Tucker, C. W., Jr., and Sampson, J. B., Acta Metal, 2, 433 (1954).

(100) Lesser, D. O., "The Effect of Irradiation on the Mechanical and Physical Properties of Structural Materials With Particular Reference to the Mark I Naval Reactor", ANL-4792 (November, 1953).

(101) Fillnow, R. H., Cook, L. A., and Johnson, W. E., "The Effect of Neutron Bombardment on the Creep Strength of Zirconium", WAPD 63 (May, 1953).

(102) Foote, Frank G., and Schumar, James F., "Metallurgy Division Quarterly Report, April, May, and June, 1951 ", ANL-4712 (June, 1951).

(103) Foote, Frank G., and Schumar, James F., "Quarterly Report, July, August, September, 1951, Metallurgy Division", ANL-4736 (September, 1951).

(104) Foote, Frank G., and Schumar, James F., "Metallurgy Division Quarterly Report, October, November, December, 1951 ", ANL4784 (December, 1951).

(105) Foote, Frank G., and Schumar, James F., "Quarterly Report, January, February, March, 1952, Metallurgy Division", ANL-4825 (March, 1952). 
(106) Foote, Frank G., and Schumar, James F., "Metallurgy Division Quarterly Report, April, May, and June, 1953", ANL-5097 (June, 1953).

(107) "SIR Program Progress Report, December, 1954, and January, 1955", KAPL-1261 (January, 1955).

(108) "SIR Program Progress Report, April and May, 1954", KAPL-1143 (May, 1954).

(109) Reynolds, M. B., "The Diffusion of Fission Gases in Metallic Fuels", KAPL-1315 (April, 1955).

(110) "Report of Metallurgy Section, June, July, August, 1953", KAPL-985 (August, 1953).

(111) Untermeyer, Samuel, "Reduction of Irradiation Damage to Uranium by Small Zirconium Additions (Interim Report)", ANL-4604 (March, 1951).

FAR:all 